\title{
1 The potential for phosphorus benefits through root placement in the rhizosphere of
}

2 phosphorus-mobilising neighbours

3

4 François P. Teste ${ }^{1,2}$, Kingsley W. Dixon ${ }^{1,3}$, Hans Lambers ${ }^{1,3,4}$, Jun Zhou ${ }^{1,5}$, Erik J.

5 Veneklaas ${ }^{1,6}$

6

7 Affiliations: ${ }^{1}$ School of Biological Sciences, The University of Western Australia, 35 Stirling

8 Highway, Crawley (Perth), WA 6009, Australia

$9 \quad{ }^{2}$ Present address: Grupo de Estudios Ambientales, IMASL-CONICET \& Universidad

10 Nacional de San Luis, Av. Ejercito de los Andes 950 (5700), San Luis, Argentina

$11{ }^{3}$ School of Molecular and Life Sciences, Curtin University, Kent Street, Bentley, WA 6102,

12 Australia

$13{ }^{4}$ College of Resources and Environmental Sciences, National Academy of Agriculture

14 Green Development; Key Laboratory of Plant-Soil Interactions of the Ministry of Education,

15 China Agricultural University, Beijing 100193, China

$16{ }^{5}$ Key Laboratory of Mountain Surface Processes and Ecological Regulation, Institute of

17 Mountain Hazards and Environment, Chinese Academy of Sciences, Chengdu 610041, China

$18{ }^{6}$ School of Agriculture and Environment, The University of Western Australia, 35 Stirling

19 Highway, Crawley (Perth), WA, 6009, Australia

20

21 Author for correspondence: François P. Teste

22 Email: francois.teste@uwa.edu.au

$23+542664520300(3055)$.

Author Contributions:

FPT, EJV, KWD, and HL designed the study. FPT analysed the data and wrote the first draft

27 of the manuscript and all authors collected data and contributed substantially to revisions. 


\section{Abstract}

29 Plants that produce specialised cluster roots, which mobilise large quantities of poorly-available 30 nutrients such as phosphorus $(\mathrm{P})$, can provide a benefit to neighbouring plants that produce 31 roots in the cluster-rhizosphere, as demonstrated previously in pot studies. To be effective, 32 such roots must be present within the short time of peak cluster activity. We tested if this 33 requirement is met, and quantified potential $\mathrm{P}$ benefits, in a hyperdiverse Mediterranean 34 woodland of southwest Australia where cluster-rooted species are prominent. Using minirhizotrons, we monitored root dynamics during the wet season in the natural habitat. We found non-cluster roots intermingling with all 57 of the observed cluster roots of the studied tree species, Banksia attenuata. Almost all (95\%) of these cases were observed in a highmoisture treatment simulating the 45-year average, but not present when we intercepted some of the rainfall. We estimate that cluster-root activity can increase $\mathrm{P}$ availability to intermingling 40 roots to a theoretical maximum of $80 \%$ of total $\mathrm{P}$ in the studied soil. Due to their high $\mathrm{P}$ remobilisation efficiency (89\%), which results from P rapidly being relocated from cluster roots within the plant, senesced Banksia cluster roots are a negligible $\mathrm{P}$ source for other roots. We conclude that, rather than serving as a $\mathrm{P}$ source, it is the cluster-root activity, particularly the

44 exudation of carboxylates, that may improve the coexistence of interacting species that are capable of root intermingling, thus potentially promoting species diversity in nutrient-poor habitats, and that this mechanism will be less effective in a drying climate.

Keywords: Banksia attenuata and B. menziesii, climate change, minirhizotron, phosphorusmobilisation facilitation, phosphorus remobilisation. 


\section{Introduction}

51 When plant roots intermingle, are there interactions among interspecific neighbours, and if so, what are the potential consequences of such interactions? Classical plant root studies demonstrate that roots of competing species tend to avoid each other, and thus reduce belowground resource competition for soil nutrients and water (Schenk 2006). Yet, recent root research, often using advanced tools to study roots in situ (Metzner et al. 2015; Schmittgen et al. 2015; van Dusschoten et al. 2016), shows that root intermingling is perhaps more common than previously thought (Mommer et al. 2016; Oburger and Schmidt 2016). The main scenarios that promote root intermingling, rather than root avoidance, have been well-documented, and include: i) kin recognition (intraspecific roots), ii) nitrogen-uptake

60 facilitation (interspecific roots), where $\mathrm{N}_{2}$-fixing plants increase the availability of $\mathrm{N}$ to other 61 plants, and iii) patchiness of soil resources (intra- and interspecific roots) where the presence 62 of localised high resource levels (e.g., N) leads to root proliferation (Chen et al. 2018; Faget et al. 2013; Hodge 2012; Li et al. 2016). However, it is not known if root intermingling is common when phosphorus $(\mathrm{P})$ is the key limiting nutrient for plant growth, and what the potential benefits of intermingling are.

In severely P-impoverished soils of the hyperdiverse sandplains of southwest Australia's biodiversity hotspot, many plants form cluster roots that are among the most efficient roots to acquire poorly-available $\mathrm{P}$ from such soils (Lambers et al. 2015). Cluster roots comprise a main axis and many determinate ephemeral rootlets (Shane and Lambers 2005). Large quantities of carboxylates, but also likely acid phosphatases, protons, and chelating substances, are released in an 'exudative burst' from cluster roots in several species (Delgado et al. 2013; Shane et al. 2004; Watt and Evans 1999), whereas in Banksia species, which have more complex cluster roots, exudation appears to occur at slower rates but for longer periods (Beeck 2017; Shi et al. 2020). The release of carboxylates effectively increases the 
concentration of $\mathrm{P}$ and some micronutrients in the soil solution, thereby making them available for uptake (Shane and Lambers 2005). The development of cluster roots that exude large quantities of carboxylates into the cluster rhizosphere is referred to as 'cluster-root activity'. As such, cluster-root activity involves a time-dependent process that increases $\mathrm{P}$ uptake by the cluster roots. Furthermore, there is evidence that, as a 'side effect', this process promotes P-uptake facilitation, which appears to occur when neighbouring plants grow along cluster-rooted plants (Gardner and Boundy 1983; Li et al. 2007; Muler et al. 2014). Yet, we lack empirical evidence showing in situ that other plant roots actually physically intermingle during these rapid biochemical rhizosphere processes (Lambers et al. 2018; Teste et al. 2018).

Root intermingling may be prevalent in P-limited environments to acquire sorbed P mobilised by carboxylates released by neighbours, but it is unclear what might direct the growth towards P-mobilising cluster roots, and what level of P-uptake benefits may result from such root interactions. Intermingling might be a random process, due to non-cluster roots being attracted by signals associated with cluster-root activity, or both non-cluster and cluster roots may be attracted by the same trigger (e.g., a high resource patch). A first step in elucidating mechanisms of intermingling with cluster roots is to demonstrate that intermingling is not random, to quantify its frequency, and to determine its timing relative to peak cluster-root activity. If non-cluster roots show a tendency to arrive in the rhizosphere of cluster roots when these are most active, this is likely an adaptive response to temporarily-enhanced resource availability.

98 Our ongoing work on foliar nutrient patterns within and in the neighbourhood of clusterrooted plant species is pointing to a considerable potential for P-mobilisation based facilitation in nutrient-poor soils (Abrahão et al. 2019). We have found increases in foliar manganese $(\mathrm{Mn})$ levels in plant species neighbouring cluster-rooted species compared with 
102 controls without cluster-rooted neighbours (Muler et al. 2014). More recent studies show that

103 plants that are potentially facilitated by carboxylate-releasing neighbours exhibit increased

104 leaf [Mn] (Yu et al. in press; Yu et al. 2020). Here, for the first time, we present evidence that

105 the fundamental conditions, relating to root positioning and rhizosphere-P dynamics, enable a

106 considerable $\mathrm{P}$ benefit for other roots occurring within the rhizosphere of cluster roots.

107 Global climate change is leading to substantial drying climates in most Mediterranean

108 ecosystems (Diffenbaugh and Field 2013; Indian Ocean Climate Initiative 2012). Southwest

109 Australia's Mediterranean ecosystems, which host a biodiversity hotspot and many cluster-

110 rooted plant species (Lambers et al. 2014; Lamont 1982; Myers et al. 2000), could be affected

111 by the drying climate. The production of cluster roots is stimulated by high surface soil

112 moisture levels (Lamont 2003), and it appears that a minimum-threshold soil moisture level is

113 required to trigger the plant into forming cluster roots (Lamont 1976; Lamont 2003). Our

114 recent study in this ecosystem demonstrated a greater presence of cluster roots at high soil

115 moisture levels compared with drier controls (Teste et al. 2018). However, effects of

116 declining soil moisture levels on root interactions remain poorly explored in the field. Since

117 plants that produce cluster roots are abundant and widespread in this biodiverse ecosystem,

118 yet are particularly sensitive to changes in soil moisture, we proposed that plant community

119 compositional shifts may continue to occur (Crosti et al. 2007; Fisher et al. 2009; Teste et al.

120 2018). In addition, we suggest that reductions in plant diversity may occur: i) if cluster-

121 rooted plants become less efficient at mining soil P due to narrower 'windows' of favourable

122 soil moisture conditions (Teste et al. 2018); ii) $\mathrm{P}$ is less mobile in dry soil than in moist soil

123 thus exacerbating point i) (Lambers et al. 2008); and iii) $\mathrm{P}$ and micronutrient uptake of

124 coexisting plants is indeed facilitated by the root activity of cluster-rooted plants (Lambers et

125 al. 2018).

126 
127 The overall aim of this study was to determine whether the spatial and temporal dynamics of

128 cluster roots and roots of neighbouring plants provide clues for a potential P-mobilisation

129 facilitative role of cluster roots. Our previous work (Muler et al. 2014; Teste et al. 2014)

130 provided the theoretical underpinning and experimental support for facilitation by cluster-

131 rooted species, but we did not yet provide visual evidence of root intermingling in situ, which

132 is fundamental to a P-facilitation hypothesis (Lambers et al. 2018). Here, we test if root

133 placement and rhizosphere $\mathrm{P}$ conditions are such that they would make root-to-root

134 facilitation possible. Using a combination of minirhizotron field and glasshouse experiments,

135 and $\mathrm{P}$ budgets during root intermingling, we estimate the potential benefits of $\mathrm{P}$ mobilisation

136 by cluster roots to interacting non-cluster rooted plants. The study aimed to test: i) is there

137 evidence of root intermingling between cluster-rooted species and other plant species? ii) Do

138 roots from neighbouring plant species intermingle before, during, or after cluster-root activity;

139 and does greater soil moisture availability intensify intermingling? iii) How much $\mathrm{P}$ is

140 potentially made available in the cluster rhizosphere?

142 Kleptoparasitism is parasitism by theft of nutriment or a key resource. Kleptoparasitism is a

143 well-documented animal-animal interaction (Gorman et al. 1998; Thompson 1986), where the

144 optimal foraging of one species of animal is taken advantage of by another species by timely

145 'robbery' of a key resource (e.g., food). This type of biological interaction has also been

146 found between carnivorous plants and predatory insects (Zomora 1995). Kleptoparasitism

147 between plants has yet to be shown, yet it may exist in P-impoverished systems, particularly if

148 timely intermingling by non-cluster rooted plant species occurs during the peak-P foraging

149 activity of cluster-rooted plants.

151 Banksia attenuata and B. menziesii (Proteaceae) were used as the focal tree species, since they produce an abundance of large compound cluster roots (Denton et al. 2007b; Shane and 
153 Lambers 2005). These Banksia species are long-lived trees with extensive lateral and deep

154 roots where cluster roots are commonly found just below the leaf litter and top layers (0 to 20

$155 \mathrm{~cm}$ ) of the soil profile (Lambers 2014; Pate and Watt 2002; Teste et al. 2018). Root dynamics

156 and interactions of all roots near the B. attenuata trees were monitored using installed

157 minirhizotron tubes and cameras, and we quantified $\mathrm{P}$ concentration and remobilisation from

158 cluster roots of B. menziesii in a glasshouse. These two Banksia species are physiologically

159 similar and prominent components of these woodlands (Denton et al. 2007a; Lambers et al.

160 2012; Pate and Dell 1984). Finally, to evaluate the ways in which other roots might benefit

161 from intermingling with cluster roots, the potential $\mathrm{P}$ availability in cluster-rhizospheres and

162 after cluster root senescence was estimated.

163

164 Methods

165 Study site

166 Experimental irrigated and unirrigated plots were established in banksia-eucalypt woodland at

167 The University of Western Australia's (UWA) Shenton Park Field Station $\left(31.96^{\circ} \mathrm{S}\right.$,

$\left.168115.79^{\circ} \mathrm{E}\right)($ Supporting Information Fig. S1). The site is located in the kwongan vegetation

169 type on the Swan Coastal Plain within the Southwest Australian Floristic Region (sensu

170 Hopper and Gioia 2004). The site is part of the Spearwood coastal dune system (McArthur

171 and Bettenay 1974; Wyrwoll et al. 2014). The sandy soils are severely nutrient-impoverished

172 (Turner et al. 2018), and the climate is Mediterranean with a mean annual temperature of

$173 \quad 19.2^{\circ} \mathrm{C}$ and average annual rainfall of $702 \mathrm{~mm}$ (Australia's Bureau of Meteorology;

174 http://www.bom.gov.au/climate/data/; 1967 to 2011), where most of the rain occurs between

175 May and September, the cooler "winter months" of the Southern Hemisphere. During these

176 winter months, most of the root growth including cluster roots occurs (Lamont 2003; Pate and

177 Beard 1982), thus the likelihood of root intermingling is high. A complete description of the

178 study site and experimental design are included in Teste et al. (2018). 
180 In May 2011, 40 minirhizotron clear tubes (Bartz Technology Corp., Carpinteria, CA, USA, 181 internal diameter $=50.8 \mathrm{~mm}$ ) were installed to a depth of $0.5 \mathrm{~m}$ at $1 \mathrm{~m}$ and $2.5 \mathrm{~m}$ from the 182 basal stem of ten B. attenuata trees with two irrigation treatments (i.e. on 10 plots $\mathrm{x} 2$ 183 distances $\times 2$ irrigation treatments $=40$ tubes). Tubes were prepared following similar 184 procedures outlined in Smit et al. (2000) and Johnson et al. (2001) to eliminate artefactual 185 effects of light and temperature. Prior to imaging roots with a BTC2 Minirhizotron Video 186 Microscope (Bartz Technology Corp., Carpinteria, CA, USA), the minirhizotron tubes were 187 left to stabilise for 11 months. From April 2012, sprinklers distributed water evenly to a 188 radial distance of $4 \mathrm{~m}$ around the minirhizotron tubes. This irrigation treatment started a 189 month before the winter rains and produced a $25 \%$ increase in monthly winter water inputs 190 (from April to October) based on 45 years of rainfall data (1967 to 2011) from a nearby 191 weather station (Subiaco treatment plant, Station \# 009151, Lat: $31.96^{\circ} \mathrm{S}$, Long: $115.79^{\circ} \mathrm{E}$;

192 Bureau of Meteorology, http://www.bom.gov.au/climate/averages/). The plots were irrigated 193 every month, and by October, we had added a total of $148 \mathrm{~mm}$ of supplementary water to 194 each plot. The minirhizotron tubes around the mature Banksia focal trees were positioned to 195 be within the radial extent of the water spray provided by the sprinklers used in the irrigation 196 treatment (Teste et al. 2018). Furthermore, we inserted the tubes within the main root zone of 197 each focal tree. As for soil depth, the range of depths used to image roots was mainly 198 determined by the limitations of the minirhizotron equipment (tubes and camera) and the 199 feasibility of gathering images within the same day in the field. Furthermore, we knew that 200 imaging beyond $50 \mathrm{~cm}$ depth was unlikely to render observations of cluster roots, since they 201 are typically restricted to the top $15 \mathrm{~cm}$ of the soil profile (Denton et al. 2007b; Pate and Watt 202 2002). 
205 A complete description of the procedures involved in the root image capture and analysis is

206 available in Teste et al. (2018). In summary, roots were imaged between 4 April 2012 and 5

207 October 2012, and root dynamics and soil moisture were monitored on a weekly basis when

208 possible. The captured minirhizotron images were then analysed with Rootfly v. 2.0.2, an

209 open-source software application (Zeng et al. 2010). Rootfly allowed us to annotate (with a

210 computer mouse) the roots, determine the type of root (cluster (Fig. 1, S2), woody or

211 herbaceous roots, based on structure and colour), and calculate the birth and death rates of

212 roots through time. In this study the minirhizotron approach was used to track root

213 intermingling over time in a non-destructive manner in situ. We annotated a 'cluster-root'

214 type only when we saw rootlets at some point in time during root-imaging from April to

215 October. Banksia roots that did not produce rootlets could not be differentiated from other

216 woody roots; therefore, they were categorised as a 'woody' root type. A 'cluster-root

217 intermingling' response was calculated based on minirhizotron images (image frame $=13.5$

$218 \mathrm{~mm}$ by $18 \mathrm{~mm}$ ) that had co-occurring root types of which at least one was a cluster root.

\section{Glasshouse experiment}

221 In August 2012, a glasshouse experiment with B. menziesii seedlings grown in nutrient-

222 impoverished Bassendean sand (see Laliberté et al. (2012) for specific soil characteristics)

223 was established with the objective to quantify cluster-root nutrient concentrations and -

224 remobilisation during senescence. Banksia menziesii seedlings were grown in 14 rhizoboxes

225 (2.2 L) and in plastic bags inside 40 polyvinyl chloride (PVC) pots (2.1 L). Our aim was to

226 simultaneously photograph and sample cluster roots at their various developmental stages.

227 Four stages were morphologically identified: stage 1, immature cluster roots; stage 2, fully-

228 formed cluster roots; stage 3, cluster roots with rusty brown colour and some loss of vigour

229 (shrinking determined visually); stage 4, dark brown or grey cluster roots with noticeable loss

230 of vigour (widespread shrinking and wrinkling determined visually). Between 10-15 January 
2013, half of the seedlings were harvested, washed and cluster roots were then cleaned and oven-dried at $70{ }^{\circ} \mathrm{C}$ for 48 hours.

233

234 Due to the nature of cluster roots, small sand particles often tightly adhere to the root cluster.

235 Therefore, once dried, the cluster roots were again cleaned to remove adhering sand to

236 accurately quantify dry weight and chemical composition of the roots. Thus, cluster roots

237 were placed between two fine mesh holders and subjected to pressurised air until most of the

238 sand was removed. Any remaining sand was accounted for, by subtracting its weight from

239 the sample dry weight, during root digests, prior to chemical analysis (see Chemical analysis

240 of cluster roots below).

242 Chemical analyses of cluster roots

243 After sand removal, fragmented cluster roots were weighed and analysed for total P and

244 silicon ( $\mathrm{Si}$ ) by atomic absorption spectrometry (Perkin Elmer 500 DV ICP-AES,

245 Massachusetts, USA), with an adapted protocol to deal with sand particles, at the ChemCentre

246 (http://www.chemcentre.wa.gov.au/), Perth, Australia. Since many cluster roots still

247 contained traces of adhering sand particles, the digestion in closed capsules was carried out to

248 avoid possible loss of acid digest solution (nitric-perchloric acid mixture) due to explosive

249 boiling-over. All remaining root samples were then re-analysed for $\mathrm{P}$ and $\mathrm{SiO}_{2}$ using an

250 Elementar Vario Macro (Hanau, Germany) directly after combustion. Further analysis of the

251 evolved gases and digests was done with an inductively coupled plasma mass spectrometer

252 (Perkin Elmer, Elan 6000 ICP-MS, Norwalk, CT, USA) or axially-configured ICP-OES for

253 low-weight samples. Total N was quantified with the Elementar Vario Macro (Hanau,

254 Germany). 
A modified Evans blue test was used to determine root vitality (Peterson et al. 2008). Two

258

259

260

261

262

263

264

265

266

267 approaches to stain the four stages of cluster roots were used; first, whole cluster roots were stained by dipping them in Evans blue solution, and, second, the main root axes without the rootlets were hand-sectioned prior to dipping. Cluster roots boiled in water for 5 minutes were used as controls for this vitality assessment. Stained rootlets were observed under a dissecting light microscope to visually determine if the root was dead (i.e. stained) or alive (i.e. clear, not stained). The proportion of dead rootlets per $5 \mathrm{~mm}$ cluster root fragment was determined with the gridline intersect method (Giovannetti and Mosse 1980).

\section{Structural dry matter}

Structural dry matter was determined for cluster-root stages 2 to 4 . First, $200 \mathrm{mg}$ of dried root material was pulverised with a Retsch Tissue Lyser (TissueLyser Qiagen, Haan, Germany) at $25 \mathrm{~Hz}$ for 5 minutes. Then $700 \mu \mathrm{L}$ of $\mathrm{NaH}_{2} \mathrm{PO}_{4}(0.1 \mathrm{M}, \mathrm{pH} 7.3)$ and $300 \mu$ l Tween-20 $(0.1 \%$, $\mathrm{v} / \mathrm{v}$ ) were added to the pulverised material, which was then vortexed, pulverised again, vortexed for 1 minute, and finally centrifuged at 8,164 g for 10 minutes. The supernatant was removed, the material allowed to dry at $60{ }^{\circ} \mathrm{C}$ for 72 hours, then re-weighed. The structural dry matter was then calculated as the difference between the initial dry weight minus the weight after releasing soluble metabolites. Structural dry matter was quantified to express the concentrations of $\mathrm{N}$ and $\mathrm{P}$ during the development of cluster roots on a structural dry weight basis; this avoids the bias of any changes in non-structural dry weight (e.g., non-structural carbohydrates) during cluster development.

\section{Estimation of the amount of phosphorus made available by cluster roots}

We consider two ways in which other roots might benefit from intermingling with cluster roots: 1) by taking up P made available through the action of cluster-root exudates (carboxylates and phosphatases), i.e. novel P pools that would not be available for non-cluster 
roots; or 2) by taking up P left behind in senesced cluster roots. To estimate the P potentially

284 made available through the release of cluster-root exudates, 10 soil samples were collected at

285 the study site, regardless of the irrigation treatment given that this field sampling was done six

286 years after the temporary irrigation treatment ceased. These field samples were taken below

287 Banksia trees from 0-0.05 m depth, adjacent to where cluster roots were imaged (Teste et al.

288 2018). Total $\mathrm{P}$ was quantified by extraction in $1 \mathrm{M} \mathrm{HCl}$ (16 hours, $1: 50$ soil to solution ratio)

289 of ashed samples $\left(550^{\circ} \mathrm{C}, 1\right.$ hour) modified after Saunders and Williams (1955). Free Pi

290 (resin-P) was extracted with anion-exchange membranes (Turner and Romero 2009).

291 Carboxylate-extractable Pi (citrate-extractable P) was assessed using a $0.05 \mathrm{M}$ solution of

292 citric acid (3 hours). Organic P (Soil organic P) was calculated as the difference between the

$2931 \mathrm{M} \mathrm{HCl}$-extracted $\mathrm{P}$ after and before ashing. This method may cause a slight overestimate of

294 the organic $\mathrm{P}$, because of a potential increase in acid-extractability of $\mathrm{P}$ in soil ash (Williams

295 et al. 1970). Results are expressed on an oven-dry $\left(105^{\circ} \mathrm{C}\right)$ weight basis.

297 To estimate the potential maximum amount of $\mathrm{P}$ available from decomposing cluster roots,

298 first, cluster root per soil weight ratio was determined, and then the P concentration of

299 senesced cluster roots (see above) was used to estimate the amount of P left behind by cluster

300 roots per unit soil dry weight. Ten patches of mature cluster roots were located by removing

301 the litter layer below Banksia trees at the study site, and pieces of this cluster-root mat (depth

$302 \sim 0-50 \mathrm{~mm}$, area $\sim 5000 \mathrm{~mm}^{2}$ ) were collected. Banksia cluster roots are easily found given

303 their large size and characteristic mat-like structures (Shane and Lambers 2005). In the lab,

304 one mini-core from each of the samples (diameter $21.5 \mathrm{~mm}$, depth $11 \mathrm{~mm}$, volume $3990 \mathrm{~mm}^{3}$ )

305 was taken, and live cluster roots from the soil (sand, organic matter, any other roots) were

306 separated by adding water and using end-over-end shaking, sonification, and manual

307 separation. Cluster root samples and soil samples were dried at $70{ }^{\circ} \mathrm{C}$, weighed, and then

308 ashed at $550{ }^{\circ} \mathrm{C}$. The cluster root dry weight was adjusted for contamination with sand, 
assuming that the ash content of cluster roots was $5 \%$ of their dry weight, based on values

310 from other slow-growing tree species (George et al. 2003; Helmisaari et al. 2009; Ostonen et al. 2005).

\section{Data analysis}

314 The frequency of roots intermingling with cluster roots was analysed as count data with

315 Poisson and negative binomial regression models (Zuur et al. 2009). Based on the image 316 analysis described above, one of three 'interaction' types was assigned to each observation

317 based on whether the co-occurring 'other roots' were first observed before (Fig. 1), during

318 (Fig. S3), or after (Fig. S4) the presence of live cluster roots. The average lifespan of cluster-

319 roots, including the immature and mature stage, was 23 days (Teste et al. 2018). For cluster

320 roots that did not fully develop by the end of the study, interaction type 'before' or 'during'

321 could still be assigned, but not 'after'. As such, we analysed the interaction type and

322 irrigation treatment as fixed effects (Table S1). When the irrigation treatment or other root

323 types affected the frequency of interaction, negative binomial models were fitted to account

324 for over-dispersion (Cameron and Trivedi 2005).

326 Total $\mathrm{P}$ and total $\mathrm{N}$ in cluster roots of different stages were compared with analysis of 327 variance and confidence intervals followed by the Tukey HSD test. We calculated a clusterroot P-remobilisation efficiency (\%) based on the mean values of stage I and other stages (e.g.

329 [stage I - stage III] / stage I). Cluster-root vitality was analysed as proportion data with

330 generalised linear models. The assumptions for the statistical models were assessed

331 graphically, with plots of residuals and boxplots for treatment variances. All graphing and

332 statistical analyses were conducted in R (R Core Team 2020) and 'ggplot2' packages

333 (Therneau 2015; Wickham 2016). 
337 Root intermingling with cluster roots

338 A total of 2091 root fragments were imaged between April and October 2012, where 57 of

339 these developed into mature cluster roots such as shown in Figs S2, S3, S4, and S5. As a

340 cluster root appeared and developed, other roots were seen in very close proximity (i.e. within

341 the same $13.5 \times 18 \mathrm{~mm}$ image frame), likely interacting and possibly acquiring $\mathrm{P}$ mobilised

342 by the cluster root (Figs S3, S4, S5). Intermingling roots of non-cluster-root species were

343 distinguished by colour, size, and lateral branching.

345 In all 57 image frames with cluster roots, at least one other root type was observed before,

346 during or after the development of a live cluster root. This is in strong contrast with the

347 overall probability of observing roots: only $11.3 \%$ of images had roots. We also found 257

348 cases of intermingling between non-cluster herbaceous and woody roots out of a total of 2034

349 non-cluster roots (i.e. $12.6 \%$ of non-cluster herbaceous roots were intermingling during their

350 emergence with non-cluster woody roots). As such, the frequency of intermingling between

351 non-cluster roots is considerably lower than that of intermingling between cluster roots and

352 non-cluster roots $\left(X^{2}=331, d f=1, P<0.001\right)$. Furthermore, the maximum number of non-

353 cluster roots intermingling with cluster roots within the same image frame was six, which

354 occurred in an irrigated plot (data not shown). The majority of root intermingling with cluster

355 roots (95\%) was observed under irrigation (155 roots) compared with non-irrigated plots (9

356 roots, Fig. 2). Furthermore, in $90 \%$ of cases, intermingling roots appeared when live cluster

357 roots were present, as opposed to before their appearance or after their senescence (Fig. 2; for

358 photographs see Figs S2, S3, S4). The majority of intermingling cluster and non-cluster roots

359 were found at the surface and upper-middle layers of the soil profile, rather than in deeper

360 layers (Fig. S5). 
362 Remobilisation of phosphorus and nitrogen from senescing cluster roots

363 To test if senesced cluster roots could serve as important sources of $\mathrm{P}$ or $\mathrm{N}$, we determined

364 total $\mathrm{P}$ and $\mathrm{N}$ concentrations in cluster roots at the first three stages of development (see

365 Methods - Glasshouse experiment). Total P concentrations of cluster roots reached very low

366 levels at stage III, the senesced stage (Fig. 3). We found a cluster-root P-remobilisation

367 efficiency of $88.5 \%$ based on the mean values of stages I and III ([stage I - stage III] / stage I)

368 from Fig. 3. Total N concentration in cluster roots peaked at developmental stage I (fully-

369 formed cluster root) and was lowest at stage III (Fig. 3). Cluster-root N-remobilisation

370 efficiency was $89.2 \%$.

371

372 Root vitality of cluster rootlets

373 We found a substantial decrease in rootlet vitality, as expected, yet there were still some

374 unstained, possibly live, rootlets at stage III (Fig. 4). However, the stain does not always bind

375 to dead roots, in this case rootlets, especially those that only recently died. Therefore, these

376 data may overestimate live rootlet percentage.

378 Phosphorus available to intermingling roots in developing and mature cluster rhizospheres

379 In order to calculate the amount of P possibly available to roots capable of intermingling with

380 cluster roots, during their development, we gathered several values from field samples and the

381 literature. First, at the study site, mean total soil $\mathrm{P}$ concentration is estimated to be $21.1 \mathrm{mg}$

$382 \mathrm{~kg}^{-1}$, very similar to $17.8 \mathrm{mg} \mathrm{kg}^{-1}$ which was measured on nearby Spearwood dunes (Turner et

383 al. 2018). Part of this $\mathrm{P}$, estimated as resin-extracted inorganic $\mathrm{P}$ (Pi; $1.35 \mathrm{mg} \mathrm{kg}^{-1}$ and 1.27

$384 \mathrm{mg} \mathrm{kg}^{-1}$ in Turner et al. (2018)) is available to any root. Additional to this freely available Pi,

385 cluster roots extract additional amounts of $\mathrm{P}$ by bringing inorganic and organic $\mathrm{P}$ in solution

386 (mobilised by carboxylates) and hydrolysing organic P (i.e. phosphatase-extractable P) 

was estimated as $2.16 \mathrm{mg} \mathrm{kg}^{-1}$ dry soil from older studies (McPharlin et al. 1994; Ozanne and Shaw 1968; Pathan et al. 2003; Watson et al. 1982). We measured Carboxylate-extractable Pi (citrate-extractable $\mathrm{P}$ ) as $1.59 \mathrm{mg} \mathrm{P} \mathrm{kg}^{-1}$ dry soil and organic $\mathrm{P}$ that could potentially be accessed (i.e. Organic-P available) by our Banksia cluster roots. This Organic-P available fraction was estimated as $16.7 \mathrm{mg} \mathrm{P} \mathrm{kg}^{-1}$ dry soil, similar to the value of $12.5 \mathrm{mg} \mathrm{P} \mathrm{kg}^{-1}$ dry soil found in recent work from our group (Zhou et al. unpublished) and similar to the $\mathrm{NaOH}-$ extractable organic $\mathrm{P}$ of $10.6 \mathrm{mg} \mathrm{P} \mathrm{kg}^{-1}$ dry soil from Turner et al. (2018).

\section{Phosphorus available to intermingling roots in senesced cluster rhizospheres}

In order to calculate the amount of $\mathrm{P}$ possibly available to roots capable of intermingling with senesced cluster roots, we gathered several values from field samples and the literature. We made these calculations, given that cluster roots produce an abundance of fine root biomass in a small volume of soil, and despite efficient remobilisation of $\mathrm{P}$ from senescing cluster roots, we hypothesised that some remaining $\mathrm{P}$ might be available to intermingling roots. As such, we first estimated this amount of $\mathrm{P}$, expressed as a soil $\mathrm{P}$ concentration, as the product of the P concentration in senesced clusters and the dry mass density of cluster roots in soil. density of cluster roots in soil were $0.0284 \mathrm{~g}$ cluster roots per g dry rhizosphere soil, similar to what was measured in another Banksia study (Pate and Watt 2002). Therefore, the amount of $\mathrm{P}$ remaining in senesced cluster roots is estimated at $118 \mathrm{mg} \mathrm{P} \mathrm{kg}^{-1}$ cluster roots $\mathrm{x} 0.0284 \mathrm{~g}$ 408 cluster roots $\mathrm{g}^{-1}$ soil $=3.36 \mathrm{mg} \mathrm{P} \mathrm{g}^{-1}$ dry rhizosphere soil (Fig. 5). As such, we estimate the

409 volume used by these cluster roots is approximately $37.8 \mathrm{mg}$ of cluster roots per $\mathrm{cm}^{3}$ of soil in 410 these sandy soils. 
413 Combining the information presented in the preceding sections, we expect non-cluster roots to

414 have access to $1.35 \mathrm{mg} \mathrm{P} \mathrm{kg}^{-1}$ soil (Free Pi, resin-P values from Turner et al. (2018) and

415 mentioned above) outside cluster rhizospheres, increasing to a potential $19.6 \mathrm{mg} \mathrm{P} \mathrm{kg}^{-1} \mathrm{soil}$

416 (i.e. Free Pi (1.35) + Carboxylate-extractable Pi (1.59) + Organic-P available (16.68) Fig. 5)

417 in cluster rhizospheres (but in competition with cluster roots), and then decreasing to a

418 potential $3.36 \mathrm{mg} \mathrm{P} \mathrm{kg}^{-1}$ soil (senesced cluster roots) after clusters have senesced (assuming

419 that $\mathrm{P}$ in senesced clusters is completely available to other roots or their mycorrhizas) (Fig. 5).

420 Based on our previous work, we estimated a mean lifespan of 23 days for Banksia cluster

421 roots (Teste et al. 2018); as such we suggest that $\mathrm{P}$ from senescing cluster roots could become

422 available to other roots from $~ 23$ days after the start of CR development.

424 Discussion

425 We documented the in situ seasonal dynamics of Banksia cluster-root formation with 426 minirhizotrons, and determined, for the first time, the degree of intermingling events by roots

427 of non-cluster-rooted species. The very high frequency of roots intermingling with cluster 428 roots, relative to the cluster roots detected with our minirhizotrons, during their development 429 and period of peak activity represents the first evidence of physical interaction between such 430 roots, and shows that P-mobilisation facilitation may potentially operate in these nutrient-poor 431 soils. Although intermingling certainly occurred between non-cluster roots, we found that the 432 presence of cluster roots significantly promoted intermingling events, since we always 433 observed the appearance of at least one other non-cluster root. Our estimates of soil P 434 availability before, during and after peak cluster-root activity, support the hypothesis that 435 potential benefits exist for non-cluster roots of invading cluster rhizospheres, and that these 436 benefits are greatest during periods of cluster-root exudation. 
439 Root intermingling was prominent, and P-uptake facilitation likely. We found that roots of

440 other non-cluster rooted species freely intermingled with all B. attenuata cluster roots that we

441 observed, especially when cluster roots were mature or developing. These intermingling

442 events were particularly pronounced when soil moisture conditions were at a historical, rather

443 than current precipitation level for this Mediterranean woodland (Teste et al. 2018). We

444 recently demonstrated that Banksia spp. may be sensitive to a drying climate, with a lower

445 incidence of cluster roots under drier soil conditions (Teste et al. 2018).

446 Further research is needed to elucidate the mechanism of intermingling, and specifically the 447 signal(s) triggering growth of roots towards cluster roots. It is unlikely that the signal is $\mathrm{P}$ 448 itself, because P migration in soil is very slow (Lambers and Oliveira 2019). Biogenic 449 volatile organic signals may be involved (Peñuelas et al. 2014a): cluster roots may release 450 VOCs into surrounding soil and prime more root proliferation from intraspecific roots. This 451 would be a novel mechanism for VOCs, but would resemble the root-to-root signalling that 452 has been documented between unstressed plants to drought-stressed plants (Falik et al. 2011; 453 Peñuelas et al. 2014b). It is also possible that both cluster roots and intermingling roots 454 respond to a common signal indicating a locally-high resource level such as resource-rich 455 patches (Hodge 2009). The signal could be a mobile nutrient, such as nitrate, or a volatile 456 signal generated by roots or soil microbes. The possibility of nitrate as a signal for root 457 proliferation, which may provide a large potential benefit for nutrients such as $\mathrm{P}$ in our study 458 system, suggests an alternative explanation for the observation in the study of van Vuuren et 459 al. (1996), where many roots grew after most of the $\mathrm{N}$ in an enriched patch had been 460 depleted.Those late-growing roots probably still had significant benefits from nutrients other 461 than $\mathrm{N}$. 
464 The P-acquisition benefits that other roots could gain from intermingling with cluster roots in

465 terms of P availability in soil during cluster-root development and senescence (i.e. during and

466 after cluster activity; Fig. 2) is considerable (Fig. 5). Such a benefit would come from the P-

467 mobilising activity of cluster roots through exuded carboxylates and phosphatases. However,

468 the $\mathrm{P}$ availability in both living and senesced cluster rhizospheres are maximum estimates,

469 given that cluster roots are likely strong competitors for P uptake, and P in senesced clusters

470 may largely be in organic forms, or immobilised by microbes, and thus not available to other

471 roots. We expect that the peak of the P-acquisition benefits would be short-lived and occur between

$472 \sim 20$ to 30 days after the initiation of the development of the cluster root, based on our glasshouse and

473 field observations of the development stages of Banksia cluster roots (Teste et al. 2018) and well-

474 documented observations of cluster-root physiology in hydroponics (Shane \& Lambers 2005).

475 We estimated that $16.9 \mathrm{mg} \mathrm{P} \mathrm{kg}^{-1}$ soil represents the theoretical maximum amount of $\mathrm{P}$

476 available to intermingling roots during the presence of an active cluster root, assuming all $\mathrm{P}$

477 made available by the cluster roots could be taken up by intermingling roots. While clusters

478 are active (matching the period of maximum exudation of carboxylates and phosphatases),

479 plant-available soil $\mathrm{P}$ increases from $1.35 \mathrm{mg} \mathrm{kg}^{-1}$ (i.e. resin-P) to a maximum of $16.9 \mathrm{mg} \mathrm{kg}^{-1}$

480 (Fig. 4). Due to the very high density of cluster rootlets relative to intermingling roots in the

481 rhizosphere, cluster roots would have a competitive advantage for uptake of the P mobilised

482 by themselves. Nevertheless, intermingling roots that invade the cluster rhizosphere, or are at

483 the outer boundary of the clusters, are positioned within a zone of influence of carboxylates

484 and phosphatases where they may benefit from mobilised P.

485 Our estimates indicate that there is more $\mathrm{P}$ in living cluster roots than extractable soil $\mathrm{P}$ in that

486 same soil volume (Fig. 5), demonstrating that both efficient soil P extraction and efficient P

487 remobilisation from senescent roots are essential for cluster roots to be effective and a

488 functional investment benefitting the plant's P economy. Intermingling roots need to compete

489 with cluster roots to access mobilised P pools; and we expected that effects from the large 
amounts of carboxylates exuded by cluster roots and their high-affinity P transporters would maximise the share of that mobilised $\mathrm{P}$ for the cluster roots. However, the theoretical

492 maximum amounts of $\mathrm{P}$ that could be gained are worth further empirical testing.

\section{Remobilisation of root phosphorus during cluster root senescence}

495 The amount of P remaining after senescence of the cluster roots might be accessible to non496 cluster roots entering or staying in that "senesced-cluster region", and although the amounts

497 are small, such roots might derive a P benefit from decomposing cluster roots in these 498 impoverished soils. We found a very high root P-remobilisation efficiency of $89 \%$ based on determining the root $\mathrm{P}$ concentrations during the development and fully senesced stages of our

500 Banksia cluster roots. Physiological studies of Hakea cluster roots with controlled

501 hydroponic systems found similarly high root P-remobilisation efficiency of $95 \%$ (Shane et

502 al. 2004). These results show only a very small amount of $P$ remains after a cluster has senesced for uptake by intermingling non-cluster roots (Fig. 5), compared with the amount that may be gained by intermingling with active cluster roots. Our observation that intermingling roots arrive when cluster roots are alive, rather than senesced (Fig. 2), supports

506 the concept that intermingling roots respond to a signal indicating the imminent opportunity

507 of enhanced resource availability ( $\mathrm{P}$ and micronutrients), and that most resources become available through cluster-root induced mobilisation, rather than cluster-root decomposition.

\section{Evidence for the potential of facilitated uptake of phosphorus}

511 The facilitated uptake of P that may occur between cluster-rooted species and other

512 interacting plant species such as mycorrhizal plant species falls under two of the three broad

513 facilitative mechanisms proposed by Wright et al. (2017). First, indirect biotic facilitation

514 may result if other roots can scavenge the $\mathrm{P}$ that is mobilised by the active cluster root.

515 Second, abiotic facilitation due to local P enrichment by senesced cluster roots remains a 
516 possibility in the most severely-impoverished soils where very small amounts of $\mathrm{P}$ can still

517 increase plant growth of other plant species capable of taking up the $\mathrm{P}$ 'mined' by the cluster

518 roots. Our findings suggest that the first mechanism, indirect biotic facilitation, is probable

519 with some level of $\mathrm{P}$ enrichment of the cluster rhizosphere during mobilisation of soil $\mathrm{P}$ as

520 previously proposed (Gardner and Boundy 1983; Lambers et al. 2013; Li et al. 2007).

521 Nutrient-mobilisation-based facilitation as proposed in Lambers et al. (2018) and

522 demonstrated in crop plants (e.g., lupin) may also be ecologically relevant for iron (Fe), zinc

$523(\mathrm{Zn})$ and manganese (Mn), since these micronutrients are also mobilised during cluster-root 524 activity (Li et al. 2014).

525 Nutrient (P, Fe, $\mathrm{Zn}$ and $\mathrm{Mn}$ )-mobilisation-based facilitation is mainly driven by: i) the release

526 of large amounts of organic acids and chelating substances from cluster roots that increase the

527 concentrations of these nutrients in the soil solution (Lambers et al. 2018); and ii) the ability

528 of other roots to first sense the activity of cluster roots and then grow in the rhizosphere of

529 cluster roots directly or via their extra-radical mycorrhizal hyphae (i.e. in the case where

530 mycorrhizal roots are intermingling). Microcosm studies using Banksia as the cluster-rooted

531 plants lend some support to this principle; improved plant growth of neighbouring and

532 interacting plants was shown (Muler et al. 2014; Teste et al. 2014). We suggest that nutrient-

533 mobilisation-based facilitation is more common than previously thought; however, more

534 formal testing is required (see section on Future directions below).

536 Potential impacts of a drying climate on interactions with cluster roots

537 Plant species compositional shifts may occur due to a drying climate, if $\mathrm{P}$ and micronutrient

538 uptake of coexisting plants is facilitated by the root activity of cluster-rooted plants (Lambers

539 et al. 2018; McIntire and Fajardo 2014). Cluster-root development and its capacity to

540 mobilise $\mathrm{P}$ from poorly-available forms in soil is affected by soil moisture levels (Lamont

541 1976; Lamont 2003). We found that lower soil moisture levels reduce cluster-root occurrence 
542 in this system (Teste et al. 2018); thus their P-mobilising activities would also be reduced in a

543 given plant community. We also found that the majority of root intermingling between non-

544 cluster roots and cluster roots occurred in the surface soil layers, where soil drying is typically

545 faster than that in deeper soil layers. Our findings suggest that a considerable amount of P

546 benefits may be obtained when coexisting plants intermingle their roots in the rhizospheres of

547 cluster-rooted plant species. Thus, plant species that depend on this type of interaction to

548 meet their P demand may be the first to succumb in plant communities dominated by cluster-

549 rooted plants during further drying of this Mediterranean environment.

550

$551 \quad$ Future directions

552 Radio-isotope $\mathrm{P}$ work (i.e. ${ }^{33} \mathrm{P}$ and ${ }^{32} \mathrm{P}$ ) would help quantify the magnitude of $\mathrm{P}$-mobilisation

553 facilitation, but documenting radioactive $\mathrm{P}$ movement in megadiverse habitats would be very

554 challenging, if not impossible. Analysis of the spatial pattern between cluster-rooted Banksia

555 plants and plants potentially interacting could convey evidence for facilitation, but the lateral

556 extent of Banksia cluster roots is far reaching ( 2x tree height in B. prionotes (Jeschke and

557 Pate 1995)), so the distance between plants may not be a good predictor of the intensity of

558 facilitative relationships. As such, current methodology such as minirhizotrons, nutrient

559 tracers, and microcosm experiments will still be needed to progress our understanding of the

560 roles of belowground facilitation in plant species coexistence. Finally, to robustly test for

561 facilitation, future studies could entail: i) identifying the plant species whose roots intermingle

562 with cluster-rooted plants; ii) quantify the differences between foliar P concentrations with

563 and without neighbouring Banksia; and iii) quantify a metric that could serve as a proxy for

564 improved fitness (e.g., seed production).

565

566

Conclusions 
567 We provide evidence for in situ root interactions between cluster-rooted Banksia species and

568 roots of other species with implications for species coexistence when soil moisture conditions

569 are favourable. We calculated the potential $\mathrm{P}$ benefits to roots growing in or near the

570 rhizosphere of clusters during and after their peak activity. The most frequent root interaction

571 type described here was when soils were relatively moist, and can be viewed as a plant

572 version of 'kleptoparasitism' (Gorman et al. 1998; Thompson 1986; Zomora 1995). These

573 are the first accounts of a kleptoparasitism-type root interaction, and we suggest that such

574 interactions occur between other cluster-rooted species and neighbouring plants with

575 considerable potential for nutrient-mobilisation-based facilitation. These interactions and

576 facilitative mechanisms are likely also relevant for other specialised root strategies (e.g.,

577 carboxylate-releasing simple cluster roots, dauciform roots, sand-binding roots, vellozioid

578 roots) and in other P-impoverished ecosystems such as campos rupestres (Abrahão et al.

579 2019; Teodoro et al. 2019). Such interactions may promote species co-existence and act as a

580 means of increasing species diversity in severely nutrient-impoverished soils.

581

\section{Acknowledgements}

583 Michael Blair and Raymond Scott provided help at the start of the experimental setup and

584 tube installations and for facilitating access to the field station. We are grateful to Jairo Palta,

585 then at CSIRO in Floreat, for lending us the Bartz minirhizotron camera. Thomas Mazet

586 played a key role with imaging during rainy days. We are especially grateful to Judith

587 Holmes and Victoria A. Marchesini for their valuable help during the root annotation with

588 RootFly. We thank Michael Smirk and Katrina Walton for their help quantifying nutrient

589 concentrations of cluster roots. Finally, we thank Simone Pedrini for the illustrations of the

590 cluster roots in Fig. 4. Funding was provided by The University of Western Australia with a

591 Research and Development Award granted to FPT and the Australian Research Council with

592 a Discovery Project (ARC DP0985685) to HL, EJV and KWD. KWD and EJV are also 
594 for the Centre for Mine Site Restoration (Project Number ICI150100041).

595

596 Compliance with ethical standards

597 Conflict of interest

598 The authors declare that they have no conflict of interest.

599

600 Ethical approval

601 This article does not contain any studies with human participants or animals performed by any

602 of the authors.

603

604

\section{Data accessibility}

605

Data will be made available as part of a separate digital file in the Electronic Supplementary

606

Material section (Data S1).

607

608

References

609

Abrahão A et al. (2019) Soil types select for plants with matching nutrient-acquisition and -

610

611

612

613

614

615

616

617

618

619

620

621

622

623

624

625

626

627

628

629

630

631 use traits in hyperdiverse and severely nutrient-impoverished campos rupestres and cerrado in Central Brazil. Journal of Ecology 107:1302-1316

Beeck D (2017) Cluster-root exudation of carboxylate and phenolic compounds by two species of Banksia. Honours thesis, The University of Western Australia, Crawley, WA, Australia

Cameron AC, Trivedi PK (2005) Microeconometrics: methods and applications. Cambridge University Press, Cambridge

Chen W, Koide RT, Eissenstat DM (2018) Root morphology and mycorrhizal type strongly influence root production in nutrient hot spots of mixed forests. Journal of Ecology 106:148-156. doi: 10.1111/1365-2745.12800

Crosti R, Dixon KW, Ladd PC, Yates CJ (2007) Changes in the structure and species dominance in vegetation over 60 years in an urban bushland remnant. Pacific Conservation Biology 13:158-170

Delgado M, Zúñiga-Feest A, Alvear M, Borie F (2013) The effect of phosphorus on clusterroot formation and functioning of Embothrium coccineum (R. et J. Forst.). Plant and Soil 373:765-773

Denton MD, Veneklaas EJ, Freimoser FM, Lambers H (2007a) Banksia species (Proteaceae) from severely phosphorus- impoverished soils exhibit extreme efficiency in the use and re- mobilization of phosphorus. Plant, Cell and Environment 30:1557-1565

Denton MD, Veneklaas EJ, Lambers H (2007b) Does phenotypic plasticity in carboxylate exudation differ among rare and widespread Banksia species (Proteaceae)? New Phytologist 173:592-599 
651

652

653

654

655

656

657

658

659

660

661

662

663

664

665

666

667

668

669

670

671

672

673

674

675

676

677

678

679

680

681

682

Diffenbaugh NS, Field CB (2013) Changes in ecologically critical terrestrial climate conditions Science 341:486-492

Faget $\mathrm{M}$ et al. (2013) Root-root interactions: extending our perspective to be more inclusive of the range of theories in ecology and agriculture using in-vivo analyses. Annals of Botany 112:253-266. doi: 10.1093/aob/mcs296

Falik O, Mordoch Y, Quansah L, Fait A, Novoplansky A (2011) Rumor has it: relay communication of stress cues in plants. PlosONE 6:1-6

Fisher JL, Loneragan WA, Dixon K, Delaney J, Veneklaas EJ (2009) Altered vegetation structure and composition linked to fire frequency and plant invasion in a biodiverse woodland. Biological Conservation 142:2270-2281

Gardner WK, Boundy KA (1983) The acquisition of phosphorus by Lupinus albus L. IV. The effect of interplanting wheat and white lupin on the growth and mineral composition of the two species. Plant and Soil 70:391-402

George K, Norby R, Hamilton J, DeLucia E (2003) Fine- root respiration in a loblolly pine and sweetgum forest growing in elevated CO2. New Phytologist 160:511-522

Giovannetti M, Mosse B (1980) An evaluation of techniques for measuring vesicular arbuscular mycorrhizal infection in roots. New Phytologist 84:489-500

Gorman ML, Mills MG, Raath JP, Speakman JR (1998) High hunting costs make African wild dogs vulnerable to kleptoparasitism by hyaenas. Nature 391:479-481

Helmisaari H-S, Saarsalmi A, Kukkola M (2009) Effects of wood ash and nitrogen fertilization on fine root biomass and soil and foliage nutrients in a Norway spruce stand in Finland. Plant and Soil 314:121-132. doi: 10.1007/s11104-008-9711-4

Hodge A (2009) Root decisions. Plant, cell \& environment 32:628-640. doi: doi:10.1111/j.1365-3040.2008.01891.x

Hodge A (2012) Plant root interactions. In: Witzany G, Baluska F (eds) Biocommunication of plants, signaling and communication in plants, vol 14. Springer-Verlag, Berlin, pp 157-169

Hopper SD, Gioia P (2004) The southwest Australian floristic region: evolution and conservation of a global hot spot of biodiversity. Annual Review of Ecology, Evolution, and Systematics 35:623-650

Initiative IOC (2012) Western Australia's weather and climate: a synthesis of Indian Ocean Climate Initiative stage 3 research. Commonwealth of Australia, Melbourne

Jeschke WD, Pate JS (1995) Mineral nutrition and transport in xylem and phloem of Banksia prionotes (Proteaceae), a tree with dimorphic root morphology. Journal of Experimental Botany 46:895-905

Johnson MG, Tingey DT, Phillips DL, Storm MJ (2001) Advancing fine root research with minirhizotrons. Environmental and Experimental Botany 45:263-289. doi: 10.1016/s0098-8472(01)00077-6

Laliberté E et al. (2012) Experimental assessment of nutrient limitation along a 2- millionyear dune chronosequence in the south- western Australia biodiversity hotspot. Journal of Ecology 100:631-642

Lambers H (2014) Plant Life on the Sandplains in Southwest Australia.

Lambers $\mathrm{H}$ et al. (2018) How belowground interactions contribute to the coexistence of mycorrhizal and non-mycorrhizal species in severely phosphorus-impoverished hyperdiverse ecosystems. Plant and Soil 424:11-33. doi: 10.1007/s11104-017-3427-2

Lambers H et al. (2012) Proteaceae from severely phosphorus-impoverished soils extensively replace phospholipids with galactolipids and sulfolipids during leaf development to achieve a high photosynthetic phosphorus-use-efficiency. New Phytologist 196:10981108. doi: 10.1111/j.1469-8137.2012.04285.x

Lambers H, Chapin FS, Pons TL (2008) Plant physiological ecology. Springer, New York, USA 
Lambers H, Clements JC, Nelson MN (2013) How a phosphorus-acquisition strategy based on carboxylate exudation powers the success and agronomic potential of lupines (Lupinus, Fabaceae). American Journal of Botany 100:263-288

Lambers $\mathrm{H}$ et al. (2015) Metabolic adaptations of the non-mycotrophic proteaceae to soils with low phosphorus. In: Plaxton W, Lambers H (eds) Annual Plant Reviews, Phosphorus Metabolism in Plants, vol 48. John Wiley \& Sons, Ltd., pp 289-336

Lambers H, Oliveira R (2019) Plant Physiological Ecology, 3rd edition. Springer International Publishing

Lambers H, Shane M, Laliberté E, Swarts N, Teste F, Zemunik G (2014) Plant Mineral Nutrition. In: Lambers H (ed) Plant Life on the Sandplains in Southwest Australia, a Global Biodiversity Hotspot. UWA Publishing, Crawley, pp 101-127

Lamont B (1982) Mechanisms for enhancing nutrient uptake in plants, with particular reference to mediterranean South Africa and Western Australia. The Botanical Review 48:597-689

Lamont BB (1976) The effects of seasonality and waterlogging on the root systems of a number of Hakea species. Australian Journal of Botany 24:691-702

Lamont BB (2003) Structure, ecology and physiology of root clusters - a review. Plant and Soil 248:1-19

Li B et al. (2016) Root exudates drive interspecific facilitation by enhancing nodulation and $\mathrm{N}_{2}$ fixation. Proceedings of the National Academy of Sciences 113:6496-6501. doi: 10.1073/pnas. 1523580113

Li L et al. (2007) Diversity enhances agricultural productivity via rhizosphere phosphorus facilitation on phosphorus-deficient soils. Proceedings of the National Academy of Sciences 104:11192-11196

Li L, Tilman D, Lambers H, Zhang FS (2014) Plant diversity and overyielding: insights from belowground facilitation of intercropping in agriculture. New Phytologist 203:63-69

McArthur WM, Bettenay E (1974) The development and distribution of the soils of the Swan Coastal Plain. CSIRO, Australia

McIntire EJB, Fajardo A (2014) Facilitation as a ubiquitous driver of biodiversity. New Phytologist 201:403-416. doi: 10.1111/nph.12478

McPharlin I, Jeffery R, Weissberg R (1994) Determination of the residual value of phosphate and soil test phosphorus calibration for carrots on a Karrakatta sand. Communications in Soil Science \& Plant Analysis 25:489-500

Metzner R et al. (2015) Direct comparison of MRI and X-ray CT technologies for 3D imaging of root systems in soil: potential and challenges for root trait quantification. Plant Methods 11. doi: 10.1186/s13007-015-0060-Z

Mommer L, Kirkegaard J, van Ruijven J (2016) Root-root interactions: towards a rhizosphere framework. Trends in plant science 21:209-217

Muler AL, Oliveira RS, Lambers H, Veneklaas EJ (2014) Does cluster-root activity benefit nutrient uptake and growth of co-existing species? Oecologia 174:23-31

Myers N, Mittermeier RA, Mittermeier CG, Da Fonseca GA, Kent J (2000) Biodiversity hotspots for conservation priorities. Nature 403:853-858

Oburger E, Schmidt H (2016) New methods to unravel rhizosphere processes. Trends in plant science 21:243-255. doi: http://dx.doi.org/10.1016/j.tplants.2015.12.005

Ostonen I, Lõhmus K, Pajuste K (2005) Fine root biomass, production and its proportion of NPP in a fertile middle-aged Norway spruce forest: comparison of soil core and ingrowth core methods. Forest Ecology and Management 212:264-277

Ozanne P, Shaw T (1968) Advantages of the recently developed phosphate sorption test over the older extractant methods for soil phosphate. In: Holmes JW (ed) Transactions of the 9th International Congress of Soil Science, vol. Volume 2. Angus and Robertson, Sydney, Australia, pp 273-280 
Pate JS, Beard JS (1982) Kwongan, plant life of the sandplain. University of Western Australia Press

Pate JS, Dell B (1984) Economy of mineral nutrients in sandplain species. In: Pate JS, Beard JS (eds) Kwongan, Plant Life of the Sandplain. University of Western Australia Press, Nedlands, Australia., pp 227-252

Pate JS, Watt M (2002) Roots of Banksia spp. (Proteaceae) with special reference to functioning of their specialized proteiod root clusters In: Eshel A, Beeckman T (eds) Plant Roots: the Hidden Half. Marcel Dekker Inc., New York, pp 989-1006

Pathan S, Aylmore L, Colmer T (2003) Soil properties and turf growth on a sandy soil amended with fly ash. Plant and Soil 256:103-114

Peñuelas J et al. (2014a) Biogenic volatile emissions from the soil. Plant, Cell and Environment 37:1866-1891

Peñuelas J et al. (2014b) Biogenic volatile emissions from the soil. Plant, cell \& environment 37:1866-1891. doi: 10.1111/pce.12340

Peterson RL, Peterson CA, Melville LH (2008) Teaching plant anatomy: through creative laboratory exercises. NRC Research Press

R Core Team (2020) R: A language and environment for statistical computing. R Foundation for Statistical Computing, Vienna, Austria

Saunders WMH, Williams EG (1955) Observatioms on the determination of total organic phosphorus in soils. Journal of Soil Science 6:254-267

Schenk HJ (2006) Root competition: beyond resource depletion. Journal of Ecology 94:725739. doi: $10.1111 / j .1365-2745.2006 .01124 . x$

Schmittgen S et al. (2015) Magnetic resonance imaging of sugar beet taproots in soil reveals growth reduction and morphological changes during foliar Cercospora beticola infestation. Journal of Experimental Botany 66:5543-5553. doi: 10.1093/jxb/erv109

Shane MW et al. (2004) Developmental physiology of cluster-root carboxylate synthesis and exudation in harsh hakea. Expression of phosphoenolpyruvate carboxylase and the alternative oxidase. Plant Physiology 135:549-560

Shane MW, Lambers H (2005) Cluster roots: a curiosity in context. Plant and Soil 274:101125

Shi J, Strack D, Albornoz FE, Han Z, Lambers H (2020) Differences in investment and functioning of cluster roots account for different distributions of Banksia attenuata and $B$. sessilis, with contrasting life history. Plant and Soil:, in press

Smit AL, Bengough AG, Engels C, van Noordwijk M, Pellerin S, van de Geijn SC (2000) Root methods: a handbook. Springer-Verlag, Berlin Heidelberg

Teodoro GS et al. (2019) Specialized roots of Velloziaceae weather quartzite rock while mobilizing phosphorus using carboxylates. Functional Ecology 33:762-773

Teste FP, Marchesini VA, Veneklaas EJ, Dixon KW, Lambers H (2018) Root dynamics and survival in a nutrient-poor and species-rich woodland under a drying climate. Plant and Soil 424:91-102. doi: 10.1007/s11104-017-3323-9

Teste FP, Veneklaas EJ, Dixon KW, Lambers H (2014) Complementary plant nutrientacquisition strategies promote growth of neighbour species. Functional Ecology 28:819-828

Therneau T (2015) A package for survival analysis in S. version 2.38, R package version 2.38 edn

Thompson D (1986) The economics of kleptoparasitism: optimal foraging, host and prey selection by gulls. Animal Behaviour 34:1189-1120

Turner BL, Hayes PE, Laliberté E (2018) A climosequence of chronosequences in southwestern Australia. European Journal of Soil Science 69:69-85. doi: doi: $10.1111 /$ ejss. 12507 
Turner BL, Romero TE (2009) Short-term changes in extractable inorganic nutrients during storage of tropical rain forest soils. Soil Science Society of America Journal 73:19721979

van Dusschoten D et al. (2016) Quantitative 3D analysis of plant roots growing in soil using magnetic resonance imaging. Plant Physiology 170:1176-1188. doi: 10.1104/pp.15.01388

van Vuuren MMI, Robinson D, Griffiths BS (1996) Nutrient inflow and root proliferation during the exploitation of a temporally and spatially discrete source of nitrogen in soil. Plant and Soil 178:185-192

Watson A, Matthiessen J, Springett B (1982) Arthropod associates and macronutrient status of the red- ink sundew (Drosera erythrorhiza Lindl.). Austral Ecology 7:13-22

Watt M, Evans JR (1999) Linking development and determinacy with organic acid efflux from proteoid roots of white lupin grown with low phosphorus and ambient or elevated atmospheric $\mathrm{CO}_{2}$ concentration. Plant Physiology 120:705-716

Wickham H (2016) ggplot2: Elegant Graphics for Data Analysis. Springer-Verlag, New York, USA.

Williams JDH, Syers JK, Walker TW, Rex RW (1970) A comparison of methods for the determination of soil organic phosphorus. Soil Science 110:13-18

Wright AJ, Wardle DA, Callaway R, Gaxiola A (2017) The overlooked role of facilitation in biodiversity experiments. Trends in Ecology \& Evolution. doi: 10.1016/j.tree.2017.02.011

Wyrwoll K-H, Turner BL, Findlater P (2014) 1a. On the origins, geomorphology and soils of the sandplains of south-western Australia. In: Lambers H (ed) Plant Life on the Sandplains in Southwest Australia, a Global Biodiversity Hotspot. UWA Publishing, Crawley, pp 3-22

Yu R-P, Li X-X, Xiao Z-H, Lambers H, Li L (in press) Phosphorus facilitation and covariation of root traits in steppe species. New Phytologist n/a. doi: 10.1111/nph.16499

Yu RP, Zhang WP, Yu YC, Yu SB, Lambers H, Li L (2020) Linking shifts in species composition induced by grazing with root traits for phosphorus acquisition in a typical steppe in Inner Mongolia. Sci Total Environ 712:136495. doi: 10.1016/j.scitotenv.2020.136495

Zeng G, Birchfield ST, Wells CE (2010) Rapid automated detection of roots in minirhizotron images. Machine Vision and Applications 21:309-317

Zomora R (1995) The trapping success of a carnivorous plant, Pinguicula vallisneriifolia: the cumulative effects of availability, attraction, retention and robbery of prey. Oikos 73:309-322

Zuur AF, Ieno EN, Walker NJ, Saveliev AA, Smith GM (2009) Mixed effects models and extensions in ecology with R. Springer, New York, NY, USA 
825 Fig. 1* Photographs of in situ root intermingling between a Banksia attenuata cluster

826 root (shown with white arrow) and other roots (shown with black arrow) of other

827 species (i.e. herbaceous and woody plants) in a banksia-eucalypt woodland (Tube 20,

828 Window 4 from 9 September to 5 October, 2012). In top image, a cluster root starts to

829 form with other roots seen below. Based on this series of images, a frequency of

830 intermingling response was generated; here, frequency $=2$, since two non-cluster roots

831 are seen in the same image frame. Since 'other roots' were present before the

832 appearance of the cluster root, we named this root interaction 'before cluster root'

833 (BeforeCR)). Also see Fig. S3 and Fig. S4 for photographic examples of the other

834 interaction types, and see Fig. 2 for differences in the frequency of interactions with

835 irrigation and amongst the two general root types. See Teste et al. (2018) for an

836 estimate of in situ survival rates of cluster roots and their rootlets. Also see Shane and

837 Lambers (2005) for photographs of Banksia cluster roots that clearly show their

838 'compound' shape. [*Figure to be possibly reworked by the journal's illustrator].

840 Fig. 2 Frequency of intermingling of cluster roots and herbaceous or woody roots

841 during April - October 2012 in a banksia-eucalypt woodland. This intermingling

842 response was based on the joint occurrence of live cluster roots with other live roots in

843 small minirhizotron image frames (height $=1.35 \mathrm{~cm}$, width $=1.8 \mathrm{~cm}$ ) that hosted at

844 least one live cluster root. The other roots appeared before the cluster root developed

845 (BeforeCR; Fig. 1), while the cluster root was alive (DuringCR; Fig. S3), or during

846 senescence (AfterCR; Fig. S4). We found the negative binomial model to be the best fit

$847 \quad($ AIC $=199$, Theta $=1.986)$ for these data; these showed a statistically significant

848 interaction between the irrigation treatment and type of interaction $(P$-value $=0.011)$,

849 while no significant effect of root type was found (see Table S1 for summary statistics).

850 Fig. 3 Concentrations of total nitrogen $(\mathrm{N})$ and phosphorus (P) across the developmental 851 stages of cluster roots. Values are means with $95 \%$ confidence intervals, and different 852 letters to indicate statistically-significant differences between means (Tukey HSD tests 853 with $P \leq 0.05)$. Shown here are four developmental stages of cluster roots: stage pre854 cluster (immature cluster roots; $n=21$ ); stage I (fully-formed cluster roots; $n=16$ ); stage

855 II (cluster roots with rusty brown colour and some loss of vigour; $n=34$ ); and stage III

856 (dark brown or grey cluster roots with noticeable loss of vigour; $n=29$ ).

857 Fig. 4 Percent of live (i.e. unstained) rootlets across the developmental stages of cluster

858 roots. Values are mean percent of live rootlets with $95 \%$ confidence intervals, and

859 different letters indicate statistically-significant differences between means (Tukey HSD

860 tests with $P \leq 0.05$ ). Shown here are three developmental stages of cluster roots: stage I

861 (fully-formed cluster roots; $\mathrm{n}=16$ ); stage II (cluster roots with rusty brown colour and

862 some loss of vigour; $\mathrm{n}=16$ ); and stage III (dark brown or grey cluster roots with

863 noticeable loss of vigour; $n=31$ ). 
864 Fig. 5 Phosphorus (P) concentrations typically found in Spearwood sandy soils, as well 865 as $\mathrm{P}$ contained in Banksia cluster roots (CR), all expressed per unit soil dry mass.

866 Carboxylate-extractable inorganic $\mathrm{P}(\mathrm{Pi})$ and organic-P are potentially available to 867 intermingling roots (indicated with root illustrations), in the short period that cluster 868 roots exude P-mobilising compounds (carboxylates and phosphatases). Phosphorus 869 remaining in senesced cluster roots is potentially available to intermingling roots after 870 CR death (indicated with root illustrations). 
871

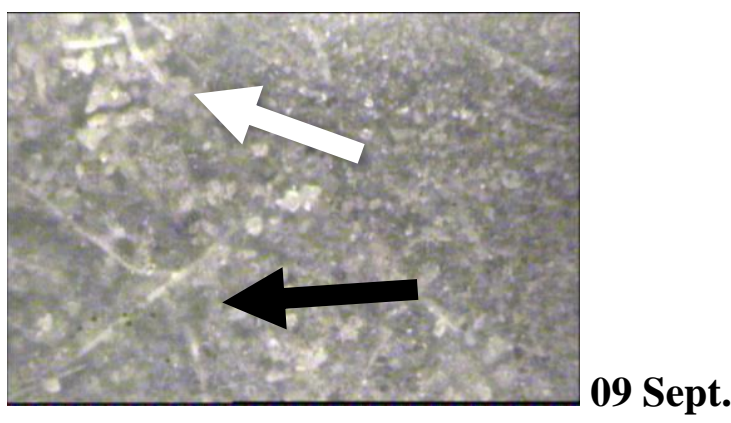

872

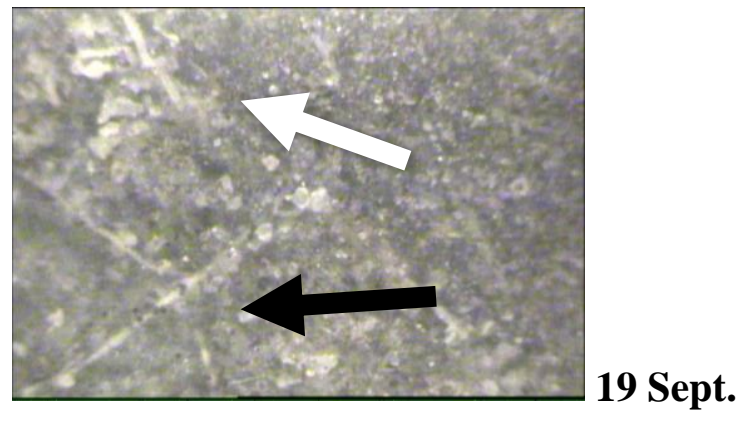

873

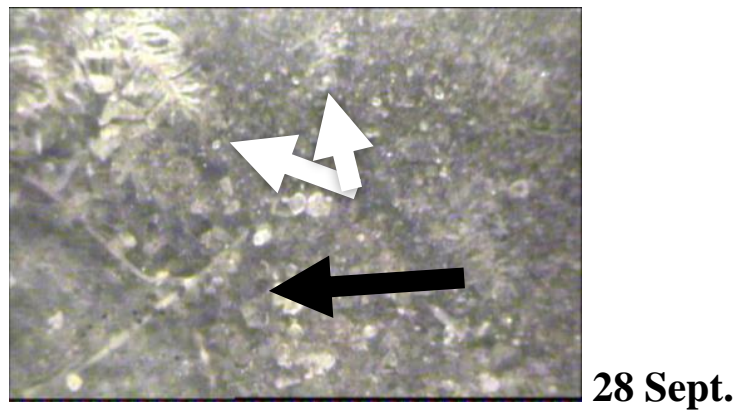

874

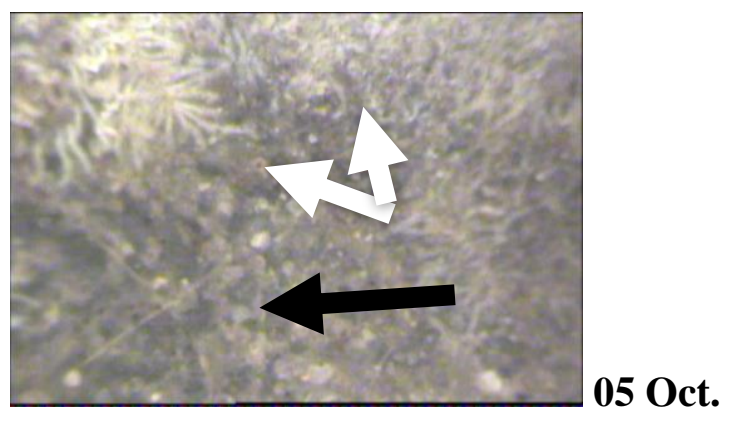

875 Fig. 1* 


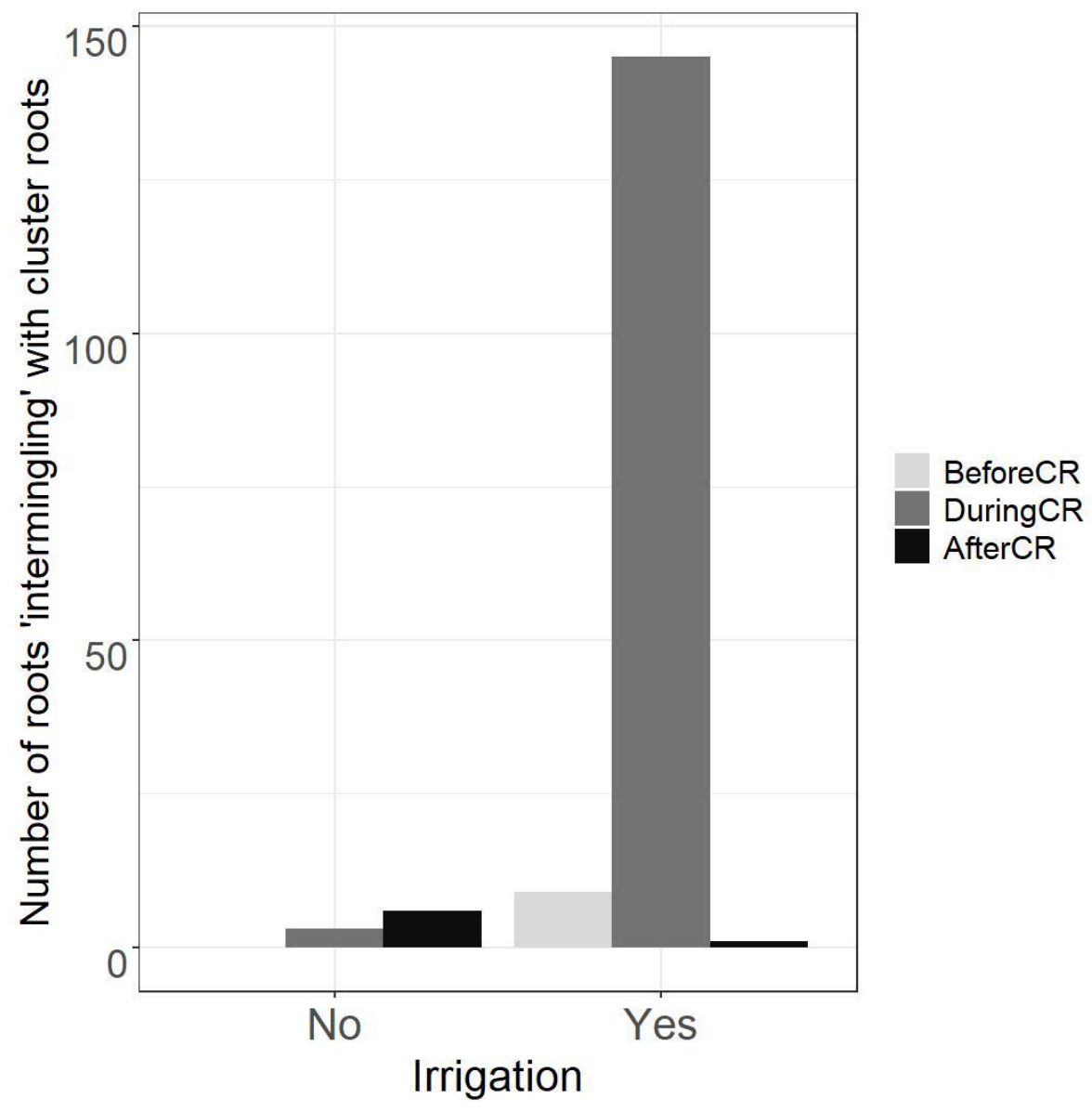

$877 \quad$ Fig. 2 


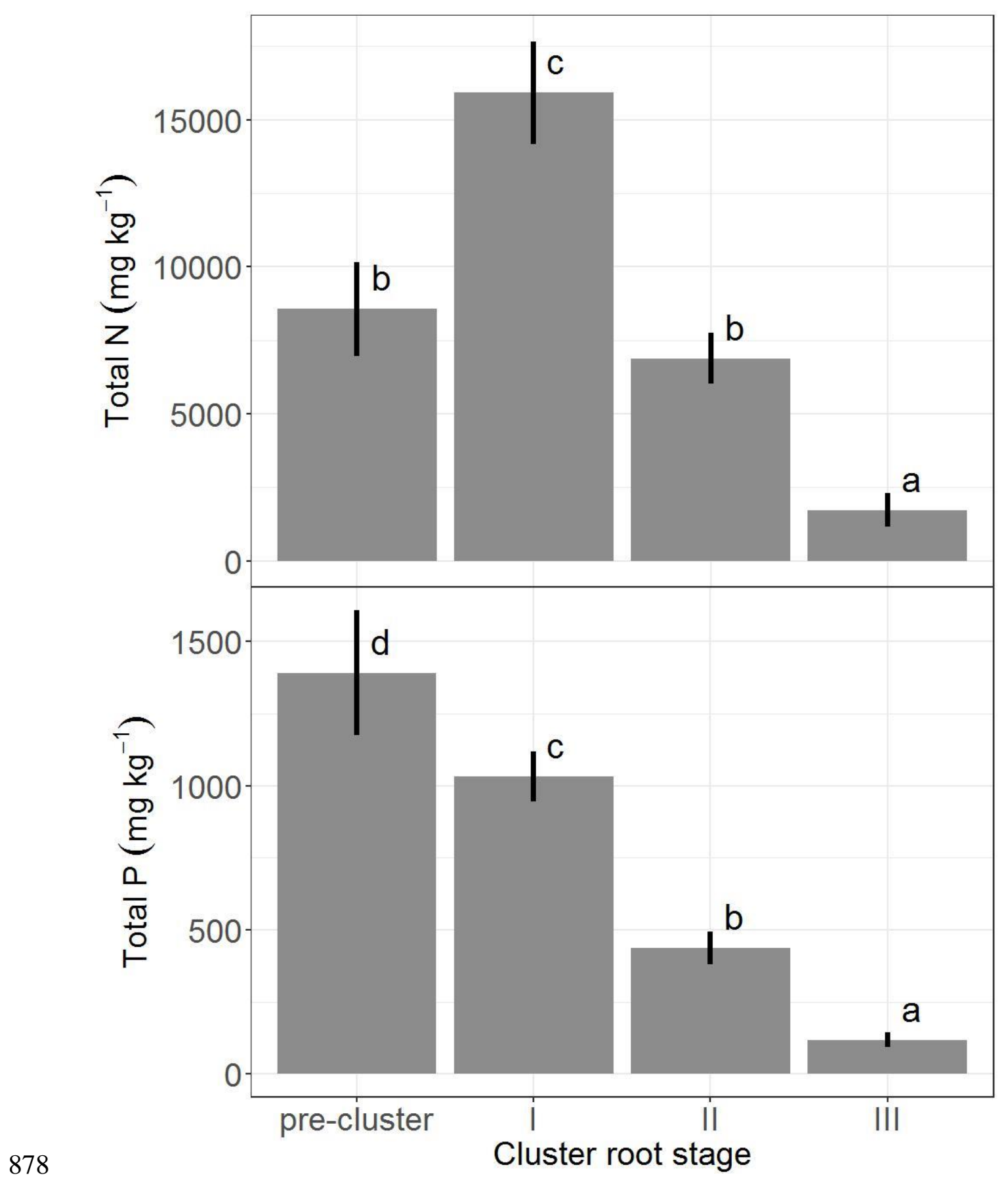

$879 \quad$ Fig. 3 


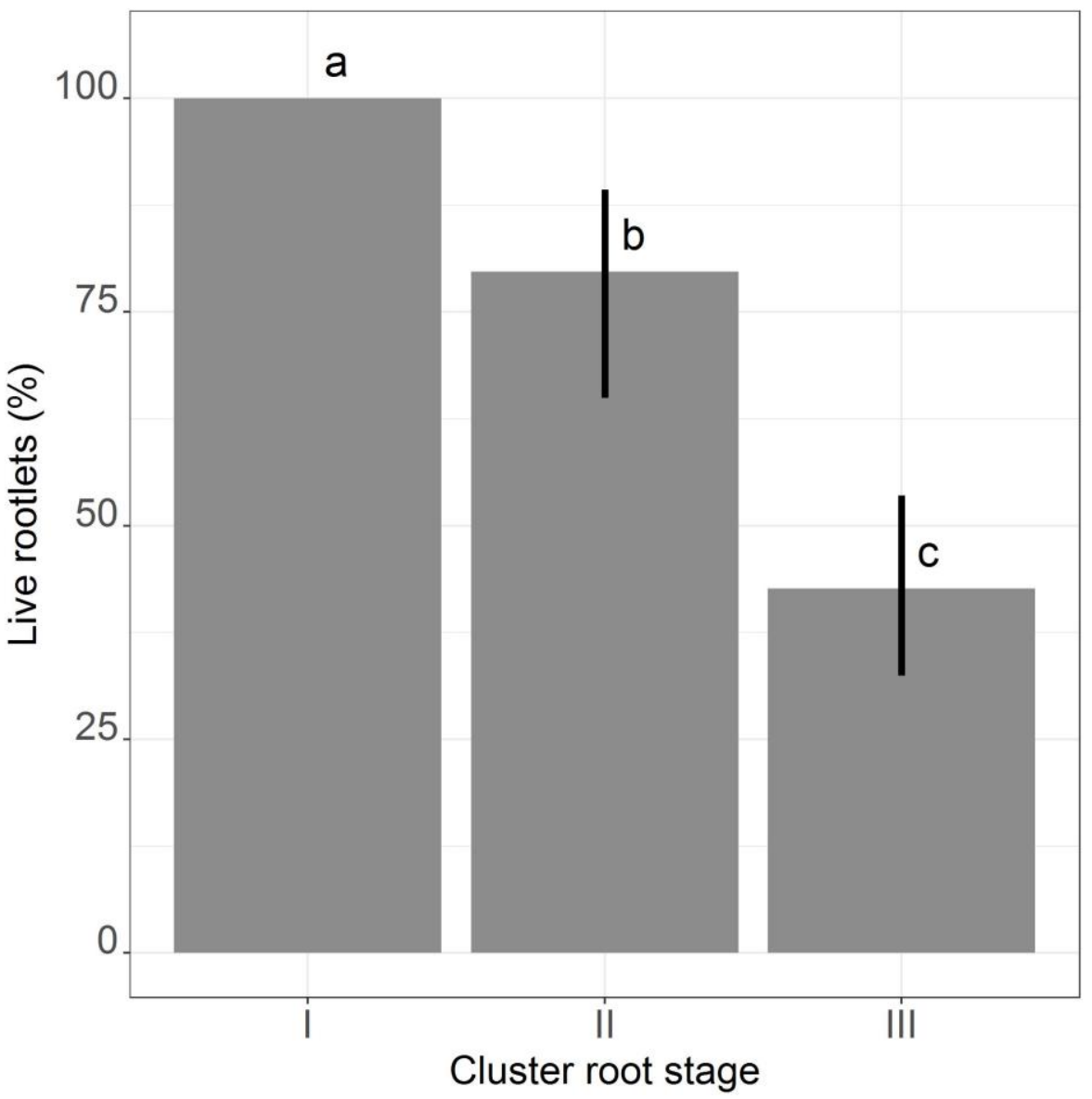

$881 \quad$ Fig. 4 


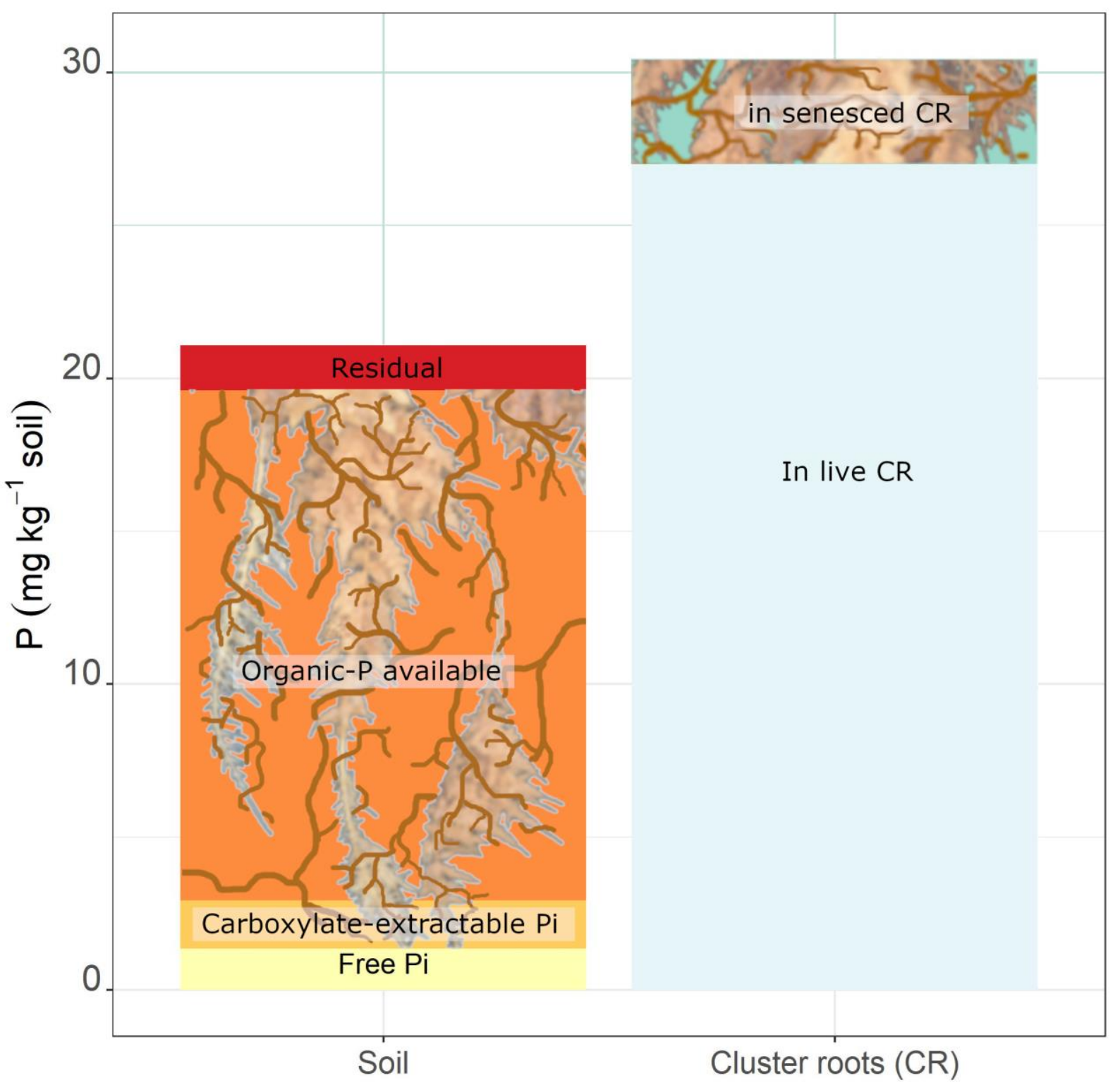

882

$883 \quad$ Fig. 5 


\section{ELECTRONIC SUPPLEMENTARY MATERIAL}

Table S1. Analysis of deviance tables of the Poisson and negative binomial regression models (full and minimal adequate model determined via the stepAIC function) for the Frequency response data (Fig. 2) of roots intermingling with live cluster roots (CR).

\section{Analysis of Deviance (Dev) summary tables}

\section{Poisson full model}

\begin{tabular}{lllllll}
\hline \multirow{2}{*}{ Source of Deviance } & & & Residual & Residual \\
& df & Deviance & df & Dev & Pr(>Chi) \\
\hline NULL & - & - & 40 & 177.39 & - \\
Irrigation & 1 & 20.109 & 39 & 157.28 & $<\mathbf{0 . 0 0 1}$ \\
InteracWhen & 2 & 13.298 & 37 & 143.98 & $\mathbf{0 . 0 0 1}$ \\
RTInterac & 1 & 0.215 & 36 & 143.76 & 0.643 \\
Irrigation:InteracWhen & 2 & 15.329 & 34 & 128.44 & $<\mathbf{0 . 0 0 1}$ \\
Irrigation:RTInterac & 1 & 0.700 & 33 & 127.73 & 0.403 \\
InteracWhen:RTInterac & 2 & 2.561 & 31 & 125.17 & 0.278 \\
Irrigation:InteracWhen:RTInterac & 2 & 0.719 & 29 & 124.45 & 0.698 \\
\hline
\end{tabular}

InteracWhen: BeforeCR, DuringCR, or AfterCR. RTInterac: the other types of roots (Herbaceous or Woody) interacting with CR. 


\begin{tabular}{llllll}
\hline \multirow{2}{*}{ Source of Deviance } & & & Residual & Residual & \\
& df & Deviance & df & Dev & $\operatorname{Pr}(>$ Chi $)$ \\
\hline NULL & - & - & 40 & 177.39 & - \\
Irrigation & 1 & 20.109 & 39 & 157.28 & $<\mathbf{0 . 0 0 1}$ \\
InteracWhen & 2 & 13.298 & 37 & 143.98 & $\mathbf{0 . 0 0 1}$ \\
Irrigation:InteracWhen & 2 & 15.196 & 35 & 128.78 & $\mathbf{0 . 0 0 1}$ \\
\hline
\end{tabular}

894

df: degrees of freedom

895

\section{Negative binomial full model}

\begin{tabular}{|c|c|c|c|c|c|}
\hline Source of Deviance & $\mathrm{df}$ & Deviance & $\begin{array}{l}\text { Residual } \\
\text { df }\end{array}$ & $\begin{array}{l}\text { Residual } \\
\text { Dev }\end{array}$ & $\operatorname{Pr}(>$ Chi $)$ \\
\hline NULL & - & - & 40 & 58.4737 & - \\
\hline Irrigation & 1 & 8.2489 & 39 & 50.2248 & 0.0041 \\
\hline InteracWhen & 2 & 4.8166 & 37 & 45.4082 & 0.09 \\
\hline RTInterac & 1 & $1 \mathrm{e}-04$ & 36 & 45.4081 & 0.9913 \\
\hline Irrigation:InteracWhen & 2 & 9.2123 & 34 & 36.1958 & 0.01 \\
\hline Irrigation:RTInterac & 1 & 0.2084 & 33 & 35.9874 & 0.648 \\
\hline InteracWhen:RTInterac & 2 & 1.5634 & 31 & 34.424 & 0.4576 \\
\hline Irrigation:InteracWhen:RTInterac & 2 & 0.5945 & 29 & 33.8295 & 0.7429 \\
\hline
\end{tabular}


897

898 Negative binomial minimal adequate model

\begin{tabular}{llllll}
\hline \multirow{2}{*}{ Source of Deviance } & & & Residual & Residual \\
& df & Deviance & df & Dev & $\operatorname{Pr}(>$ Chi $)$ \\
\hline NULL & - & - & 40 & 57.0737 & - \\
Irrigation & 1 & 8.059 & 39 & 49.0146 & $\mathbf{0 . 0 0 4 5}$ \\
InteracWhen & 2 & 4.7076 & 37 & 44.307 & 0.095 \\
Irrigation:InteracWhen & 2 & 9.0556 & 35 & 35.2514 & $\mathbf{0 . 0 1 0 8}$
\end{tabular}

df: degrees of freedom. 
901 Fig. S1 Location of the research plots (white triangle) where this study using

902 minirhizotron tubes was carried out. A photo of the irrigation treatment in action on Plot

9036 from Teste et al. (2018) with a Banksia attenuata tree in the centre with white-capped

904 minirhizotron tubes all around. Also shown is the Bartz BTC2 Minirhizotron video

905 camera imaging on Plot 2. Plots were situated in remnant banksia-eucalypt (Eucalyptus

906 gomphocephala) banksia woodland of the UWA Shenton Park Field Station (31 '56' S,

$9071^{115^{\circ}} 47^{\prime}$ E) that is situated on the Swan Coastal Plain, Western Australia.

908 Fig. S2* Photographs of Banksia attenuata cluster-root appearance (shown with arrow)

909 and development in situ in a banksia-eucalypt woodland (Tube 2, Window 4 from 29

910 August to 5 October 2012). See Teste et al. (2018) for an estimate of in situ survival

911 rates of cluster roots and their rootlets. Also please see Shane and Lambers (2005) for

912 photographs of Banksia cluster roots that clearly show their 'compound' shape.

913 [*Figure to be possibly reworked by the journal's illustrator].

914 Fig. S3* Photographs of in situ root intermingling between a Banksia attenuata cluster

915 root and other roots of other species (i.e. herbaceous and woody plants) in a banksia-

916 eucalypt woodland (Tube 20, Window 5 from 29 August to 5 October, 2012). Since

917 'other roots' appeared during the development of a live cluster root we named this root

918 interaction 'during cluster root (DuringCR)). See Fig. 2 for differences in the frequency

919 of interactions with irrigation and amongst the two general root types. [*Figure to be

920 possibly reworked by the journal's illustrator].

921 Fig. S4* Photographs of in situ root intermingling between a Banksia attenuata cluster

922 root and other roots of other species (i.e. herbaceous and woody plants) in a banksia-

923 eucalypt woodland (Tube 2, Window 19 from 22 August to 19 September, 2012). Since

924 'other roots' appeared after the development of the cluster root we named this root

925 interaction 'after cluster root (AfterCR)). See Fig. 2 for differences in the frequency of

926 interactions with irrigation and amongst the two general root types. [*Figure to be

927 possibly reworked by the journal's illustrator].

928 Fig. S5 Frequency of other roots (herbaceaous and woody) intermingling with cluster

929 roots over distinct soil depth ranges ( 0 to $10 \mathrm{~cm}, 11$ to $20 \mathrm{~cm}$, and 21 to $40 \mathrm{~cm}$ ) during

930 months of peak root growth (April - October) of 2012 in a banksia-eucalypt woodland.

931 This intermingling response was based on the joint occurrence of live cluster roots with

932 other live roots in small minirhizotron image frames (height $=1.35 \mathrm{~cm}$, width $=1.8 \mathrm{~cm}$ )

933 that hosted at least one live cluster root. The other roots appeared before the cluster root

934 developed (BeforeCR; Fig. 1), while the cluster root was alive (DuringCR; Fig. S3), or

935 during senescence (AfterCR; Fig. S4). 


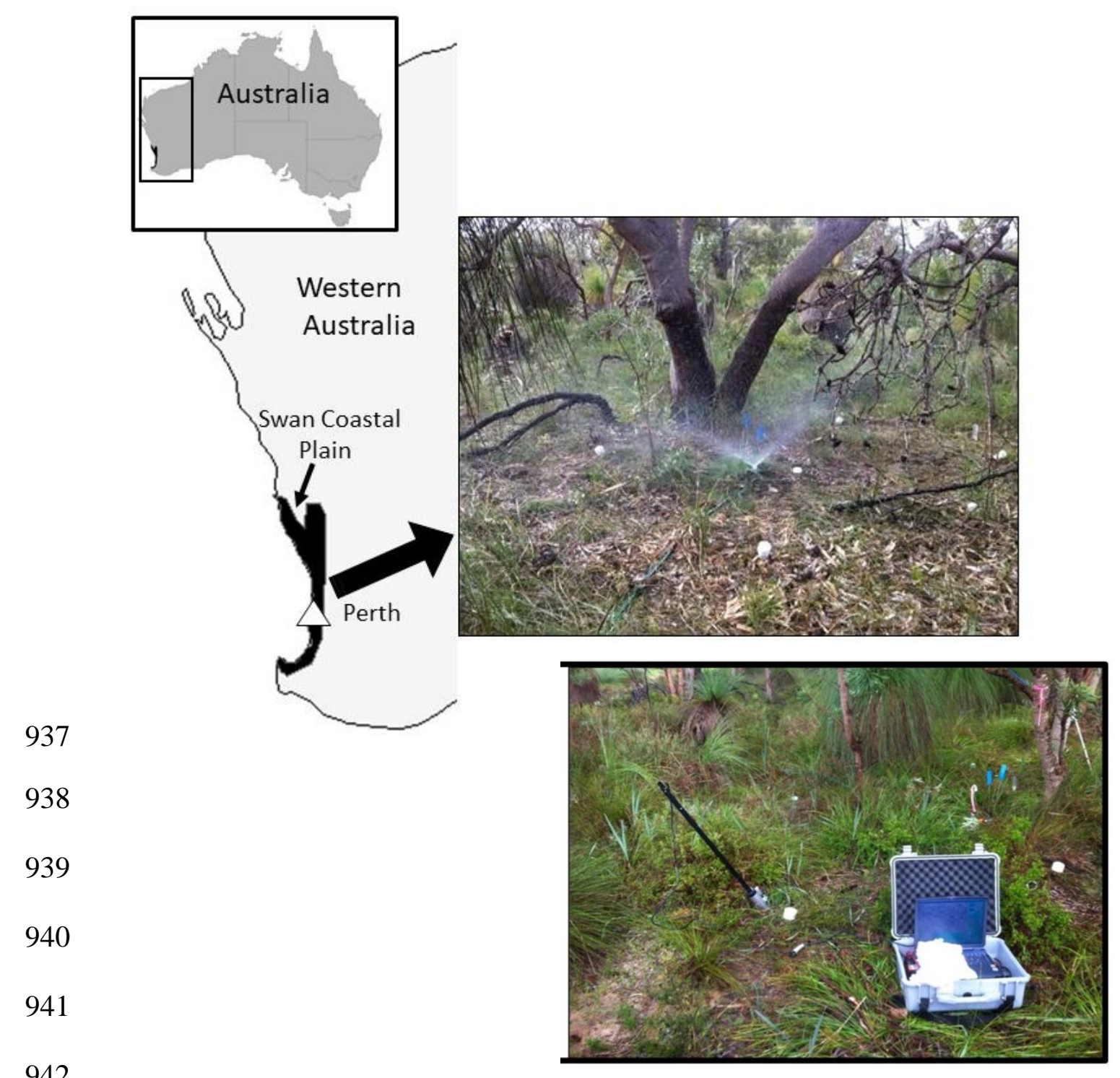

942

$943 \quad$ Fig. S1. 


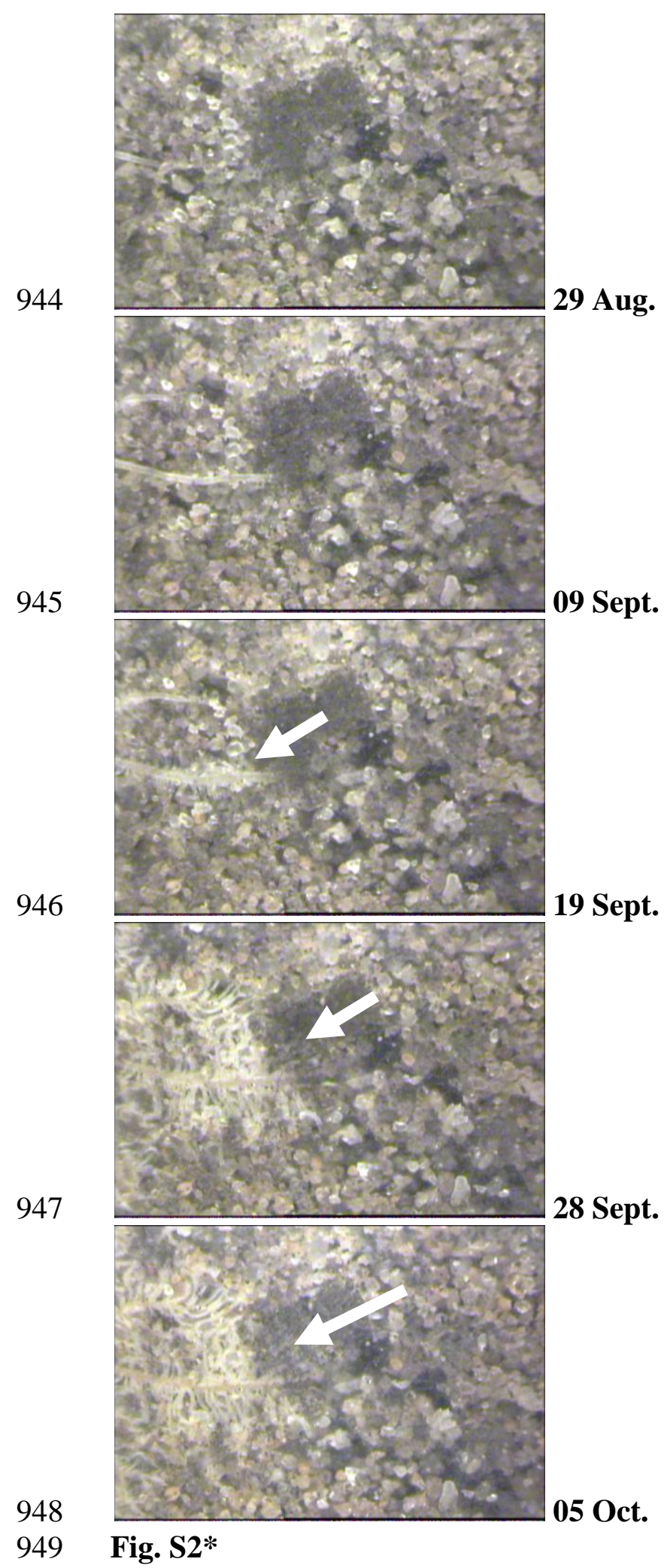




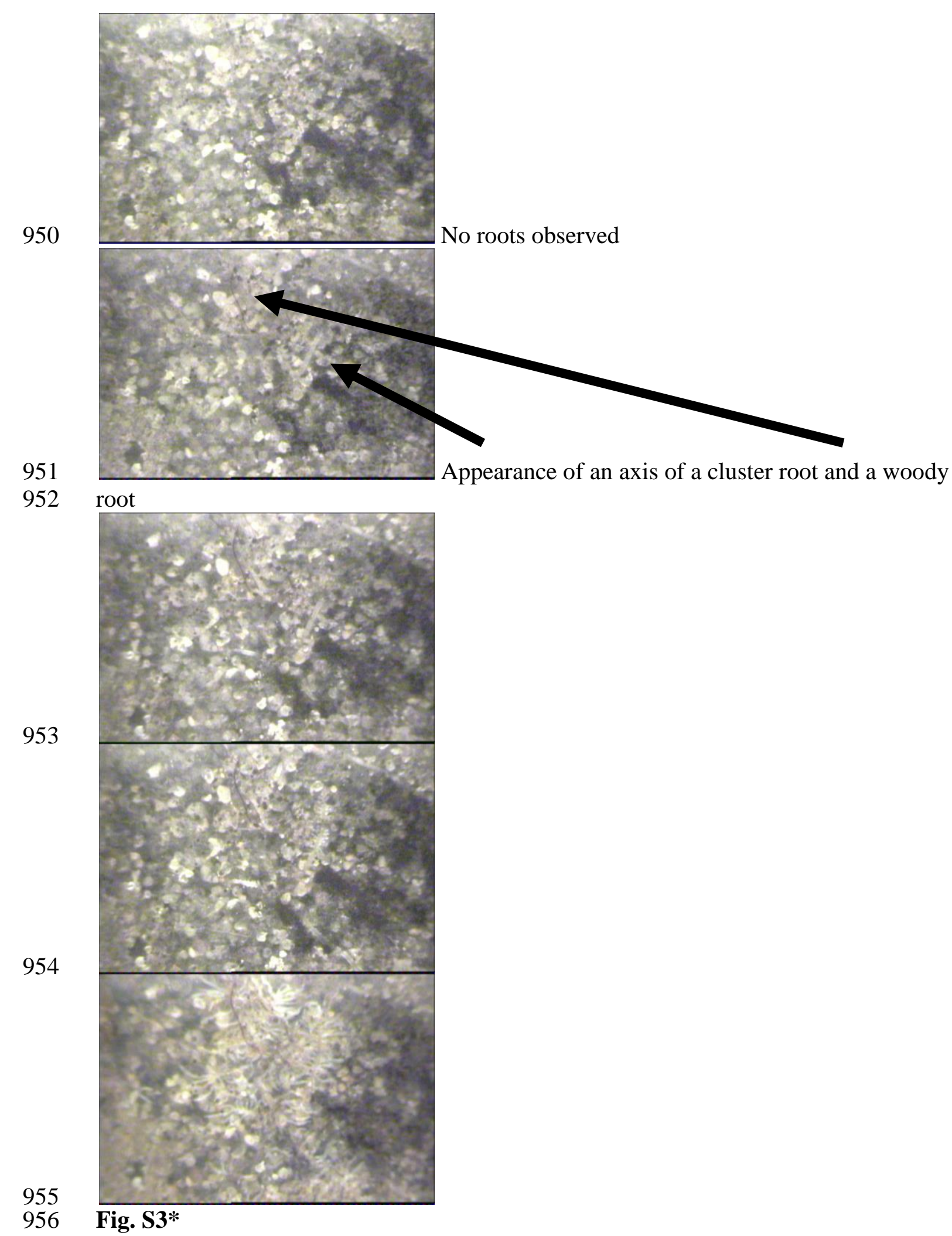




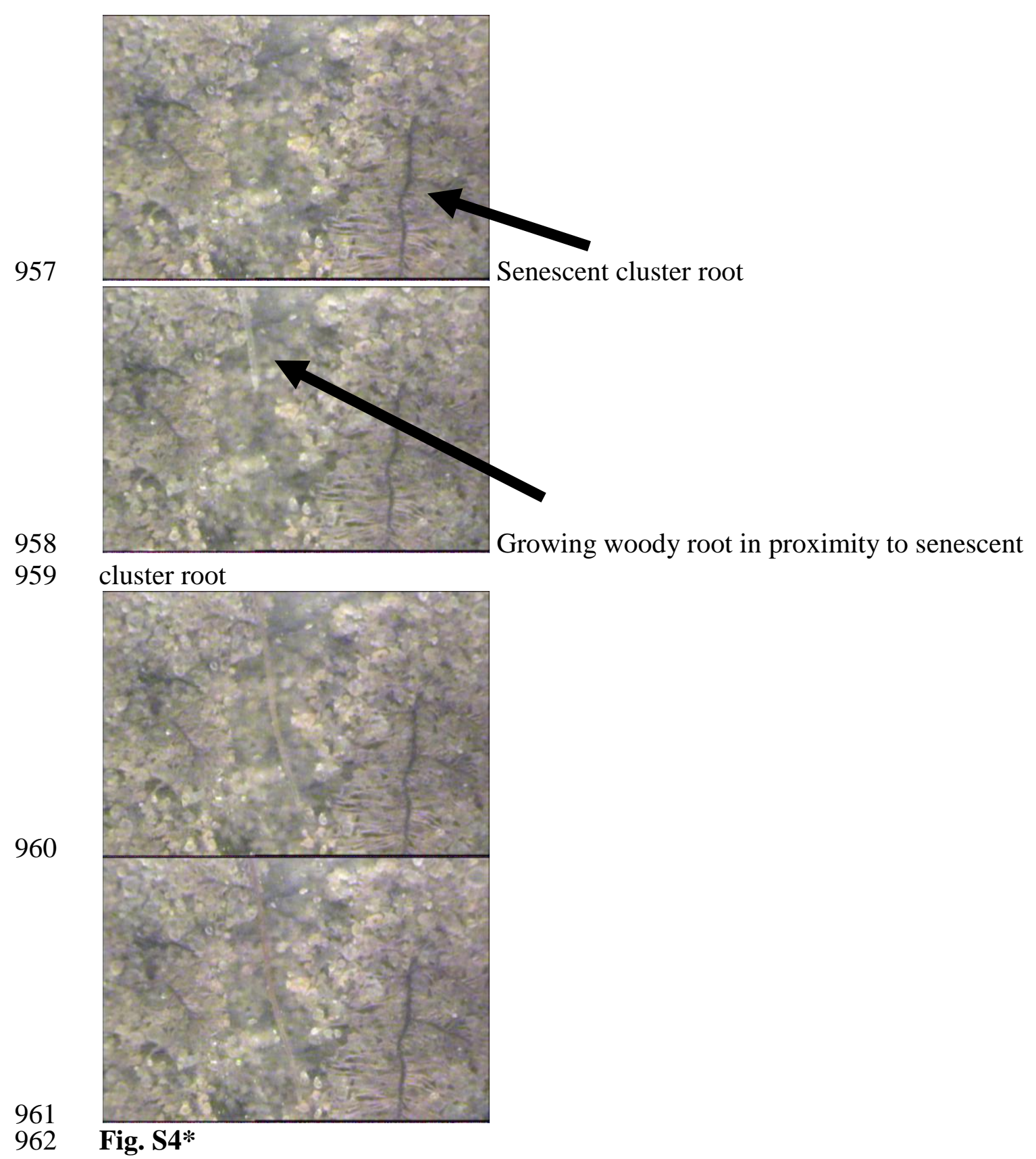




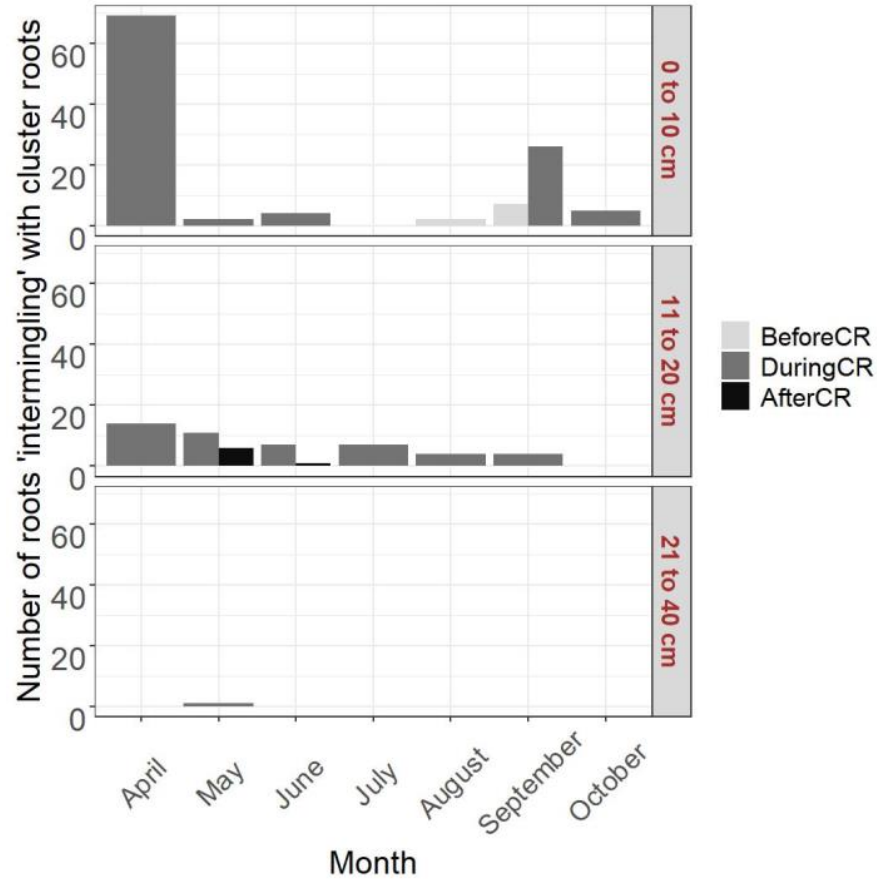

964 


\section{$965 \quad$ Data S1}

966 Data table S2 (separate Microsoft Excel file) has all data associated with this study. 
1 The potential for phosphorus benefits through root placement in the rhizosphere of phosphorus-mobilising neighbours

3

4 François P. Teste ${ }^{1,2}$, Kingsley W. Dixon ${ }^{1,3}$, Hans Lambers ${ }^{1,3,4}$, Jun Zhou ${ }^{1,5}$, Erik J.

5 Veneklaas ${ }^{1,6}$

7 Affiliations: ${ }^{1}$ School of Biological Sciences, The University of Western Australia, 35 Stirling

8 Highway, Crawley (Perth), WA 6009, Australia

$9 \quad{ }^{2}$ Present address: Grupo de Estudios Ambientales, IMASL-CONICET \& Universidad

10 Nacional de San Luis, Av. Ejercito de los Andes 950 (5700), San Luis, Argentina

$11{ }^{3}$ School of Molecular and Life Sciences, Curtin University, Kent Street, Bentley, WA 6102,

12 Australia

$13{ }^{4}$ College of Resources and Environmental Sciences, National Academy of Agriculture

14 Green Development; Key Laboratory of Plant-Soil Interactions of the Ministry of Education,

15 China Agricultural University, Beijing 100193, China

$16{ }^{5}$ Key Laboratory of Mountain Surface Processes and Ecological Regulation, Institute of

17 Mountain Hazards and Environment, Chinese Academy of Sciences, Chengdu 610041, China

$18{ }^{6}$ School of Agriculture and Environment, The University of Western Australia, 35 Stirling

19 Highway, Crawley (Perth), WA, 6009, Australia

21 Author for correspondence: François P. Teste

22 Email: francois.teste@uwa.edu.au

$23+542664520300(3055)$.

24

\section{Author Contributions:}

26 FPT, EJV, KWD, and HL designed the study. FPT analysed the data and wrote the first draft of the manuscript and all authors collected data and contributed substantially to revisions. 


\section{Abstract}

Plants that produce specialised cluster roots, which mobilise large quantities of poorly-available nutrients such as phosphorus $(\mathrm{P})$, can provide a benefit to neighbouring plants that produce roots in the cluster-rhizosphere, as demonstrated previously in pot studies. To be effective, such roots must be present within the short time of peak cluster activity. We tested if this requirement is met, and quantified potential $\mathrm{P}$ benefits, in a hyperdiverse Mediterranean woodland of southwest Australia where cluster-rooted species are prominent. Using minirhizotrons, we monitored root dynamics during the wet season in the natural habitat. We found non-cluster roots intermingling with all 57 of the observed cluster roots of the studied tree species, Banksia attenuata. Almost all (95\%) of these cases were observed in a highmoisture treatment simulating the 45-year average, but not present when we intercepted some of the rainfall. We estimate that cluster-root activity can increase $\mathrm{P}$ availability to intermingling roots to a theoretical maximum of $80 \%$ of total $\mathrm{P}$ in the studied soil. Due to their high $\mathrm{P}$ remobilisation efficiency (89\%), which results from P rapidly being relocated from cluster roots within the plant, senesced Banksia cluster roots are a negligible P source for other roots. We conclude that, rather than serving as a $\mathrm{P}$ source, it is the cluster-root activity, particularly the

44 exudation of carboxylates, that may improve the coexistence of interacting species that are capable of root intermingling, thus potentially promoting species diversity in nutrient-poor habitats, and that this mechanism will be less effective in a drying climate.

Keywords: Banksia attenuata and B. menziesii, climate change, minirhizotron, phosphorusmobilisation facilitation, phosphorus remobilisation. 
51 When plant roots intermingle, are there interactions among interspecific neighbours, and if so, what are the potential consequences of such interactions? Classical plant root studies demonstrate that roots of competing species tend to avoid each other, and thus reduce belowground resource competition for soil nutrients and water (Schenk 2006). Yet, recent root research, often using advanced tools to study roots in situ •r-(Metzner et al. 2015; Schmittgen et al. 2015; van Dusschoten et al. 2016), shows that root intermingling is perhaps more common than previously thought (Mommer et al. 2016; Oburger and Schmidt 2016).

58 The main scenarios that promote root intermingling, rather than root avoidance, have been

59 well-documented, and include: i) kin recognition (intraspecific roots), ii) nitrogen-uptake

60 facilitation (interspecific roots), where $\mathrm{N}_{2}$-fixing plants increase the availability of $\mathrm{N}$ to other 61 plants, and iii) patchiness of soil resources (intra- and interspecific roots) where the presence of localised high resource levels (e.g., N) leads to root proliferation (Chen et al. 2018; Faget et

63 al. 2013; Hodge 2012; Li et al. 2016). However, it is not known if root intermingling is

64 common when phosphorus (P) is the key limiting nutrient for plant growth, and what the potential benefits of intermingling are.

66

67 In severely P-impoverished soils of the hyperdiverse sandplains of southwest Australia's

68 biodiversity hotspot, many plants form cluster roots that are among the most efficient roots to

69 acquire poorly-available $P$ from such soils (Lambers et al. 2015). Cluster roots comprise a

70 main axis and many determinate ephemeral rootlets (Shane and Lambers 2005). Large

71 quantities of carboxylates, but also likely acid phosphatases, protons, and chelating substances, are released in an 'exudative burst' from cluster roots in several species (Delgado et al. 2013; Shane et al. 2004; Watt and Evans 1999), whereas in Banksia species, which have more complex cluster roots, exudation appears to occur at slower rates but for longer periods

(Beeck 2017; Shi et al. 2020). The release of carboxylates effectively increases the 
concentration of $\mathrm{P}$ and some micronutrients in the soil solution, thereby making them available for uptake (Shane and Lambers 2005). The development of cluster roots that exude large quantities of carboxylates into the cluster rhizosphere is referred to as "cluster-root activity'. As such, cluster-root activity involves a time-dependent process that increases $\mathrm{P}$ uptake by the cluster roots. Furthermore, there is evidence that, as a 'side effect', this process promotes P-uptake facilitation, which appears to occur when neighbouring plants grow along cluster-rooted plants (Gardner and Boundy 1983; Li et al. 2007; Muler et al. 2014). Yet, we lack empirical evidence showing in situ that other plant roots actually physically intermingle during these rapid biochemical rhizosphere processes (Lambers et al. 2018; Teste et al. 2018).

Root intermingling may be prevalent in P-limited environments to acquire sorbed P mobilised by carboxylates released by neighbours, but it is unclear what might direct the growth towards P-mobilising cluster roots, and what level of P-uptake benefits may result from such root interactions. Intermingling might be a random process, due to non-cluster roots being attracted by signals associated with cluster-root activity, or both non-cluster and cluster roots may be attracted by the same trigger (e.g., a high resource patch). A first step in elucidating mechanisms of intermingling with cluster roots is to demonstrate that intermingling is not random, to quantify its frequency, and to determine its timing relative to peak cluster-root activity. If non-cluster roots show a tendency to arrive in the rhizosphere of cluster roots when these are most active, this is likely an adaptive response to temporarily-enhanced resource availability.

Our ongoing work on foliar nutrient patterns within and in the neighbourhood of clusterrooted plant species is pointing to a considerable potential for P-mobilisation based facilitation in nutrient-poor soils (Abrahão et al. 2019). We have found increases in foliar manganese (Mn) levels in plant species neighbouring cluster-rooted species compared with 
controls without cluster-rooted neighbours (Muler et al. 2014). More recent studies show that plants that are potentially facilitated by carboxylate-releasing neighbours exhibit increased leaf [Mn] (Yu et al. in press; Yu et al. 2020). Here, for the first time, we present evidence that the fundamental conditions, relating to root positioning and rhizosphere-P dynamics, enable a considerable P benefit for other roots occurring within the rhizosphere of cluster roots.

Global climate change is leading to substantial drying climates in most Mediterranean ecosystems (Diffenbaugh and Field 2013; Indian Ocean Climate Initiative 2012). Southwest Australia's Mediterranean ecosystems, which host a biodiversity hotspot and many clusterrooted plant species (Lambers et al. 2014; Lamont 1982; Myers et al. 2000), could be affected by the drying climate. The production of cluster roots is stimulated by high surface soil moisture levels (Lamont 2003), and it appears that a minimum-threshold soil moisture level is required to trigger the plant into forming cluster roots (Lamont 1976; Lamont 2003). Our recent study in this ecosystem demonstrated a greater presence of cluster roots at high soil moisture levels compared with drier controls (Teste et al. 2018). However, effects of declining soil moisture levels on root interactions remain poorly explored in the field. Since plants that produce cluster roots are abundant and widespread in this biodiverse ecosystem, yet are particularly sensitive to changes in soil moisture, we proposed that plant community compositional shifts may continue to occur (Crosti et al. 2007; Fisher et al. 2009; Teste et al. 2018). In addition, we suggest that reductions in plant diversity may occur: i) if clusterrooted plants become less efficient at mining soil P due to narrower 'windows' of favourable soil moisture conditions (Teste et al. 2018); ii) P is less mobile in dry soil than in moist soil thus exacerbating point i) (Lambers et al. 2008); and iii) $\mathrm{P}$ and micronutrient uptake of coexisting plants is indeed facilitated by the root activity of cluster-rooted plants (Lambers et al. 2018). 
The overall aim of this study was to determine whether the spatial and temporal dynamics of cluster roots and roots of neighbouring plants provide clues for a potential P-mobilisation facilitative role of cluster roots. Our previous work (Muler et al. 2014; Teste et al. 2014) provided the theoretical underpinning and experimental support for facilitation by clusterrooted species, but we did not yet provide visual evidence of root intermingling in situ, which is fundamental to a P-facilitation hypothesis (Lambers et al. 2018). Here, we test if root placement and rhizosphere $\mathrm{P}$ conditions are such that they would make root-to-root facilitation possible. Using a combination of minirhizotron field and glasshouse experiments, and $\mathrm{P}$ budgets during root intermingling, we estimate the potential benefits of $\mathrm{P}$ mobilisation by cluster roots to interacting non-cluster rooted plants. The study aimed to test: i) is there evidence of root intermingling between cluster-rooted species and other plant species? ii) Do roots from neighbouring plant species intermingle before, during, or after cluster-root activity; and does greater soil moisture availability intensify intermingling? iii) How much $\mathrm{P}$ is potentially made available in the cluster rhizosphere?

\section{Kleptoparasitism is parasitism by theft of nutriment or a key resource. Kleptoparasitism is a} well-documented animal-animal interaction (Gorman et al. 1998; Thompson 1986), where the optimal foraging of one species of animal is taken advantage of by another species by timely 'robbery' of a key resource (e.g., food). This type of biological interaction has also been found between carnivorous plants and predatory insects (Zomora 1995). Kleptoparasitism between plants has yet to be shown, yet it may exist in P-impoverished systems, particularly if timely intermingling by non-cluster rooted plant species occurs during the peak-P foraging activity of cluster-rooted plants. 
Lambers 2005). These Banksia species are long-lived trees with extensive lateral and deep roots where cluster roots are commonly found just below the leaf litter and top layers (0 to 20 $\mathrm{cm}$ ) of the soil profile (Lambers 2014; Pate and Watt 2002; Teste et al. 2018). Root dynamics and interactions of all roots near the B. attenuata trees were monitored using installed minirhizotron tubes and cameras, and we quantified $\mathrm{P}$ concentration and remobilisation from cluster roots of B. menziesii in a glasshouse. These two Banksia species are physiologically similar and prominent components of these woodlands (Denton et al. 2007a; Lambers et al. 2012; Pate and Dell 1984). Finally, to evaluate the ways in which other roots might benefit from intermingling with cluster roots, the potential $\mathrm{P}$ availability in cluster-rhizospheres and after cluster root senescence was estimated.

\section{Methods}

Study site

Experimental irrigated and unirrigated plots were established in banksia-eucalypt woodland at The University of Western Australia's (UWA) Shenton Park Field Station $\left(31.96^{\circ} \mathrm{S}\right.$, $\left.115.79^{\circ} \mathrm{E}\right)($ Supporting Information Fig. S1). The site is located in the kwongan vegetation type on the Swan Coastal Plain within the Southwest Australian Floristic Region (sensu Hopper and Gioia 2004). The site is part of the Spearwood coastal dune system (McArthur and Bettenay 1974; Wyrwoll et al. 2014). The sandy soils are severely nutrient-impoverished (Turner et al. 2018), and the climate is Mediterranean with a mean annual temperature of $19.2^{\circ} \mathrm{C}$ and average annual rainfall of $702 \mathrm{~mm}$ (Australia's Bureau of Meteorology; http://www.bom.gov.au/climate/data/; 1967 to 2011), where most of the rain occurs between May and September, the cooler "winter months" of the Southern Hemisphere. During these winter months, most of the root growth including cluster roots occurs (Lamont 2003; Pate and Beard 1982), thus the likelihood of root intermingling is high. A complete description of the study site and experimental design are included in Teste et al. (2018). 
In May 2011, 40 minirhizotron clear tubes (Bartz Technology Corp., Carpinteria, CA, USA, internal diameter $=50.8 \mathrm{~mm}$ ) were installed to a depth of $0.5 \mathrm{~m}$ at $1 \mathrm{~m}$ and $2.5 \mathrm{~m}$ from the basal stem of ten B. attenuata trees with two irrigation treatments (i.e. on 10 plots $\times 2$ distances $\mathrm{x} 2$ irrigation treatments $=40$ tubes). Tubes were prepared following similar procedures outlined in Smit et al. (2000) and Johnson et al. (2001) to eliminate artefactual effects of light and temperature. Prior to imaging roots with a BTC2 Minirhizotron Video Microscope (Bartz Technology Corp., Carpinteria, CA, USA), the minirhizotron tubes were left to stabilise for 11 months. From April 2012, sprinklers distributed water evenly to a radial distance of $4 \mathrm{~m}$ around the minirhizotron tubes. This irrigation treatment started a month before the winter rains and produced a $25 \%$ increase in monthly winter water inputs (from April to October) based on 45 years of rainfall data (1967 to 2011) from a nearby weather station (Subiaco treatment plant, Station \# 009151, Lat: $31.96^{\circ} \mathrm{S}$, Long: $115.79^{\circ} \mathrm{E}$; Bureau of Meteorology, http://www.bom.gov.au/climate/averages/). The plots were irrigated every month, and by October, we had added a total of $148 \mathrm{~mm}$ of supplementary water to each plot. The minirhizotron tubes around the mature Banksia focal trees were positioned to be within the radial extent of the water spray provided by the sprinklers used in the irrigation treatment (Teste et al. 2018). Furthermore, we inserted the tubes within the main root zone of each focal tree. As for soil depth, the range of depths used to image roots was mainly determined by the limitations of the minirhizotron equipment (tubes and camera) and the feasibility of gathering images within the same day in the field. Furthermore, we knew that imaging beyond $50 \mathrm{~cm}$ depth was unlikely to render observations of cluster roots, since they are typically restricted to the top $15 \mathrm{~cm}$ of the soil profile (Denton et al. 2007b; Pate and Watt 2002). 

available in Teste et al. (2018). In summary, roots were imaged between 4 April 2012 and 5 October 2012, and root dynamics and soil moisture were monitored on a weekly basis when possible. The captured minirhizotron images were then analysed with Rootfly v. 2.0.2, an open-source software application (Zeng et al. 2010). Rootfly allowed us to annotate (with a computer mouse) the roots, determine the type of root (cluster (Fig. 1, S2), woody or herbaceous roots, based on structure and colour), and calculate the birth and death rates of roots through time. In this study the minirhizotron approach was used to track root intermingling over time in a non-destructive manner in situ. We annotated a 'cluster-root' type only when we saw rootlets at some point in time during root-imaging from April to October. Banksia roots that did not produce rootlets could not be differentiated from other woody roots; therefore, they were categorised as a 'woody' root type. A 'cluster-root intermingling' response was calculated based on minirhizotron images (image frame $=13.5$ $\mathrm{mm}$ by $18 \mathrm{~mm}$ ) that had co-occurring root types of which at least one was a cluster root.

\section{Glasshouse experiment}

In August 2012, a glasshouse experiment with B. menziesii seedlings grown in nutrientimpoverished Bassendean sand (see Laliberté et al. (2012) for specific soil characteristics) was established with the objective to quantify cluster-root nutrient concentrations and remobilisation during senescence. Banksia menziesii seedlings were grown in 14 rhizoboxes (2.2 L) and in plastic bags inside 40 polyvinyl chloride (PVC) pots $(2.1 \mathrm{~L})$. Our aim was to simultaneously photograph and sample cluster roots at their various developmental stages. Four stages were morphologically identified: stage 1, immature cluster roots; stage 2, fullyformed cluster roots; stage 3, cluster roots with rusty brown colour and some loss of vigour (shrinking determined visually); stage 4 , dark brown or grey cluster roots with noticeable loss of vigour (widespread shrinking and wrinkling determined visually). Between 10-15 January 
2013, half of the seedlings were harvested, washed and cluster roots were then cleaned and oven-dried at $70{ }^{\circ} \mathrm{C}$ for 48 hours.

Due to the nature of cluster roots, small sand particles often tightly adhere to the root cluster.

Therefore, once dried, the cluster roots were again cleaned to remove adhering sand to accurately quantify dry weight and chemical composition of the roots. Thus, cluster roots were placed between two fine mesh holders and subjected to pressurised air until most of the sand was removed. Any remaining sand was accounted for, by subtracting its weight from the sample dry weight, during root digests, prior to chemical analysis (see Chemical analysis of cluster roots below).

\section{Chemical analyses of cluster roots}

After sand removal, fragmented cluster roots were weighed and analysed for total P and silicon $(\mathrm{Si})$ by atomic absorption spectrometry (Perkin Elmer 500 DV ICP-AES, Massachusetts, USA), with an adapted protocol to deal with sand particles, at the ChemCentre (http://www.chemcentre.wa.gov.au/), Perth, Australia. Since many cluster roots still contained traces of adhering sand particles, the digestion in closed capsules was carried out to avoid possible loss of acid digest solution (nitric-perchloric acid mixture) due to explosive boiling-over. All remaining root samples were then re-analysed for $\mathrm{P}$ and $\mathrm{SiO}_{2}$ using an Elementar Vario Macro (Hanau, Germany) directly after combustion. Further analysis of the evolved gases and digests was done with an inductively coupled plasma mass spectrometer (Perkin Elmer, Elan 6000 ICP-MS, Norwalk, CT, USA) or axially-configured ICP-OES for low-weight samples. Total $\mathrm{N}$ was quantified with the Elementar Vario Macro (Hanau, Germany).

\section{Cluster-root vitality}


A modified Evans blue test was used to determine root vitality (Peterson et al. 2008). Two approaches to stain the four stages of cluster roots were used; first, whole cluster roots were stained by dipping them in Evans blue solution, and, second, the main root axes without the rootlets were hand-sectioned prior to dipping. Cluster roots boiled in water for 5 minutes were used as controls for this vitality assessment. Stained rootlets were observed under a dissecting light microscope to visually determine if the root was dead (i.e. stained) or alive (i.e. clear, not stained). The proportion of dead rootlets per $5 \mathrm{~mm}$ cluster root fragment was determined with the gridline intersect method (Giovannetti and Mosse 1980).

Structural dry matter

Structural dry matter was determined for cluster-root stages 2 to 4. First, $200 \mathrm{mg}$ of dried root material was pulverised with a Retsch Tissue Lyser (TissueLyser Qiagen, Haan, Germany) at $25 \mathrm{~Hz}$ for 5 minutes. Then $700 \mu \mathrm{L}$ of $\mathrm{NaH}_{2} \mathrm{PO}_{4}(0.1 \mathrm{M}, \mathrm{pH} 7.3)$ and $300 \mu 1$ Tween-20 (0.1\%, v/v) were added to the pulverised material, which was then vortexed, pulverised again, vortexed for 1 minute, and finally centrifuged at $8,164 \mathrm{~g}$ for 10 minutes. The supernatant was removed, the material allowed to dry at $60{ }^{\circ} \mathrm{C}$ for 72 hours, then re-weighed. The structural dry matter was then calculated as the difference between the initial dry weight minus the weight after releasing soluble metabolites. Structural dry matter was quantified to express the concentrations of $\mathrm{N}$ and $\mathrm{P}$ during the development of cluster roots on a structural dry weight basis; this avoids the bias of any changes in non-structural dry weight (e.g., non-structural carbohydrates) during cluster development.

\section{Estimation of the amount of phosphorus made available by cluster roots}

We consider two ways in which other roots might benefit from intermingling with cluster roots: 1) by taking up P made available through the action of cluster-root exudates (carboxylates and phosphatases), i.e. novel P pools that would not be available for non-cluster 
roots; or 2) by taking up $\mathrm{P}$ left behind in senesced cluster roots. To estimate the P potentially made available through the release of cluster-root exudates, 10 soil samples were collected at the study site, regardless of the irrigation treatment given that this field sampling was done six years after the temporary irrigation treatment ceased. These field samples were taken below Banksia trees from 0-0.05 m depth, adjacent to where cluster roots were imaged (Teste et al. 2018). Total $\mathrm{P}$ was quantified by extraction in $1 \mathrm{M} \mathrm{HCl}$ (16 hours, 1:50 soil to solution ratio) of ashed samples $\left(550^{\circ} \mathrm{C}, 1\right.$ hour) modified after Saunders and Williams (1955). Free Pi (resin-P) was extracted with anion-exchange membranes (Turner and Romero 2009).

Carboxylate-extractable Pi (citrate-extractable P) was assessed using a $0.05 \mathrm{M}$ solution of citric acid (3 hours). Organic P (Soil organic P) was calculated as the difference between the $1 \mathrm{M} \mathrm{HCl}$-extracted $\mathrm{P}$ after and before ashing. This method may cause a slight overestimate of the organic $\mathrm{P}$, because of a potential increase in acid-extractability of $\mathrm{P}$ in soil ash (Williams et al. 1970). Results are expressed on an oven-dry $\left(105^{\circ} \mathrm{C}\right)$ weight basis.

To estimate the potential maximum amount of $\mathrm{P}$ available from decomposing cluster roots, first, cluster root per soil weight ratio was determined, and then the $\mathrm{P}$ concentration of senesced cluster roots (see above) was used to estimate the amount of P left behind by cluster roots per unit soil dry weight. Ten patches of mature cluster roots were located by removing the litter layer below Banksia trees at the study site, and pieces of this cluster-root mat (depth $\sim 0-50 \mathrm{~mm}$, area $\sim 5000 \mathrm{~mm}^{2}$ ) were collected. Banksia cluster roots are easily found given their large size and characteristic mat-like structures (Shane and Lambers 2005). In the lab, one mini-core from each of the samples (diameter $21.5 \mathrm{~mm}$, depth $11 \mathrm{~mm}$, volume $3990 \mathrm{~mm}^{3}$ ) was taken, and live cluster roots from the soil (sand, organic matter, any other roots) were separated by adding water and using end-over-end shaking, sonification, and manual separation. Cluster root samples and soil samples were dried at $70{ }^{\circ} \mathrm{C}$, weighed, and then ashed at $550{ }^{\circ} \mathrm{C}$. The cluster root dry weight was adjusted for contamination with sand, 

al. 2005).

assuming that the ash content of cluster roots was $5 \%$ of their dry weight, based on values from other slow-growing tree species (George et al. 2003; Helmisaari et al. 2009; Ostonen et

\section{Data analysis}

The frequency of roots intermingling with cluster roots was analysed as count data with Poisson and negative binomial regression models (Zuur et al. 2009). Based on the image analysis described above, one of three 'interaction' types was assigned to each observation based on whether the co-occurring 'other roots' were first observed before (Fig. \$21 ), during (Fig. S3), or after (Fig. S4) the presence of live cluster roots. The average lifespan of clusterroots, including the immature and mature stage, was 23 days (Teste et al. 2018). For cluster roots that did not fully develop by the end of the study, interaction type 'before' or 'during' could still be assigned, but not 'after'. As such, we analysed the interaction type and irrigation treatment as fixed effects (Table S1). When the irrigation treatment or other root types affected the frequency of interaction, negative binomial models were fitted to account for over-dispersion (Cameron and Trivedi 2005).

Total $\mathrm{P}$ and total $\mathrm{N}$ in cluster roots of different stages were compared with analysis of variance and confidence intervals followed by the Tukey HSD test. We calculated a clusterroot P-remobilisation efficiency (\%) based on the mean values of stage I and other stages (e.g. [stage I - stage III] / stage I). Cluster-root vitality was analysed as proportion data with generalised linear models. The assumptions for the statistical models were assessed graphically, with plots of residuals and boxplots for treatment variances. All graphing and statistical analyses were conducted in R (R Core Team 2020) and 'ggplot2' packages (Therneau 2015; Wickham 2016). 


\section{Results}

A total of 2091 root fragments were imaged between April and October 2012, where 57 of these developed into mature cluster roots such as shown in Figs S2, S3, S4, and S5. As a cluster root appeared and developed, other roots were seen in very close proximity (i.e. within the same 13.5 x $18 \mathrm{~mm}$ image frame), likely interacting and possibly acquiring P mobilised by the cluster root (Figs S3, S4, S5). Intermingling roots of non-cluster-root species were distinguished by colour, size, and lateral branching.

In all 57 image frames with cluster roots, at least one other root type was observed before, during or after the development of a live cluster root. This is in strong contrast with the overall probability of observing roots: only $11.3 \%$ of images had roots. We also found 257 cases of intermingling between non-cluster herbaceous and woody roots out of a total of 2034 non-cluster roots (i.e. $12.6 \%$ of non-cluster herbaceous roots were intermingling during their emergence with non-cluster woody roots). As such, the frequency of intermingling between non-cluster roots is considerably lower than that of intermingling between cluster roots and non-cluster roots $\left(X^{2}=331, d f=1, P<0.001\right)$. Furthermore, the maximum number of noncluster roots intermingling with cluster roots within the same image frame was six, which occurred in an irrigated plot (data not shown). The majority of root intermingling with cluster roots $(95 \%)$ was observed under irrigation (155 roots) compared with non-irrigated plots (9 roots, Fig. 2). Furthermore, in $90 \%$ of cases, intermingling roots appeared when live cluster roots were present, as opposed to before their appearance or after their senescence (Fig. 2; for photographs see Figs S2, S3, S4). The majority of intermingling cluster and non-cluster roots were found at the surface and upper-middle layers of the soil profile, rather than in deeper layers (Fig. S5). 
362 Remobilisation of phosphorus and nitrogen from senescing cluster roots

To test if senesced cluster roots could serve as important sources of $\mathrm{P}$ or $\mathrm{N}$, we determined total $\mathrm{P}$ and $\mathrm{N}$ concentrations in cluster roots at the first three stages of development (see

Methods - Glasshouse experiment). Total P concentrations of cluster roots reached very low

efficiency of $88.5 \%$ based on the mean values of stages I and III ([stage I - stage III] / stage I) from Fig. 3. Total N concentration in cluster roots peaked at developmental stage I (fullyefficiency was $89.2 \%$.

\section{Root vitality of cluster rootlets}

We found a substantial decrease in rootlet vitality, as expected, yet there were still some unstained, possibly live, rootlets at stage III (Fig. 4). However, the stain does not always bind to dead roots, in this case rootlets, especially those that only recently died. Therefore, these data may overestimate live rootlet percentage.

Phosphorus available to intermingling roots in developing and mature cluster rhizospheres

$\underline{\text { In order to calculate the amount of P possibly available to roots capable of intermingling with }}$ cluster roots, during their development, we gathered several values from field samples and the

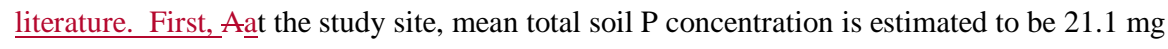
$\mathrm{kg}^{-1}$, very similar to $17.8 \mathrm{mg} \mathrm{kg}^{-1}$ which was measured on nearby Spearwood dunes (Turner et al. 2018). Part of this $\mathrm{P}$, estimated as resin-extracted inorganic $\mathrm{P}$ (Pi; $1.35 \mathrm{mg} \mathrm{kg}^{-1}$ and 1.27 $\mathrm{mg} \mathrm{kg}^{-1}$ in Turner et al. (2018)) is available to any root. Additional to this freely available Pi, cluster roots extract additional amounts of $\mathrm{P}$ by bringing inorganic and organic $\mathrm{P}$ in solution (mobilised by carboxylates) and hydrolysing organic P (i.e. phosphatase-extractable P) 

was estimated as $2.16 \mathrm{mg} \mathrm{kg}^{-1}$ dry soil from older studies (McPharlin et al. 1994; Ozanne and Shaw 1968; Pathan et al. 2003; Watson et al. 1982). We measured Carboxylate-extractable Pi (citrate-extractable $\mathrm{P}$ ) as $1.59 \mathrm{mg} \mathrm{P} \mathrm{kg}^{-1}$ dry soil and organic $\mathrm{P}$ that could potentially be accessed (i.e. Organic-P available) by our Banksia cluster roots. This Organic-P available fraction was estimated as $16.7 \mathrm{mg} \mathrm{P} \mathrm{kg}^{-1}$ dry soil, similar to the value of $12.5 \mathrm{mg} \mathrm{P} \mathrm{kg}^{-1}$ dry soil found in recent work from our group (Zhou et al. unpublished) and similar to the $\mathrm{NaOH}$ extractable organic $\mathrm{P}$ of $10.6 \mathrm{mg} \mathrm{P} \mathrm{kg}^{-1}$ dry soil from Turner et al. (2018).

\section{Phosphorus available to intermingling roots in senesced cluster rhizospheres}

$\underline{\text { In order to calculate the amount of P possibly available to roots capable of intermingling with }}$ senesced cluster roots, we gathered several values from field samples and the literature. We made these calculations, given that cluster roots produce an abundance of fine root biomass in a small volume of soil, and despite efficient remobilisation of $\mathrm{P}$ from senescing cluster roots, we hypothesised that some remaining $\mathrm{P}$ might be available to intermingling roots. As such, we first estimated this amount of $\mathrm{P}$, expressed as a soil $\mathrm{P}$ concentration, as the product of the P concentration in senesced clusters and the dry mass density of cluster roots in soil. Senesced clusters contain $118 \mathrm{mg} \mathrm{P} \mathrm{kg}^{-1}$ dry weight; stage III in Fig. 3). Estimates for the density of cluster roots in soil were $0.0284 \mathrm{~g}$ cluster roots per $\mathrm{g}$ dry rhizosphere soil, similar to what was measured in another Banksia study (Pate and Watt 2002). Therefore, the amount of $\mathrm{P}$ remaining in senesced cluster roots is estimated at $118 \mathrm{mg} \mathrm{P} \mathrm{kg}^{-1}$ cluster roots $\mathrm{x} 0.0284 \mathrm{~g}$ cluster roots $\mathrm{g}^{-1}$ soil $=3.36 \mathrm{mg} \mathrm{P} \mathrm{g}^{-1}$ dry rhizosphere soil (Fig. 5). As such, we estimate the volume used by these cluster roots is approximately $37.8 \mathrm{mg}$ of cluster roots per $\mathrm{cm}^{3}$ of soil in these sandy soils.

411 

have access to $1.35 \mathrm{mg} \mathrm{P} \mathrm{kg}^{-1}$ soil (Free Pi, resin-P values from Turner et al. (2018) and mentioned above) outside cluster rhizospheres, increasing to a potential $19.6 \mathrm{mg} \mathrm{P} \mathrm{kg}^{-1}$ soil (i.e. Free Pi (1.35) + Carboxylate-extractable Pi (1.59) + Organic-P available (16.68) Fig. 5) in cluster rhizospheres (but in competition with cluster roots), and then decreasing to a potential $3.36 \mathrm{mg} \mathrm{P} \mathrm{kg}^{-1}$ soil (senesced cluster roots) after clusters have senesced (assuming that $\mathrm{P}$ in senesced clusters is completely available to other roots or their mycorrhizas) (Fig. 5). Based on our previous work, we estimated a mean lifespan of 23 days for Banksia cluster roots (Teste et al. 2018); as such we suggest that $P$ from senescing cluster roots could become available to other roots from $\sim 23$ days after the start of CR development.

\section{Discussion}

We documented the in situ seasonal dynamics of Banksia cluster-root formation with minirhizotrons, and determined, for the first time, the degree of intermingling events by roots of non-cluster-rooted species. The very high frequency of roots intermingling with cluster roots, relative to the cluster roots detected with our minirhizotrons, during their development and period of peak activity represents the first evidence of physical interaction between such roots, and shows that P-mobilisation facilitation may potentially operate in these nutrient-poor soils. Although intermingling certainly occurred between non-cluster roots, we found that the presence of cluster roots significantly promoted intermingling events, since we always observed the appearance of at least one other non-cluster root. Our estimates of soil $\mathrm{P}$ availability before, during and after peak cluster-root activity, support the hypothesis that potential benefits exist for non-cluster roots of invading cluster rhizospheres, and that these benefits are greatest during periods of cluster-root exudation. 

other non-cluster rooted species freely intermingled with all B. attenuata cluster roots that we observed, especially when cluster roots were mature or developing. These intermingling events were particularly pronounced when soil moisture conditions were at a historical, rather than current precipitation level for this Mediterranean woodland (Teste et al. 2018). We recently demonstrated that Banksia spp. may be sensitive to a drying climate, with a lower incidence of cluster roots under drier soil conditions (Teste et al. 2018). Further research is needed to elucidate the mechanism of intermingling, and specifically the signal(s) triggering growth of roots towards cluster roots. It is unlikely that the signal is $\mathrm{P}$ itself, because P migration in soil is very slow (Lambers and Oliveira 2019). Biogenic volatile organic signals may be involved (Peñuelas et al. 2014a): cluster roots may release VOCs into surrounding soil and prime more root proliferation from intraspecific roots. This would be a novel mechanism for VOCs, but would resemble the root-to-root signalling that has been documented between unstressed plants to drought-stressed plants (Falik et al. 2011; Peñuelas et al. 2014b). It is also possible that both cluster roots and intermingling roots respond to a common signal indicating a locally-high resource level such as resource-rich patches (Hodge 2009). The signal could be a mobile nutrient, such as nitrate, or a volatile signal generated by roots or soil microbes. The possibility of nitrate as a signal for root proliferation, which may provide a large potential benefit for nutrients such as $\mathrm{P}$ in our study system, suggests an alternative explanation for the observation in the study of van Vuuren et al. (1996), where many roots grew after most of the $\mathrm{N}$ in an enriched patch had been depleted.Those late-growing roots probably still had significant benefits ferom nutrients other than N. 
The P-acquisition benefits that other roots could gain from intermingling with cluster roots in terms of $\mathrm{P}$ availability in soil during cluster-root development and senescence (i.e. during and after cluster activity; Fig. 2) is considerable (Fig. 5). Such a benefit would come from the Pmobilising activity of cluster roots through exuded carboxylates and phosphatases. However, the $\mathrm{P}$ availability in both living and senesced cluster rhizospheres are maximum estimates, given that cluster roots are likely strong competitors for $\mathrm{P}$ uptake, and $\mathrm{P}$ in senesced clusters may largely be in organic forms, or immobilised by microbes, and thus not available to other roots. We expect that the peak of the P-acquisition benefits would be short-lived and occur between $\sim 20$ to 30 days after the initiation of the development of the cluster root, based on our glasshouse and field observations of the development stages of Banksia cluster roots (Teste et al. 2018)= and welldocumented observations of cluster-root physiology in hydroponics (Shane \& Lambers 2005). We estimated that $16.9 \mathrm{mg} \mathrm{P} \mathrm{kg}^{-1}$ soil represents the theoretical maximum amount of $\mathrm{P}$ available to intermingling roots during the presence of an active cluster root, assuming all $\mathrm{P}$ made available by the cluster roots could be taken up by intermingling roots. While clusters are active (matching the period of maximum exudation of carboxylates and phosphatases), plant-available soil $\mathrm{P}$ increases from $1.35 \mathrm{mg} \mathrm{kg}^{-1}$ (i.e. resin-P) to a maximum of $16.9 \mathrm{mg} \mathrm{kg}^{-1}$ (Fig. 4). Due to the very high density of cluster rootlets relative to intermingling roots in the rhizosphere, cluster roots would have a competitive advantage for uptake of the P mobilised by themselves. Nevertheless, intermingling roots that invade the cluster rhizosphere, or are at the outer boundary of the clusters, are positioned within a zone of influence of carboxylates and phosphatases where they may benefit from mobilised $\mathrm{P}$.

Our estimates indicate that there is more $\mathrm{P}$ in living cluster roots than extractable soil $\mathrm{P}$ in that same soil volume (Fig. 5), demonstrating that both efficient soil $\mathrm{P}$ extraction and efficient $\mathrm{P}$ remobilisation from senescent roots are essential for cluster roots to be effective and a functional investment benefitting the plant's P economy. Intermingling roots need to compete

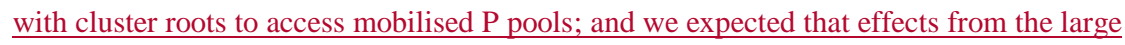


amounts of carboxylates exuded by cluster roots and their high-affinity P transporters would maximise the share of that mobilised $\mathrm{P}$ for the cluster roots. However, the theoretical maximum amounts of $\mathrm{P}$ that could be gained are worth further empirical testing.

\section{Remobilisation of root phosphorus during cluster root senescence}

The amount of $\mathrm{P}$ remaining after senescence of the cluster roots might be accessible to noncluster roots entering or staying in that "senesced-cluster region", and although the amounts are small, such roots might derive a $\mathrm{P}$ benefit from decomposing cluster roots in these impoverished soils. We found a very high root P-remobilisation efficiency of $89 \%$ based on determining the root $\mathrm{P}$ concentrations during the development and fully senesced stages of our Banksia cluster roots. Physiological studies of Hakea cluster roots with controlled hydroponic systems found similarly high root P-remobilisation efficiency of 95\% (Shane et al. 2004). These results show only a very small amount of $P$ remains after a cluster has senesced for uptake by intermingling non-cluster roots (Fig. 5), compared with the amount that may be gained by intermingling with active cluster roots. Our observation that intermingling roots arrive when cluster roots are alive, rather than senesced (Fig. 2), supports the concept that intermingling roots respond to a signal indicating the imminent opportunity of enhanced resource availability ( $\mathrm{P}$ and micronutrients), and that most resources become available through cluster-root induced mobilisation, rather than cluster-root decomposition.

\section{Evidence for the potential of facilitated uptake of phosphorus}

The facilitated uptake of $\mathrm{P}$ that may occur between cluster-rooted species and other interacting plant species such as mycorrhizal plant species falls under two of the three broad facilitative mechanisms proposed by Wright et al. (2017). First, indirect biotic facilitation may result if other roots can scavenge the $\mathrm{P}$ that is mobilised by the active cluster root. Second, abiotic facilitation due to local $\mathrm{P}$ enrichment by senesced cluster roots remains a 
possibility in the most severely-impoverished soils where very small amounts of $\mathrm{P}$ can still increase plant growth of other plant species capable of taking up the P 'mined' by the cluster roots. Our findings suggest that the first mechanism, indirect biotic facilitation, is probable with some level of $\mathrm{P}$ enrichment of the cluster rhizosphere during mobilisation of soil $\mathrm{P}$ as previously proposed (Gardner and Boundy 1983; Lambers et al. 2013; Li et al. 2007). Nutrient-mobilisation-based facilitation as proposed in Lambers et al. (2018) and demonstrated in crop plants (e.g., lupin) may also be ecologically relevant for iron (Fe), zinc (Zn) and manganese (Mn), since these micronutrients are also mobilised during cluster-root activity (Li et al. 2014). Nutrient ( $\mathrm{P}, \mathrm{Fe}, \mathrm{Zn}$ and $\mathrm{Mn}$ )-mobilisation-based facilitation is mainly driven by: i) the release of large amounts of organic acids and chelating substances from cluster roots that increase the concentrations of these nutrients in the soil solution (Lambers et al. 2018); and ii) the ability of other roots to first sense the activity of cluster roots and then grow in the rhizosphere of cluster roots directly or via their extra-radical mycorrhizal hyphae (i.e. in the case where mycorrhizal roots are intermingling). Microcosm studies using Banksia as the cluster-rooted plants lend some support to this principle; improved plant growth of neighbouring and interacting plants was shown (Muler et al. 2014; Teste et al. 2014). We suggest that nutrientmobilisation-based facilitation is more common than previously thought; however, more formal testing is required (see section on Future directions below).

\section{Potential impacts of a drying climate on interactions with cluster roots} Plant species compositional shifts may occur due to a drying climate, if $\mathrm{P}$ and micronutrient uptake of coexisting plants is facilitated by the root activity of cluster-rooted plants (Lambers et al. 2018; McIntire and Fajardo 2014). Cluster-root development and its capacity to mobilise P from poorly-available forms in soil is affected by soil moisture levels (Lamont 1976; Lamont 2003). We found that lower soil moisture levels reduce cluster-root occurrence 
in this system (Teste et al. 2018); thus their P-mobilising activities would also be reduced in a given plant community. We also found that the majority of root intermingling between noncluster roots and cluster roots occurred in the surface soil layers, where soil drying is typically faster than that in deeper soil layers. Our findings suggest that a considerable amount of $\mathrm{P}$ benefits may be obtained when coexisting plants intermingle their roots in the rhizospheres of cluster-rooted plant species. Thus, plant species that depend on this type of interaction to meet their P demand may be the first to succumb in plant communities dominated by clusterrooted plants during further drying of this Mediterranean environment.

\section{Future directions}

Radio-isotope $\mathrm{P}$ work (i.e. ${ }^{33} \mathrm{P}$ and ${ }^{32} \mathrm{P}$ ) would help quantify the magnitude of $\mathrm{P}$-mobilisation facilitation, but documenting radioactive $\mathrm{P}$ movement in megadiverse habitats would be very challenging, if not impossible. Analysis of the spatial pattern between cluster-rooted Banksia plants and plants potentially interacting could convey evidence for facilitation, but the lateral extent of Banksia cluster roots is far reaching ( $2 \mathrm{x}$ tree height in B. prionotes (Jeschke and Pate 1995)), so the distance between plants may not be a good predictor of the intensity of facilitative relationships. As such, current methodology such as minirhizotrons, nutrient tracers, and microcosm experiments will still be needed to progress our understanding of the roles of belowground facilitation in plant species coexistence. Finally, to robustly test for facilitation, future studies could entail: i) identifying the plant species whose roots intermingle with cluster-rooted plants; ii) quantify the differences between foliar P concentrations with and without neighbouring Banksia; and iii) quantify a metric that could serve as a proxy for improved fitness (e.g., seed production).

\section{Conclusions}



roots of other species with implications for species coexistence when soil moisture conditions are favourable. We calculated the potential $\mathrm{P}$ benefits to roots growing in or near the rhizosphere of clusters during and after their peak activity. The most frequent root interaction type described here was when soils were relatively moist, and can be viewed as a plant version of 'kleptoparasitism' (Gorman et al. 1998; Thompson 1986; Zomora 1995). These are the first accounts of a kleptoparasitism-type root interaction, and we suggest that such interactions occur between other cluster-rooted species and neighbouring plants with considerable potential for nutrient-mobilisation-based facilitation. These interactions and facilitative mechanisms are likely also relevant for other specialised root strategies (e.g., carboxylate-releasing simple cluster roots, dauciform roots, sand-binding roots, vellozioid roots) and in other P-impoverished ecosystems such as campos rupestres (Abrahão et al. 2019; Teodoro et al. 2019). Such interactions may promote species co-existence and act as a means of increasing species diversity in severely nutrient-impoverished soils.

\section{Acknowledgements}

Michael Blair and Raymond Scott provided help at the start of the experimental setup and tube installations and for facilitating access to the field station. We are grateful to Jairo Palta, then at CSIRO in Floreat, for lending us the Bartz minirhizotron camera. Thomas Mazet played a key role with imaging during rainy days. We are especially grateful to Judith Holmes and Victoria A. Marchesini for their valuable help during the root annotation with RootFly. We thank Michael Smirk and Katrina Walton for their help quantifying nutrient concentrations of cluster roots. Finally, we thank Simone Pedrini for the illustrations of the cluster roots in Fig. 4. Funding was provided by The University of Western Australia with a Research and Development Award granted to FPT and the Australian Research Council with

592 a Discovery Project (ARC DP0985685) to HL, EJV and KWD. KWD and EJV are also 


\section{Compliance with ethical standards}

\section{Conflict of interest}

The authors declare that they have no conflict of interest.

\section{Ethical approval}

This article does not contain any studies with human participants or animals performed by any of the authors.

\section{Data accessibility}

Data will be made available as part of a separate digital file in the Electronic Supplementary

Material section (Data S1).

\section{References}

Abrahão A et al. (2019) Soil types select for plants with matching nutrient-acquisition and use traits in hyperdiverse and severely nutrient-impoverished campos rupestres and cerrado in Central Brazil. Journal of Ecology 107:1302-1316

Beeck D (2017) Cluster-root exudation of carboxylate and phenolic compounds by two species of Banksia. Honours thesis, The University of Western Australia, Crawley, WA, Australia

Cameron AC, Trivedi PK (2005) Microeconometrics: methods and applications. Cambridge University Press, Cambridge

Chen W, Koide RT, Eissenstat DM (2018) Root morphology and mycorrhizal type strongly influence root production in nutrient hot spots of mixed forests. Journal of Ecology 106:148-156. doi: 10.1111/1365-2745.12800

Crosti R, Dixon KW, Ladd PC, Yates CJ (2007) Changes in the structure and species dominance in vegetation over 60 years in an urban bushland remnant. Pacific Conservation Biology 13:158-170

Delgado M, Zúñiga-Feest A, Alvear M, Borie F (2013) The effect of phosphorus on clusterroot formation and functioning of Embothrium coccineum (R. et J. Forst.). Plant and Soil 373:765-773

Denton MD, Veneklaas EJ, Freimoser FM, Lambers H (2007a) Banksia species (Proteaceae) from severely phosphorus- impoverished soils exhibit extreme efficiency in the use and re- mobilization of phosphorus. Plant, Cell and Environment 30:1557-1565

Denton MD, Veneklaas EJ, Lambers H (2007b) Does phenotypic plasticity in carboxylate exudation differ among rare and widespread Banksia species (Proteaceae)? New Phytologist 173:592-599 
Diffenbaugh NS, Field CB (2013) Changes in ecologically critical terrestrial climate conditions Science 341:486-492

Faget M et al. (2013) Root-root interactions: extending our perspective to be more inclusive of the range of theories in ecology and agriculture using in-vivo analyses. Annals of Botany 112:253-266. doi: 10.1093/aob/mcs296

Falik O, Mordoch Y, Quansah L, Fait A, Novoplansky A (2011) Rumor has it: relay communication of stress cues in plants. PlosONE 6:1-6

Fisher JL, Loneragan WA, Dixon K, Delaney J, Veneklaas EJ (2009) Altered vegetation structure and composition linked to fire frequency and plant invasion in a biodiverse woodland. Biological Conservation 142:2270-2281

Gardner WK, Boundy KA (1983) The acquisition of phosphorus by Lupinus albus L. IV. The effect of interplanting wheat and white lupin on the growth and mineral composition of the two species. Plant and Soil 70:391-402

George K, Norby R, Hamilton J, DeLucia E (2003) Fine- root respiration in a loblolly pine and sweetgum forest growing in elevated CO2. New Phytologist 160:511-522

Giovannetti M, Mosse B (1980) An evaluation of techniques for measuring vesicular arbuscular mycorrhizal infection in roots. New Phytologist 84:489-500

Gorman ML, Mills MG, Raath JP, Speakman JR (1998) High hunting costs make African wild dogs vulnerable to kleptoparasitism by hyaenas. Nature 391:479-481

Helmisaari H-S, Saarsalmi A, Kukkola M (2009) Effects of wood ash and nitrogen fertilization on fine root biomass and soil and foliage nutrients in a Norway spruce stand in Finland. Plant and Soil 314:121-132. doi: 10.1007/s11104-008-9711-4

Hodge A (2009) Root decisions. Plant, cell \& environment 32:628-640. doi: doi:10.1111/j.1365-3040.2008.01891.x

Hodge A (2012) Plant root interactions. In: Witzany G, Baluska F (eds) Biocommunication of plants, signaling and communication in plants, vol 14. Springer-Verlag, Berlin, pp 157-169

Hopper SD, Gioia P (2004) The southwest Australian floristic region: evolution and conservation of a global hot spot of biodiversity. Annual Review of Ecology, Evolution, and Systematics 35:623-650

Initiative IOC (2012) Western Australia's weather and climate: a synthesis of Indian Ocean Climate Initiative stage 3 research. Commonwealth of Australia, Melbourne

Jeschke WD, Pate JS (1995) Mineral nutrition and transport in xylem and phloem of Banksia prionotes (Proteaceae), a tree with dimorphic root morphology. Journal of Experimental Botany 46:895-905

Johnson MG, Tingey DT, Phillips DL, Storm MJ (2001) Advancing fine root research with minirhizotrons. Environmental and Experimental Botany 45:263-289. doi: $10.1016 / \mathrm{s} 0098-8472(01) 00077-6$

Laliberté E et al. (2012) Experimental assessment of nutrient limitation along a 2- millionyear dune chronosequence in the south- western Australia biodiversity hotspot. Journal of Ecology 100:631-642

Lambers H (2014) Plant Life on the Sandplains in Southwest Australia.

Lambers $\mathrm{H}$ et al. (2018) How belowground interactions contribute to the coexistence of mycorrhizal and non-mycorrhizal species in severely phosphorus-impoverished hyperdiverse ecosystems. Plant and Soil 424:11-33. doi: 10.1007/s11104-017-3427-2

Lambers H et al. (2012) Proteaceae from severely phosphorus-impoverished soils extensively replace phospholipids with galactolipids and sulfolipids during leaf development to achieve a high photosynthetic phosphorus-use-efficiency. New Phytologist 196:10981108. doi: 10.1111/j.1469-8137.2012.04285.x

Lambers H, Chapin FS, Pons TL (2008) Plant physiological ecology. Springer, New York, USA 
Lambers H, Clements JC, Nelson MN (2013) How a phosphorus-acquisition strategy based on carboxylate exudation powers the success and agronomic potential of lupines (Lupinus, Fabaceae). American Journal of Botany 100:263-288

Lambers $\mathrm{H}$ et al. (2015) Metabolic adaptations of the non-mycotrophic proteaceae to soils with low phosphorus. In: Plaxton W, Lambers H (eds) Annual Plant Reviews, Phosphorus Metabolism in Plants, vol 48. John Wiley \& Sons, Ltd., pp 289-336

Lambers H, Oliveira R (2019) Plant Physiological Ecology, 3rd edition. Springer International Publishing

Lambers H, Shane M, Laliberté E, Swarts N, Teste F, Zemunik G (2014) Plant Mineral Nutrition. In: Lambers H (ed) Plant Life on the Sandplains in Southwest Australia, a Global Biodiversity Hotspot. UWA Publishing, Crawley, pp 101-127

Lamont B (1982) Mechanisms for enhancing nutrient uptake in plants, with particular reference to mediterranean South Africa and Western Australia. The Botanical Review 48:597-689

Lamont BB (1976) The effects of seasonality and waterlogging on the root systems of a number of Hakea species. Australian Journal of Botany 24:691-702

Lamont BB (2003) Structure, ecology and physiology of root clusters - a review. Plant and Soil 248:1-19

Li B et al. (2016) Root exudates drive interspecific facilitation by enhancing nodulation and $\mathrm{N}_{2}$ fixation. Proceedings of the National Academy of Sciences 113:6496-6501. doi: $10.1073 /$ pnas. 1523580113

Li L et al. (2007) Diversity enhances agricultural productivity via rhizosphere phosphorus facilitation on phosphorus-deficient soils. Proceedings of the National Academy of Sciences 104:11192-11196

Li L, Tilman D, Lambers H, Zhang FS (2014) Plant diversity and overyielding: insights from belowground facilitation of intercropping in agriculture. New Phytologist 203:63-69

McArthur WM, Bettenay E (1974) The development and distribution of the soils of the Swan Coastal Plain. CSIRO, Australia

McIntire EJB, Fajardo A (2014) Facilitation as a ubiquitous driver of biodiversity. New Phytologist 201:403-416. doi: 10.1111/nph.12478

McPharlin I, Jeffery R, Weissberg R (1994) Determination of the residual value of phosphate and soil test phosphorus calibration for carrots on a Karrakatta sand. Communications in Soil Science \& Plant Analysis 25:489-500

Metzner R et al. (2015) Direct comparison of MRI and X-ray CT technologies for 3D imaging of root systems in soil: potential and challenges for root trait quantification. Plant Methods 11. doi: 10.1186/s13007-015-0060-Z

Mommer L, Kirkegaard J, van Ruijven J (2016) Root-root interactions: towards a rhizosphere framework. Trends in plant science 21:209-217

Muler AL, Oliveira RS, Lambers H, Veneklaas EJ (2014) Does cluster-root activity benefit nutrient uptake and growth of co-existing species? Oecologia 174:23-31

Myers N, Mittermeier RA, Mittermeier CG, Da Fonseca GA, Kent J (2000) Biodiversity hotspots for conservation priorities. Nature 403:853-858

Oburger E, Schmidt H (2016) New methods to unravel rhizosphere processes. Trends in plant science 21:243-255. doi: http://dx.doi.org/10.1016/j.tplants.2015.12.005

Ostonen I, Lõhmus K, Pajuste K (2005) Fine root biomass, production and its proportion of NPP in a fertile middle-aged Norway spruce forest: comparison of soil core and ingrowth core methods. Forest Ecology and Management 212:264-277

Ozanne P, Shaw T (1968) Advantages of the recently developed phosphate sorption test over the older extractant methods for soil phosphate. In: Holmes JW (ed) Transactions of the 9th International Congress of Soil Science, vol. Volume 2. Angus and Robertson, Sydney, Australia, pp 273-280 
Pate JS, Beard JS (1982) Kwongan, plant life of the sandplain. University of Western Australia Press

Pate JS, Dell B (1984) Economy of mineral nutrients in sandplain species. In: Pate JS, Beard JS (eds) Kwongan, Plant Life of the Sandplain. University of Western Australia Press, Nedlands, Australia., pp 227-252

Pate JS, Watt M (2002) Roots of Banksia spp. (Proteaceae) with special reference to functioning of their specialized proteiod root clusters In: Eshel A, Beeckman T (eds) Plant Roots: the Hidden Half. Marcel Dekker Inc., New York, pp 989-1006

Pathan S, Aylmore L, Colmer T (2003) Soil properties and turf growth on a sandy soil amended with fly ash. Plant and Soil 256:103-114

Peñuelas J et al. (2014a) Biogenic volatile emissions from the soil. Plant, Cell and Environment 37:1866-1891

Peñuelas J et al. (2014b) Biogenic volatile emissions from the soil. Plant, cell \& environment 37:1866-1891. doi: 10.1111/pce.12340

Peterson RL, Peterson CA, Melville LH (2008) Teaching plant anatomy: through creative laboratory exercises. NRC Research Press

R Core Team (2020) R: A language and environment for statistical computing. R Foundation for Statistical Computing, Vienna, Austria

Saunders WMH, Williams EG (1955) Observatioms on the determination of total organic phosphorus in soils. Journal of Soil Science 6:254-267

Schenk HJ (2006) Root competition: beyond resource depletion. Journal of Ecology 94:725739. doi: $10.1111 / j .1365-2745.2006 .01124 . x$

Schmittgen S et al. (2015) Magnetic resonance imaging of sugar beet taproots in soil reveals growth reduction and morphological changes during foliar Cercospora beticola infestation. Journal of Experimental Botany 66:5543-5553. doi: 10.1093/jxb/erv109

Shane MW et al. (2004) Developmental physiology of cluster-root carboxylate synthesis and exudation in harsh hakea. Expression of phosphoenolpyruvate carboxylase and the alternative oxidase. Plant Physiology 135:549-560

Shane MW, Lambers H (2005) Cluster roots: a curiosity in context. Plant and Soil 274:101125

Shi J, Strack D, Albornoz FE, Han Z, Lambers H (2020) Differences in investment and functioning of cluster roots account for different distributions of Banksia attenuata and B. sessilis, with contrasting life history. Plant and Soil:, in press

Smit AL, Bengough AG, Engels C, van Noordwijk M, Pellerin S, van de Geijn SC (2000) Root methods: a handbook. Springer-Verlag, Berlin Heidelberg

Teodoro GS et al. (2019) Specialized roots of Velloziaceae weather quartzite rock while mobilizing phosphorus using carboxylates. Functional Ecology 33:762-773

Teste FP, Marchesini VA, Veneklaas EJ, Dixon KW, Lambers H (2018) Root dynamics and survival in a nutrient-poor and species-rich woodland under a drying climate. Plant and Soil 424:91-102. doi: 10.1007/s11104-017-3323-9

Teste FP, Veneklaas EJ, Dixon KW, Lambers H (2014) Complementary plant nutrientacquisition strategies promote growth of neighbour species. Functional Ecology 28:819-828

Therneau T (2015) A package for survival analysis in S. version 2.38, R package version 2.38 edn

Thompson D (1986) The economics of kleptoparasitism: optimal foraging, host and prey selection by gulls. Animal Behaviour 34:1189-1120

Turner BL, Hayes PE, Laliberté E (2018) A climosequence of chronosequences in southwestern Australia. European Journal of Soil Science 69:69-85. doi: doi: 10.1111/ejss. 12507 
Turner BL, Romero TE (2009) Short-term changes in extractable inorganic nutrients during storage of tropical rain forest soils. Soil Science Society of America Journal 73:19721979

van Dusschoten D et al. (2016) Quantitative 3D analysis of plant roots growing in soil using magnetic resonance imaging. Plant Physiology 170:1176-1188. doi: $10.1104 /$ pp. 15.01388

van Vuuren MMI, Robinson D, Griffiths BS (1996) Nutrient inflow and root proliferation during the exploitation of a temporally and spatially discrete source of nitrogen in soil. Plant and Soil 178:185-192

Watson A, Matthiessen J, Springett B (1982) Arthropod associates and macronutrient status of the red- ink sundew (Drosera erythrorhiza Lindl.). Austral Ecology 7:13-22

Watt M, Evans JR (1999) Linking development and determinacy with organic acid efflux from proteoid roots of white lupin grown with low phosphorus and ambient or elevated atmospheric $\mathrm{CO}_{2}$ concentration. Plant Physiology 120:705-716

Wickham H (2016) ggplot2: Elegant Graphics for Data Analysis. Springer-Verlag, New York, USA.

Williams JDH, Syers JK, Walker TW, Rex RW (1970) A comparison of methods for the determination of soil organic phosphorus. Soil Science 110:13-18

Wright AJ, Wardle DA, Callaway R, Gaxiola A (2017) The overlooked role of facilitation in biodiversity experiments. Trends in Ecology \& Evolution. doi: 10.1016/j.tree.2017.02.011

Wyrwoll K-H, Turner BL, Findlater P (2014) 1a. On the origins, geomorphology and soils of the sandplains of south-western Australia. In: Lambers H (ed) Plant Life on the Sandplains in Southwest Australia, a Global Biodiversity Hotspot. UWA Publishing, Crawley, pp 3-22

Yu R-P, Li X-X, Xiao Z-H, Lambers H, Li L (in press) Phosphorus facilitation and covariation of root traits in steppe species. New Phytologist n/a. doi: 10.1111/nph.16499

Yu RP, Zhang WP, Yu YC, Yu SB, Lambers H, Li L (2020) Linking shifts in species composition induced by grazing with root traits for phosphorus acquisition in a typical steppe in Inner Mongolia. Sci Total Environ 712:136495. doi: 10.1016/j.scitotenv.2020.136495

Zeng G, Birchfield ST, Wells CE (2010) Rapid automated detection of roots in minirhizotron images. Machine Vision and Applications 21:309-317

Zomora R (1995) The trapping success of a carnivorous plant, Pinguicula vallisneriifolia: the cumulative effects of availability, attraction, retention and robbery of prey. Oikos 73:309-322

Zuur AF, Ieno EN, Walker NJ, Saveliev AA, Smith GM (2009) Mixed effects models and extensions in ecology with R. Springer, New York, NY, USA 
825 Fig. 1* Photographs of in situ root intermingling between a Banksia attenuata cluster root (shown with white arrow) and other roots (shown with black arrow) of other species (i.e. herbaceous and woody plants) in a banksia-eucalypt woodland (Tube 20, Window 4 from 9 September to 5 October, 2012). In top image, a cluster root starts to form with other roots seen below. Based on this series of images, a frequency of intermingling response was generated; here, frequency $=2$, since two non-cluster roots are seen in the same image frame. Since 'other roots' were present before the appearance of the cluster root, we named this root interaction 'before cluster root' (BeforeCR)). Also see Fig. S3 and Fig. S4 for photographic examples of the other interaction types, and see Fig. 2 for differences in the frequency of interactions with irrigation and amongst the two general root types. See Teste et al. (2018) for an estimate of in situ survival rates of cluster roots and their rootlets. Also see Shane and Lambers (2005) for photographs of Banksia cluster roots that clearly show their 'compound' shape. [*Figure to be possibly reworked by the journal's illustrator].

Fig. 2 Frequency of intermingling of cluster roots and herbaceous or woody roots during April - October 2012 in a banksia-eucalypt woodland. This intermingling response was based on the joint occurrence of live cluster roots with other live roots in small minirhizotron image frames (height $=1.35 \mathrm{~cm}$, width $=1.8 \mathrm{~cm}$ ) that hosted at least one live cluster root. The other roots appeared before the cluster root developed (BeforeCR; Fig. 1S2), while the cluster root was alive (DuringCR; Fig. S3), or during senescence (AfterCR; Fig. S4). We found the negative binomial model to be the best fit (AIC $=199$, Theta $=1.986)$ for these data; these showed a statistically significant interaction between the irrigation treatment and type of interaction $(P$-value $=0.011)$, while no significant effect of root type was found (see Table $S 1$ for summary statistics).

850 Fig. 3 Concentrations of total nitrogen $(\mathrm{N})$ and phosphorus (P) across the developmental 851 stages of cluster roots. Values are means with $95 \%$ confidence intervals, and different 852 letters to indicate statistically-significant differences between means (Tukey HSD tests 853 with $P \leq 0.05$ ). Shown here are four developmental stages of cluster roots: stage pre854 cluster (immature cluster roots; $n=21$ ); stage I (fully-formed cluster roots; $n=16$ ); stage 855 II (cluster roots with rusty brown colour and some loss of vigour; $n=34$ ); and stage III 856 (dark brown or grey cluster roots with noticeable loss of vigour; $n=29$ ).

857 Fig. 4 Percent of live (i.e. unstained) rootlets across the developmental stages of cluster 858 roots. Values are mean percent of live rootlets with $95 \%$ confidence intervals, and 859 different letters indicate statistically-significant differences between means (Tukey HSD 860 tests with $P \leq 0.05$ ). Shown here are three developmental stages of cluster roots: stage I 861 (fully-formed cluster roots; $\mathrm{n}=16$ ); stage II (cluster roots with rusty brown colour and 862 some loss of vigour; $n=16$ ); and stage III (dark brown or grey cluster roots with 863 noticeable loss of vigour; $n=31$ ). 
864 Fig. 5 Phosphorus (P) concentrations typically found in Spearwood sandy soils, as well 865 as $\mathrm{P}$ contained in Banksia cluster roots (CR), all expressed per unit soil dry mass.

866 Carboxylate-extractable inorganic $\mathrm{P}(\mathrm{Pi})$ and organic-P are potentially available to 867 intermingling roots (indicated with root illustrations), in the short period that cluster 868 roots exude P-mobilising compounds (carboxylates and phosphatases). Phosphorus 869 remaining in senesced cluster roots is potentially available to intermingling roots after 870 CR death (indicated with root illustrations). 
871

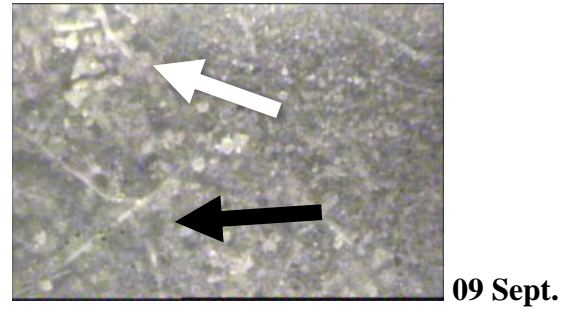

872

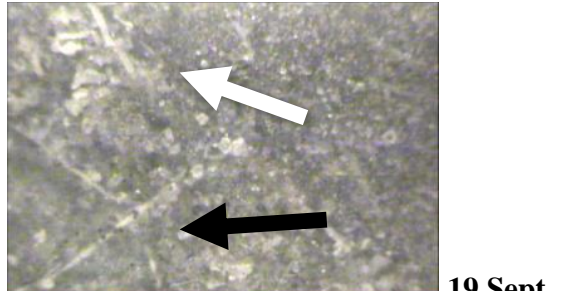

873
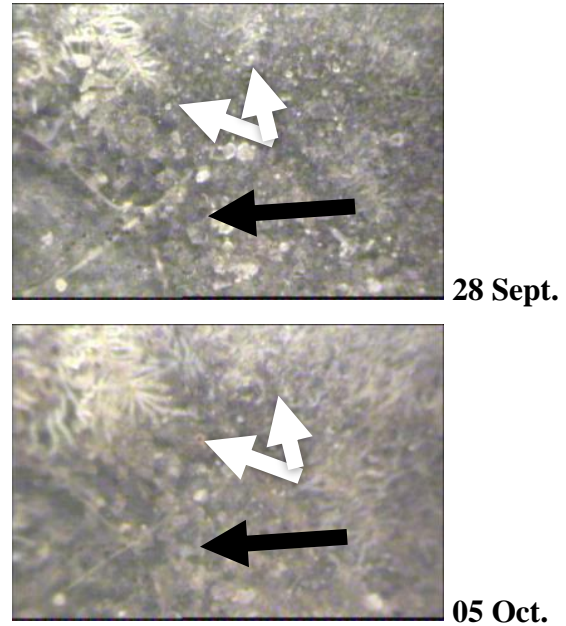

875 Fig. 1* 


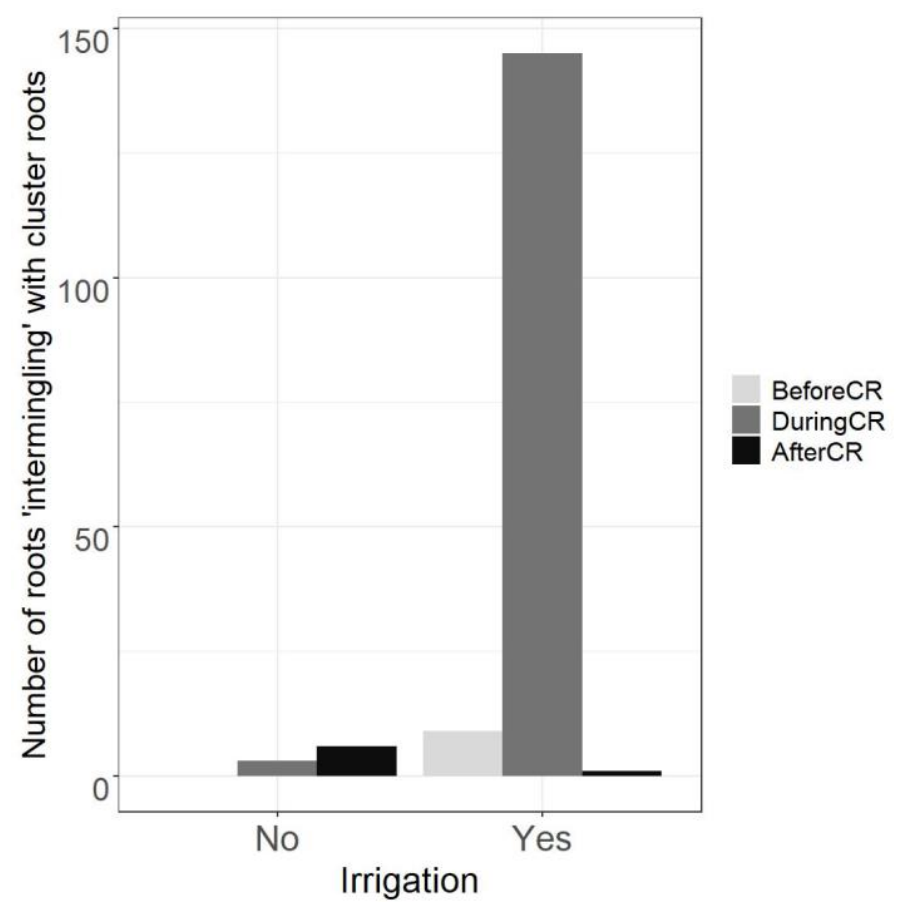

$877 \quad$ Fig. 2 


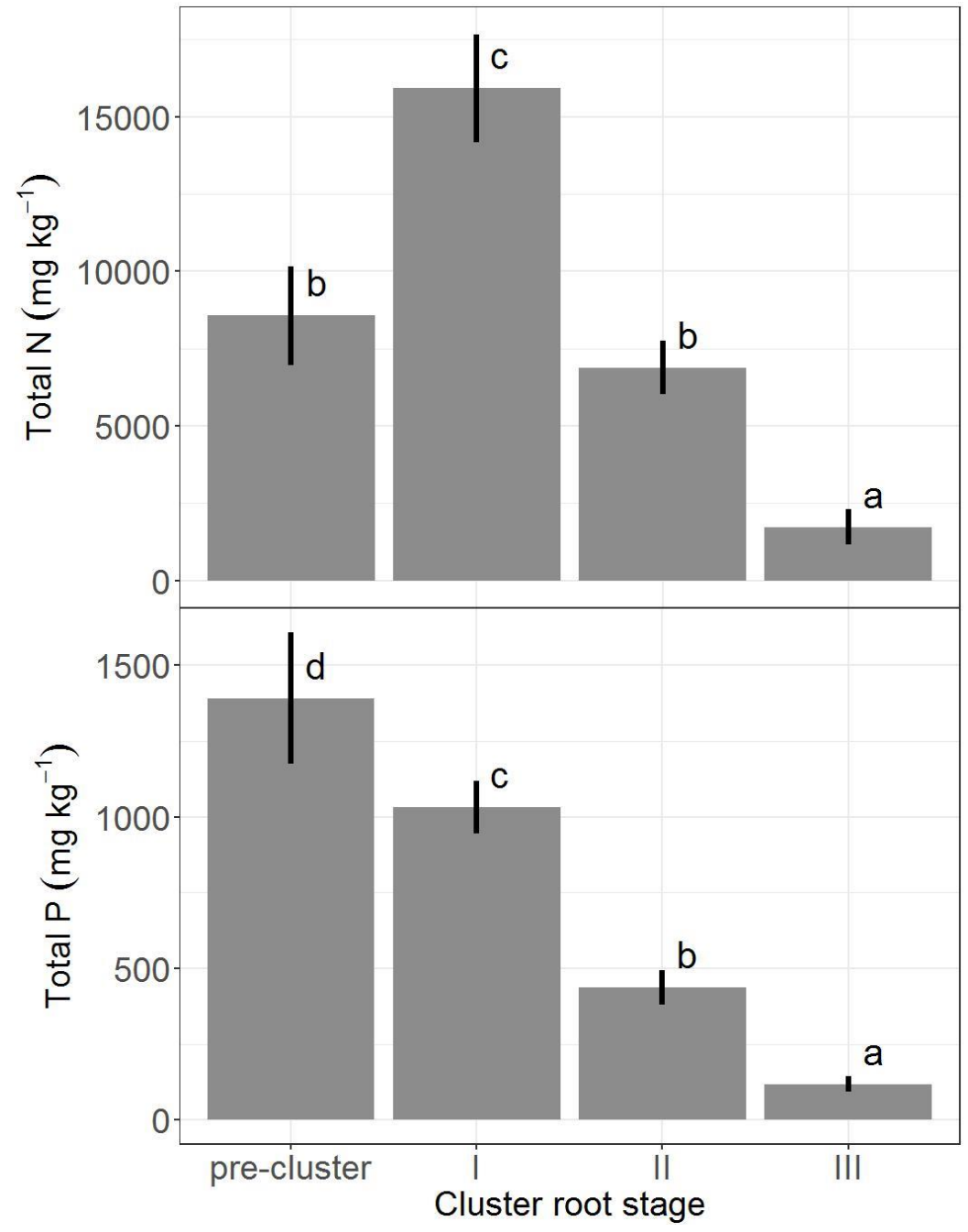

Fig. 3 


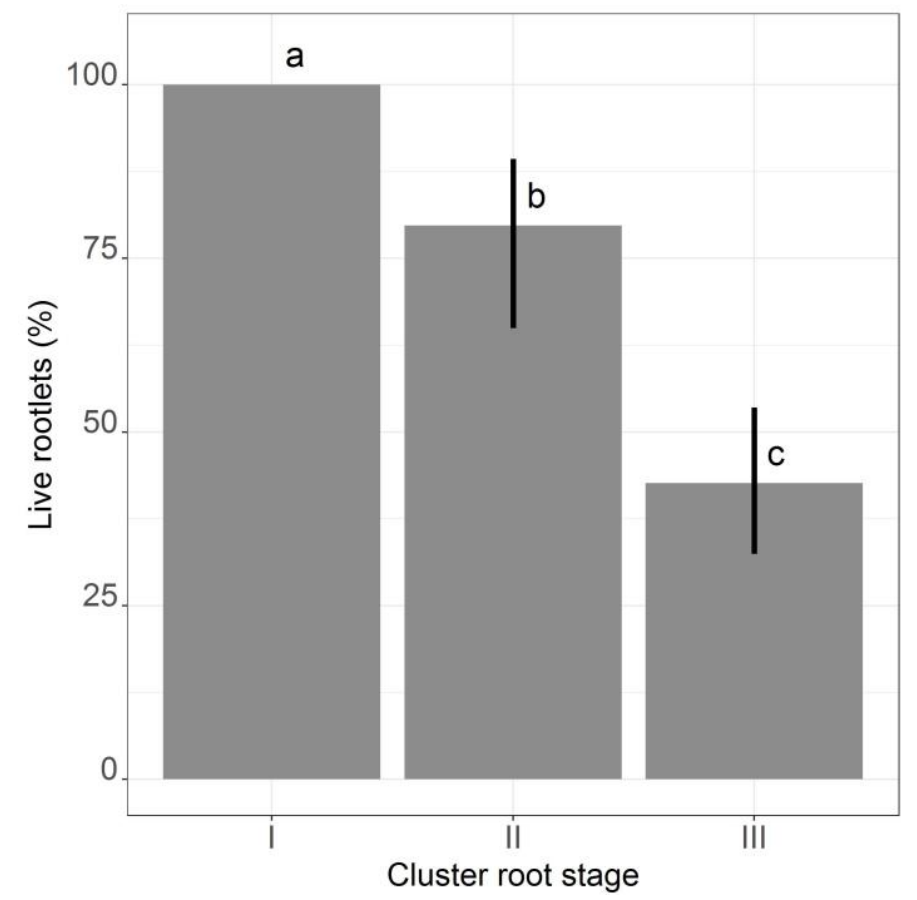

$881 \quad$ Fig. 4 


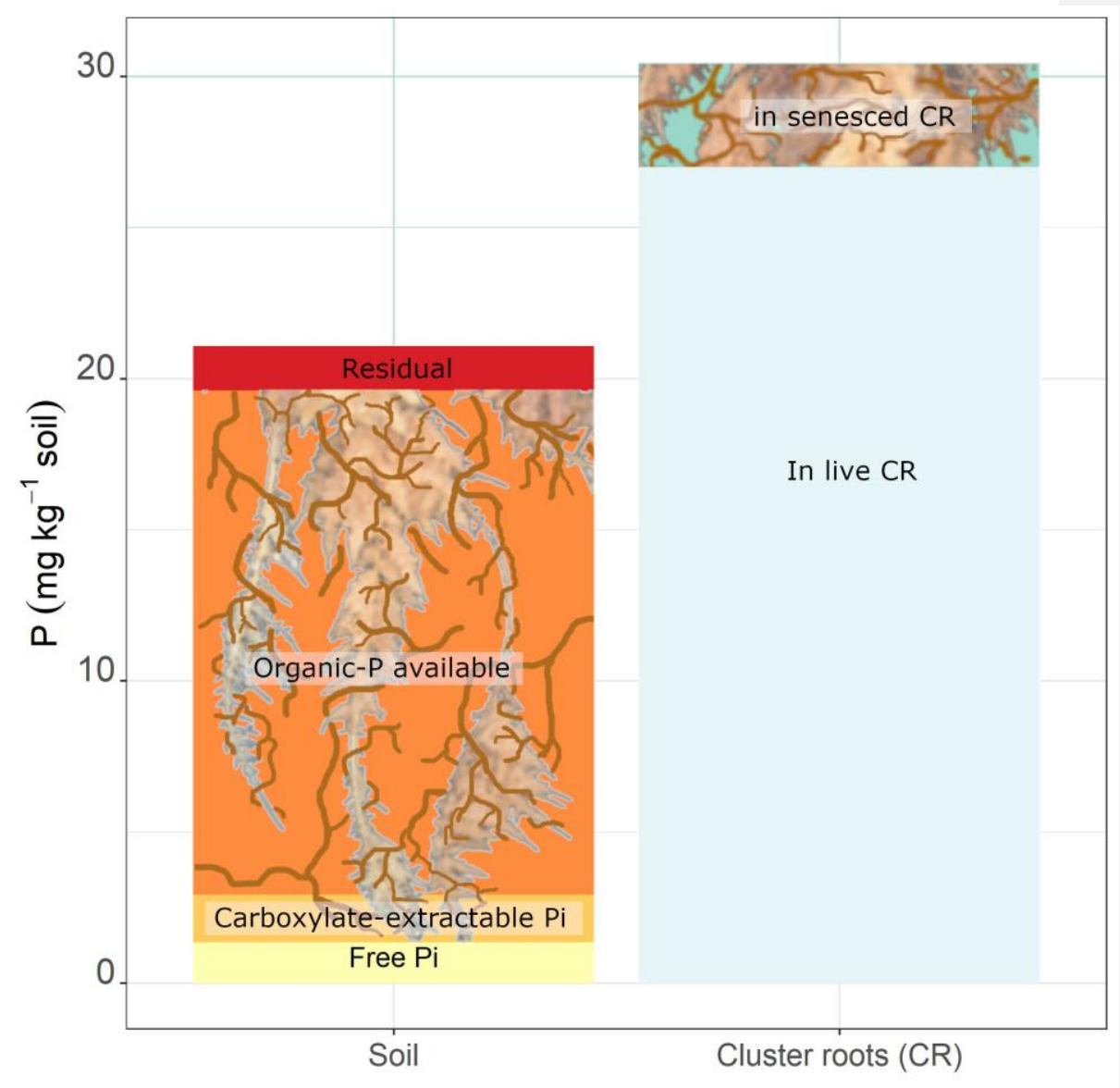

882

Fig. 5 
885 Table S1. Analysis of deviance tables of the Poisson and negative binomial regression models (full and minimal adequate model

Analysis of Deviance (Dev) summary tables

Poisson full mode

\begin{tabular}{|c|c|c|c|c|c|}
\hline Source of Deviance & df & Deviance & $\begin{array}{l}\text { Residual } \\
\text { df }\end{array}$ & $\begin{array}{l}\text { Residual } \\
\text { Dev }\end{array}$ & $\operatorname{Pr}(>\mathrm{Chi})$ \\
\hline NULL & - & - & 40 & 177.39 & - \\
\hline Irrigation & 1 & 20.109 & 39 & 157.28 & $<0.001$ \\
\hline InteracWhen & 2 & 13.298 & 37 & 143.98 & 0.001 \\
\hline RTInterac & 1 & 0.215 & 36 & 143.76 & 0.643 \\
\hline Irrigation:InteracWhen & 2 & 15.329 & 34 & 128.44 & $<0.001$ \\
\hline Irrigation:RTInterac & 1 & 0.700 & 33 & 127.73 & 0.403 \\
\hline InteracWhen:RTInterac & 2 & 2.561 & 31 & 125.17 & 0.278 \\
\hline Irrigation:InteracWhen:RTInterac & 2 & 0.719 & 29 & 124.45 & 0.698 \\
\hline
\end{tabular}


Poisson minimal adequate model

\begin{tabular}{llllll}
\hline \multirow{2}{*}{ Source of Deviance } & & & Residual & Residual & \\
& df & Deviance & df & Dev & $\operatorname{Pr}(>$ Chi) \\
\hline NULL & - & - & 40 & 177.39 & - \\
Irrigation & 1 & 20.109 & 39 & 157.28 & $<\mathbf{0 . 0 0 1}$ \\
InteracWhen & 2 & 13.298 & 37 & 143.98 & $\mathbf{0 . 0 0 1}$ \\
Irrigation:InteracWhen & 2 & 15.196 & 35 & 128.78 & $\mathbf{0 . 0 0 1}$ \\
\hline
\end{tabular}

894

895

896

Negative binomial full model

\begin{tabular}{lllllll}
\hline \multirow{2}{*}{ Source of Deviance } & & & Residual & Residual \\
& df & Deviance & df & Dev & Pr(>Chi) \\
\hline NULL & - & - & 40 & 58.4737 & - \\
Irrigation & 1 & 8.2489 & 39 & 50.2248 & $\mathbf{0 . 0 0 4 1}$ \\
InteracWhen & 2 & 4.8166 & 37 & 45.4082 & 0.09 \\
RTInterac & 1 & $1 \mathrm{e}-04$ & 36 & 45.4081 & 0.9913 \\
Irrigation:InteracWhen & 2 & 9.2123 & 34 & 36.1958 & $\mathbf{0 . 0 1}$ \\
Irrigation:RTInterac & 1 & 0.2084 & 33 & 35.9874 & 0.648 \\
InteracWhen:RTInterac & 2 & 1.5634 & 31 & 34.424 & 0.4576 \\
Irrigation:InteracWhen:RTInterac & 2 & 0.5945 & 29 & 33.8295 & 0.7429 \\
\hline
\end{tabular}

897

898 Negative binomial minimal adequate model 


\begin{tabular}{llllll}
\hline \multirow{2}{*}{ Source of Deviance } & & & Residual & Residual & \\
& df & Deviance & df & Dev & $\operatorname{Pr}(>$ Chi) \\
\hline NULL & - & - & 40 & 57.0737 & - \\
Irrigation & 1 & 8.059 & 39 & 49.0146 & $\mathbf{0 . 0 0 4 5}$ \\
InteracWhen & 2 & 4.7076 & 37 & 44.307 & 0.095 \\
Irrigation:InteracWhen & 2 & 9.0556 & 35 & 35.2514 & $\mathbf{0 . 0 1 0 8}$ \\
\hline
\end{tabular}

899 df: degrees of freedom. 
901 Fig. S1 Location of the research plots (white triangle) where this study using

902 minirhizotron tubes was carried out. A photo of the irrigation treatment in action on Plot 9036 from Teste et al. (2018) with a Banksia attenuata tree in the centre with white-capped 904 minirhizotron tubes all around. Also shown is the Bartz BTC2 Minirhizotron video 905 camera imaging on Plot 2. Plots were situated in remnant banksia-eucalypt (Eucalyptus 906 gomphocephala) banksia woodland of the UWA Shenton Park Field Station (31 ${ }^{\circ} 56^{\prime}$ S,

$907115^{\circ} 47^{\prime}$ E) that is situated on the Swan Coastal Plain, Western Australia.

908 Fig. S2* Photographs of Banksia attenuata cluster-root appearance (shown with arrow) 909 and development in situ in a banksia-eucalypt woodland (Tube 2, Window 4 from 29 910 August to 5 October 2012). See Teste et al. (2018) for an estimate of in situ survival 911 rates of cluster roots and their rootlets. Also please see Shane and Lambers (2005) for 912 photographs of Banksia cluster roots that clearly show their 'compound' shape.

913 [*Figure to be possibly reworked by the journal's illustrator].

914 Fig. S3* Photographs of in situ root intermingling between a Banksia attenuata cluster 915 root and other roots of other species (i.e. herbaceous and woody plants) in a banksia916 eucalypt woodland (Tube 20, Window 5 from 29 August to 5 October, 2012). Since 917 'other roots' appeared during the development of a live cluster root we named this root 918 interaction 'during cluster root (DuringCR)). See Fig. 2 for differences in the frequency 919 of interactions with irrigation and amongst the two general root types. [*Figure to be 920 possibly reworked by the journal's illustrator].

921 Fig. S4* Photographs of in situ root intermingling between a Banksia attenuata cluster 922 root and other roots of other species (i.e. herbaceous and woody plants) in a banksia923 eucalypt woodland (Tube 2, Window 19 from 22 August to 19 September, 2012). Since 924 'other roots' appeared after the development of the cluster root we named this root 925 interaction 'after cluster root (AfterCR)). See Fig. 2 for differences in the frequency of 926 interactions with irrigation and amongst the two general root types. [*Figure to be 927 possibly reworked by the journal's illustrator].

928 Fig. S5 Frequency of other roots (herbaceaous and woody) intermingling with cluster 929 roots over distinct soil depth ranges ( 0 to $10 \mathrm{~cm}, 11$ to $20 \mathrm{~cm}$, and 21 to $40 \mathrm{~cm}$ ) during 930 months of peak root growth (April - October) of 2012 in a banksia-eucalypt woodland. 931 This intermingling response was based on the joint occurrence of live cluster roots with 932 other live roots in small minirhizotron image frames (height $=1.35 \mathrm{~cm}$, width $=1.8 \mathrm{~cm}$ ) 933 that hosted at least one live cluster root. The other roots appeared before the cluster root 934 developed (BeforeCR; Fig. 1S2), while the cluster root was alive (DuringCR; Fig. S3), 935 or during senescence (AfterCR; Fig. S4). 


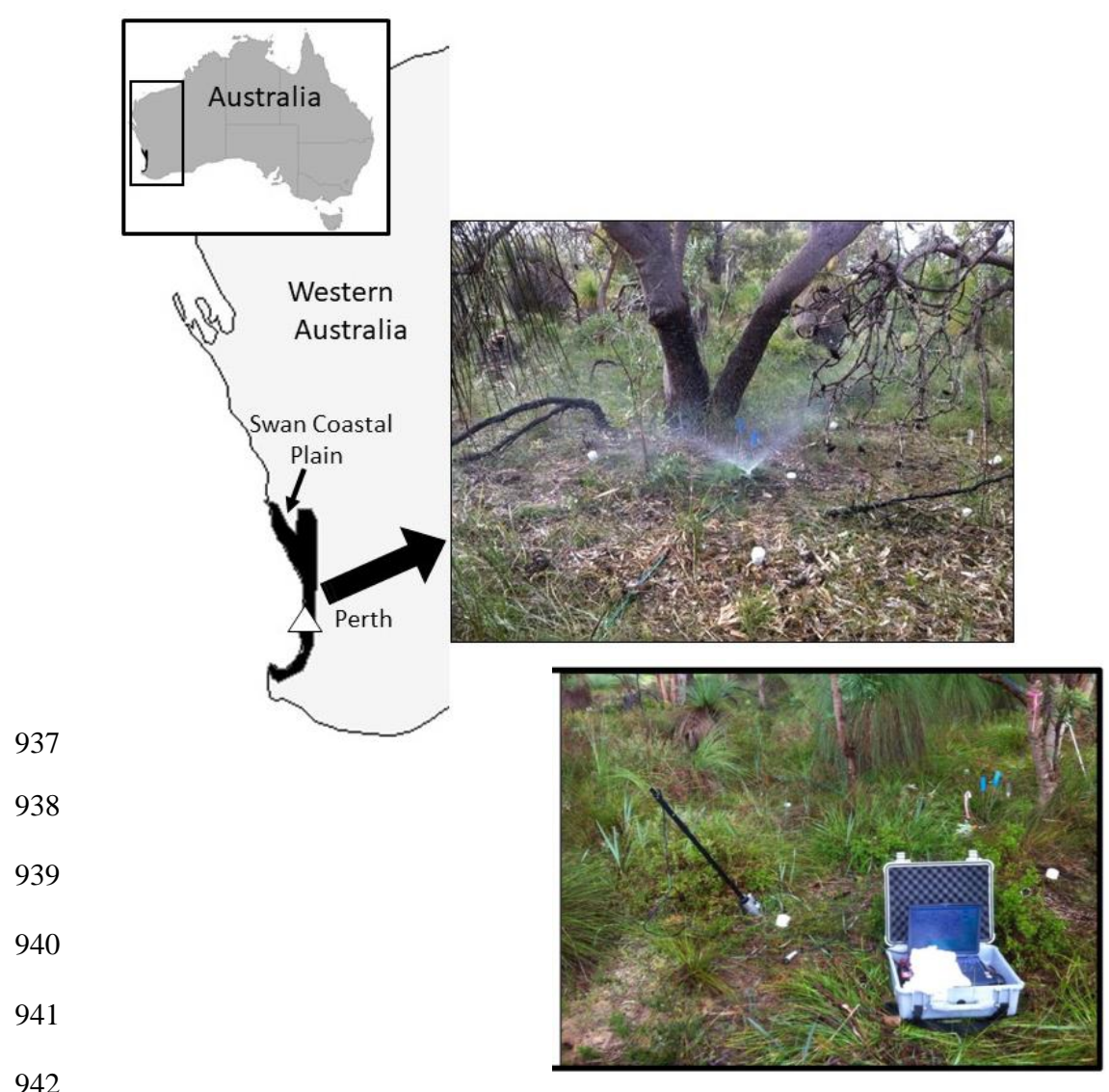

943 Fig. S1. 


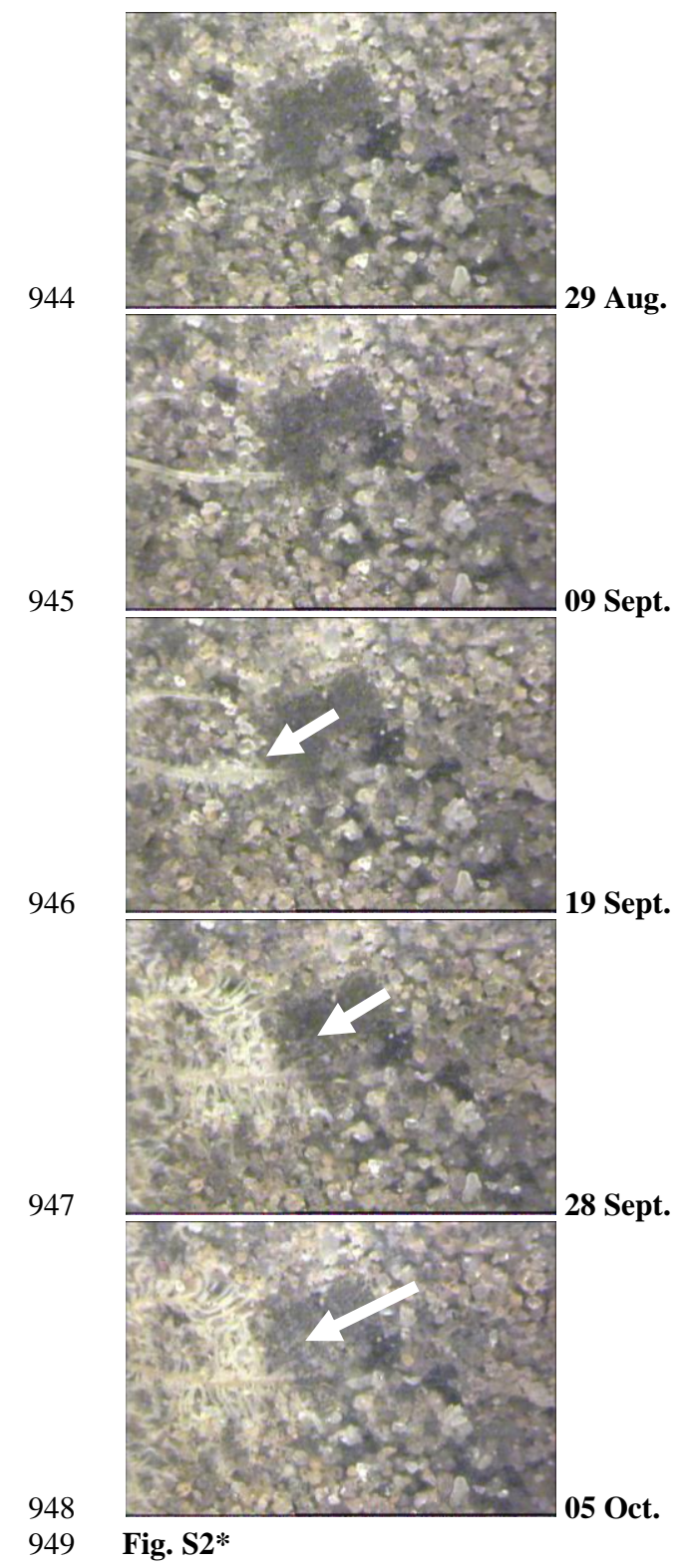




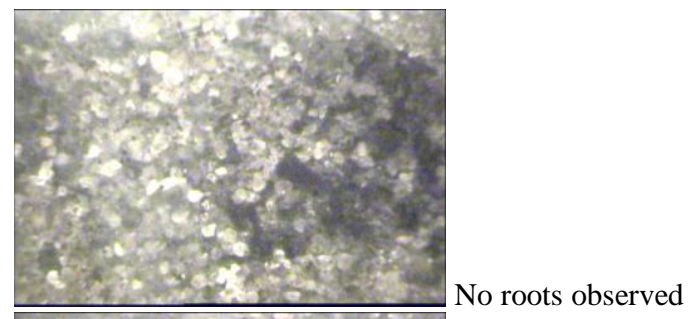

951
952
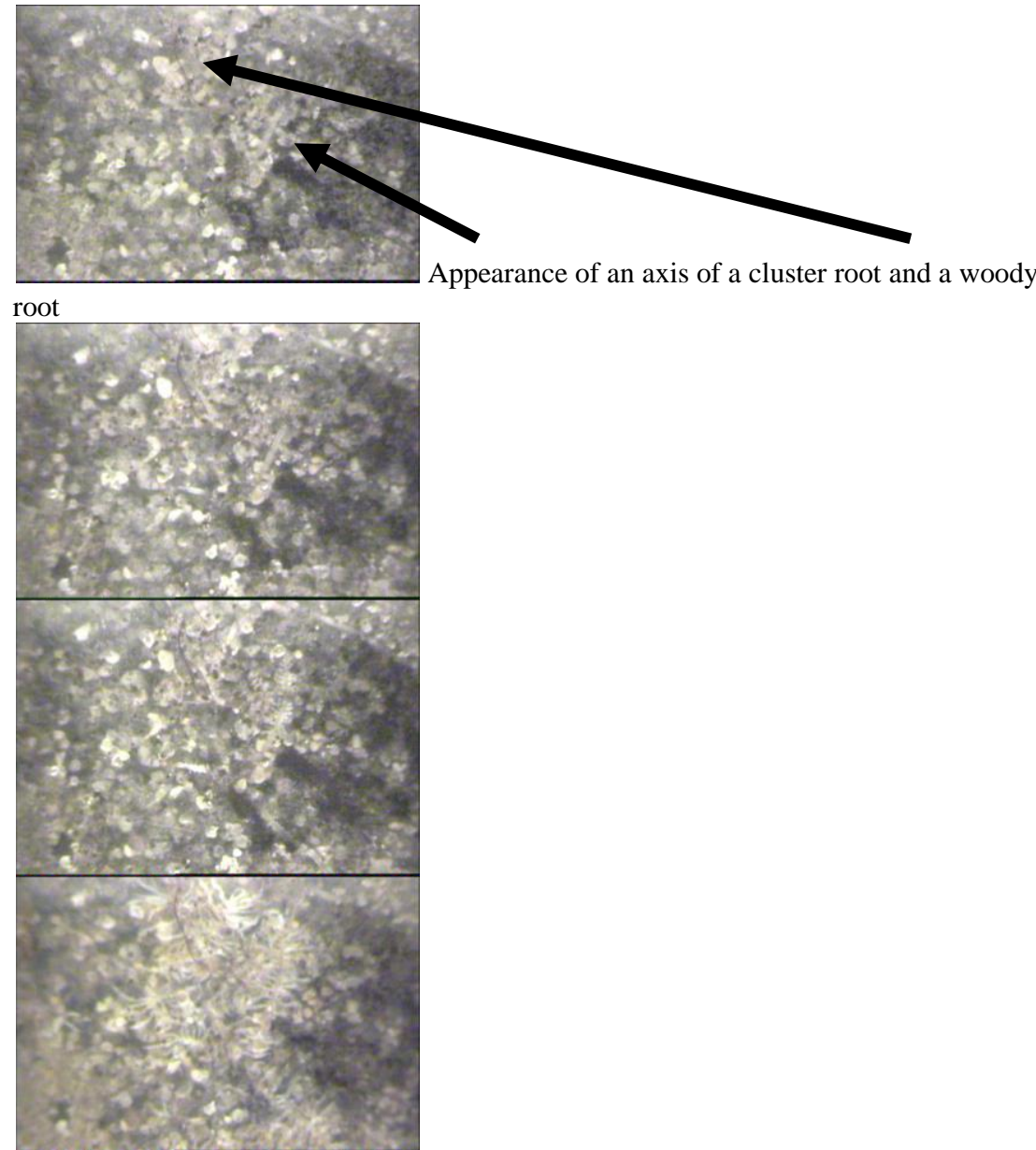

955

956 Fig. S3* 


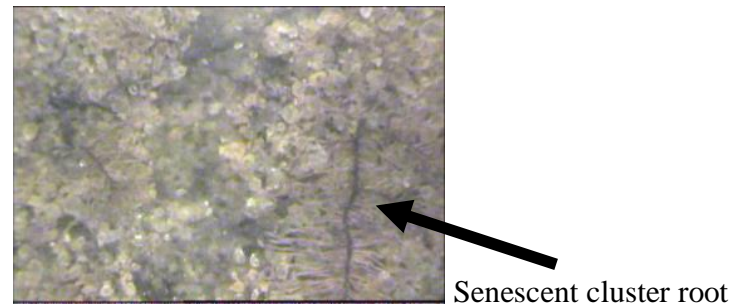

958

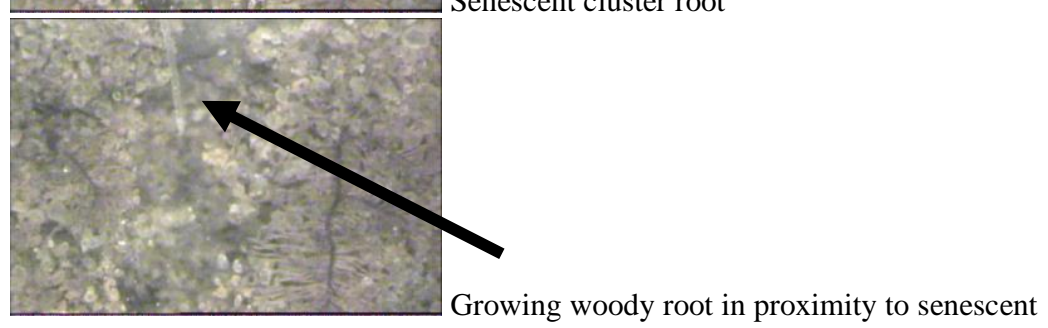

959 cluster root

960

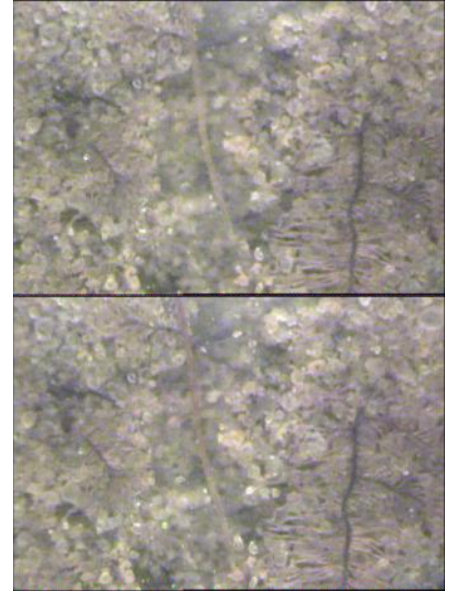

961

962 Fig. S4* 


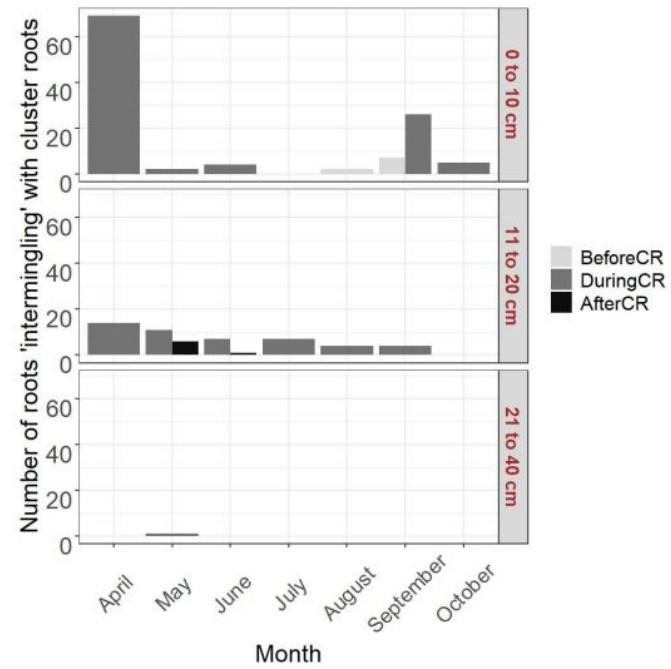

963 
965 Data S1

966 Data table S2 (separate Microsoft Excel file) has all data associated with this study. 